
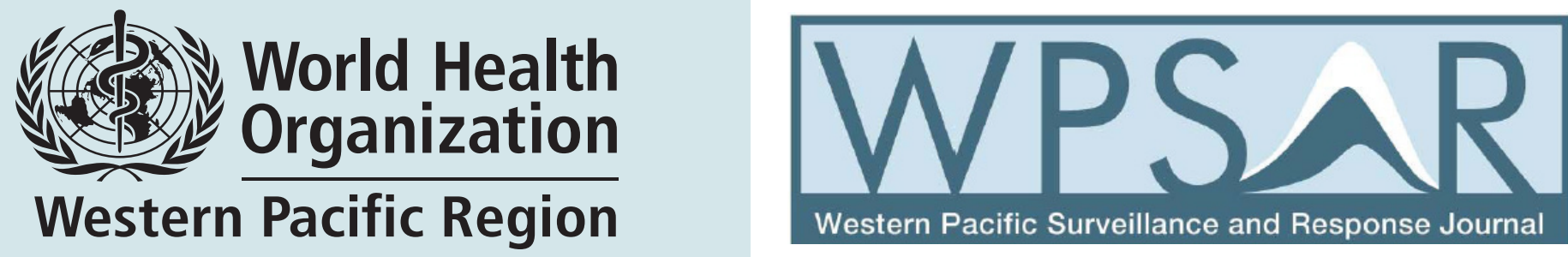

Volume 7, Number 2, 2016, Pages 1-50

p-ISSN: 2094-7321 e-ISSN: 2094-7313

Surveillance Reports

Tuberculosis in foreign students in Japan, 2010-2014: a comparison with the notification rates in their countries of origin

Ota M, Uchimura K, Kato S

Profile of tuberculosis among the foreignborn population in Japan, 2007-2014

Kawatsu L, Uchimura K, Izumo K, Ohkado A, Ishikawa N

\section{Risk Assessment}

Assessment of the risk posed to Singapore by the 2015 Middle East respiratory syndrome outbreak in the Republic of Korea

Zhang EX, Oh OSH, See W, Raj P, James L, Tey JSH

\section{Original Researches}

External quality assessment of dengue and chikungunya diagnostics in the Asia Pacific region, 2015

Soh LT, Squires RC, Tan LK, Pok KY, Yang HT, Liew C, Shah AS, Abubakar S, Hasabe F, Ng LC, Konings $F$
Prevalence of resistance to second-line tuberculosis drug among multidrugresistanct tuberculosis patients in Viet Nam, 2011

Nguyen HB, Nguyen NV, Tran HTG, Nguyen HV, Bui QTT

Regional Analysis

Epidemiology and control of tuberculosis in the Western Pacific Region: update with 2013 case notification data

Hiatt T, Nishikiori N

\section{Western Pacific Surveillance and Response}

Open access journal with continuous publication

Western Pacific Surveillance and Response (WPSAR) is an open access journal dedicated to the surveillance of and response to public health events. The goal of the journal is to create a platform for timely information sharing both within our region and globally to enhance surveillance and response activities. WPSAR is a continuous publication which means articles will be published online as soon as they have completed the review and editing process. Every three months articles will be batched for a print issue. It is a publication managed by the World Health Organization Regional Office for the Western Pacific. 


\section{EDITORIAL TEAM}

\author{
Ailan Li \\ Executive Editor
}

Ka Yeung Cheng

Coordinating Editor

Elizabeth Mangali

Assistant Editor

Associate Editors

Jorge Mendoza Aldana

Frank Konings

Ying-Ru Lo

Dapeng Luo

Nobuyuki Nishikiori

Manju Rani

Boris Pavlin

\section{Copyright notice}

Rights and permissions (c) World Health Organization 2016.

Some rights reserved.

p-ISSN: 2094-7321

e-ISSN: 2094-7313

The articles in this publication are published by the World Health Organization and contain contributions by individual authors. The articles are available under the Creative Commons Attribution 3.0 IGO license (CC BY 3.0 IGO http:// creativecommons.org/licenses/by/3.0/igo/legalcode), which permits unrestricted use, distribution and reproduction in any medium, provided the original work is properly cited. In any use of these articles, there should be no suggestion that WHO endorses any specific organization, products or services. The use of the WHO logo is not permitted.

The World Health Organization does not necessarily own each component of the content contained within these articles and does not therefore warrant that the use of any third-party-owned individual component or part contained in the articles will not infringe on the rights of those third parties. The risk of claims resulting from such infringement rests solely with you. If you wish to re-use a component of the articles attributed to a third party, it is your responsibility to determine whether permission is needed for that re-use and to obtain permission from the copyright owner. Examples of components can include, but are not limited to, tables, figures or images.

Any mediation relating to disputes arising under this license shall be conducted in accordance with the WIPO Mediation Rules (www.wipo.int/amc/en/mediation/rules). Any inquiries should be addressed to publications@wpro.who.int.

\section{Disclaimer}

The designations employed and the presentation of the information in this publication do not imply the expression of any opinion whatsoever on the part of the World Health Organization concerning the legal status of any country, territory, city or area or of its authorities, or concerning the delimitation of its frontiers or boundaries.

The mention of specific companies or of certain manufacturers' products does not imply that they are endorsed or recommended by the World Health Organization in preference to others of a similar nature that are not mentioned. Errors and omissions excepted, the names of proprietary products are distinguished by initial capital letters.

\author{
Western Pacific Surveillance and Response \\ World Health Organization \\ Office for the Western Pacific Region \\ United Nations Avenue \\ 1000 Manila, Philippines \\ wpsar@wpro.who.int \\ www.wpro.who.int/wpsar/en
}




\title{
Tuberculosis in foreign students in Japan, 2010-2014: a comparison with the notification rates in their countries of origin
}

\author{
Masaki Ota, ${ }^{a}$ Kazuhiro Uchimura ${ }^{a}$ and Seiya Kato ${ }^{a}$ \\ Correspondence to Masaki Ota (email: otam@jata.or.jp).
}

This study characterizes the foreign students with tuberculosis (TB) registered in Japan from 2010 to 2014 and compares their TB notification rates with those in their countries of origin. The TB notification rates in foreign students were retrieved from the National Epidemiological Surveillance of Infectious Disease system in Japan. National TB notification data from 16 countries and areas were extracted from the World Health Organization's and the official health websites of the countries and areas.

There were 1128 foreign students in Japan who developed TB between 2010 and 2014; nearly half of the cases were from China ( $n=530,46.9 \%)$, and $688(61.0 \%)$ were male with a median age of 23 years. The TB notification data for foreign students were highest in students from the Philippines (675/100 000 person years, 95\% confidence interval: 372-977). The notification rates in foreign students from seven countries were significantly higher than the average notification rate in their countries of origin (China, Indonesia, Mongolia, Myanmar, Nepal, the Philippines and Viet Nam). The Republic of Korea and Taiwan, China had significantly lower rates in foreign students than in their countries of origin.

The notification rates for foreign students in Japan may reflect a more accurate risk of developing TB among the immigrants to Japan than the TB notification rates in their countries of origin. These results may be helpful to identify the immigrants' countries/areas of origin with the necessity of pre-entry TB screening.

J apan has successfully reduced the burden of tuberculosis (TB) in the past six decades from 590684 cases (698 per 100000 population) in 1951 to 19615 cases (15.4 per 100000 population) in 2014. ${ }^{1,2}$ However, imported TB from immigrants is still a challenge in eliminating TB in Japan. The proportion of immigrants among all TB cases in Japan has steadily increased from $2.4 \%$ in 2000 to $5.6 \%$ in 2014 . Immigrants accounted for $43 \%$ of the TB cases among those aged 20 to 29 years in 2014 . $^{1,3}$

The TB notification rates in foreign countries can be referenced for assessing the risk of TB importation from their immigrants. However, the estimate might not reflect the actual disease burden accurately. ${ }^{4-6}$ Calculating the notification rates for TB in immigrants to Japan by country of origin is a challenge since some cases are temporary visitors who cannot be distinguished in the record. Illegal and undocumented immigrants who do not count in the denominator for calculating the TB notification rates may lead to overestimating the TB burden. For most of the immigrant occupation designations, the total number of people engaged in that occupation (i.e. denominator) is not available.
To our best knowledge, it is only possible to determine the TB notification rate in foreign students in Japan because the National TB Surveillance System of Japan records the cases' occupations, and foreign students (student visa holders) are surveyed by the Japan Students Services Organization (JASSO) annually. ${ }^{7}$

This study characterizes the foreign students with TB registered from 2010 to 2014 and compares their notification rates with those in their countries of origin to investigate if there are discrepancies between them.

\section{METHODS}

\section{Study population}

This study aimed to include all foreign students in Japan. Both long-term and short-term (with a stay of less than one year) students were included. The study included students from 16 countries and areas: Bangladesh; Cambodia; China; Taiwan, China; India; Indonesia; Malaysia; Mongolia; Myanmar; Nepal; the Philippines; Republic of Korea; the Russian Federation; Sri Lanka; Thailand and Viet Nam. Other foreign countries were

\footnotetext{
Research Institute of Tuberculosis, Japan Anti-Tuberculosis Association, Kiyose, Tokyo, Japan. 
excluded as TB cases were less than four in the study period or the number of students from those countries was too small (less than 300 students) to be listed in the JASSO survey.

Foreign students studying at accredited educational institutions, including high schools, colleges/universities and vocational/professional schools, make up about $75 \%$ of foreign students in Japan. ${ }^{7}$ They undergo health screening at entry to the schools with chest X-rays as required by the School Health and Safety Act of $1958 .{ }^{8}$ The other $25 \%$ of foreign students, mostly entering unaccredited Japanese language schools, may or may not be offered health screening. Suspected TB cases are referred to nearby health facilities for TB laboratory confirmation testing (confirmed by sputum smear, TB culture, polymerase chain reaction and other identification tests such as a Capilia TB-Neo test [Tauns Co. Ltd., Izunokuni, Shizuoka, Japan] that are described elsewhere). ${ }^{9}$

\section{The National TB Surveillance System}

The National TB Surveillance System of Japan has been described elsewhere. ${ }^{10}$ Briefly, once a TB case is diagnosed, physicians are required by law to report the diagnosis to the local health department using a standard notification form. Collected data include the patient's identity, demographics, epidemiological, clinical and laboratory testing information. A public health nurse from the local health office interviews the case to obtain additional information (for example, occupation and details about the case contacts for contact investigation). Data are then deposited into the National Epidemiological Surveillance of Infectious Disease system of Japan (NESID). ${ }^{10}$ TB data of local and foreign students were retrieved from NESID for analysis.

\section{TB notification data among foreign students in Japan}

Information on age, sex, year of registration, mode of detection and country of origin of the TB cases, who were local and foreign students, were obtained from NESID. The notification rates for TB among foreign students were calculated as the number of TB cases registered in Japan from 2010 to 2014 divided by the number of foreign students in Japan at that period by country/area. The number of foreign students in Japan was obtained from JASSO's annual survey. ${ }^{7}$

\section{National TB notification data in foreign countries and areas}

The national TB notification data were obtained from the World Health Organization's website. ${ }^{2}$ TB notification data for Taiwan, China were obtained from the website of the Centers for Disease Control, Department of Health, Taiwan, China. ${ }^{11}$ Population estimate of different countries and areas were obtained from the United Nations Population Division's web site. ${ }^{12}$

\section{Statistical methods}

Descriptive analyses were done for the TB cases and notification rates in the foreign students and those of their countries of origin. The 95\% confidence intervals (Cl) were calculated by binomial test. Statistical analyses were conducted by $R$ software version 3.0.1 (R Foundation for Statistical Computing, Vienna, Austria).

\section{Ethics statement}

This is a review of routine TB surveillance data, and we obtained a waiver of ethical clearance from the institutional review board of the Research Institute of Tuberculosis, Tokyo, Japan (IRB\#: 27-16).

\section{RESULTS}

\section{Total TB cases}

In total, there were 1128 TB cases among the foreign students registered in Japan between 2010 and 2014; $688(61.0 \%)$ were males with a median age of 23 years. In comparison, among the Japanese students with TB $(n=872), 57.2 \%$ were males and the median age was 21 years old. The majority $(86.7 \%$ of the foreign students and $91.5 \%$ of the Japanese students) of the student TB cases were age 18 to 27 years. These cases were detected either through health screening at the educational institutions (57.3\% for foreign students and $45.1 \%$ for Japanese students) or during self-healthcare seeking at clinics and hospitals (42.7\% for foreign students and $54.9 \%$ for Japanese students) (Table 1 ). The foreign students with TB accounted for $56.4 \%$ of all the students with TB $(n=2000)$ and for $1.05 \%$ of all the TB cases $(n=107335)$ in Japan registered in the same period. The number of TB cases with known occupations was 104862 in that period. The majority of the foreign students with TB were from China 
Table 1. Number of TB cases in students, Japan, 2010-2014

\begin{tabular}{lrrrr}
\hline \multicolumn{1}{c}{ Characteristics } & \multicolumn{2}{c}{ Foreign students } & \multicolumn{2}{c}{ Local students } \\
& $n$ & $\%$ & \multicolumn{1}{c}{$\boldsymbol{n}$} & $\%$ \\
\hline Age (years) & & & & \\
$\quad$ 18-22 & 453 & 40.2 & 657 & 75.3 \\
$23-27$ & 525 & 46.5 & 141 & 16.2 \\
$\quad$ 27 & 150 & 13.3 & 74 & 8.5 \\
Sex & & & & \\
$\quad$ Male & 688 & 61.0 & 499 & 57.2 \\
$\quad$ Female & 440 & 39.0 & 373 & 42.8 \\
$\quad$ TB detection in Japan & & & & \\
$\quad$ Health screening & 646 & 57.3 & 393 & 45.1 \\
$\quad$ Self-health-care seeking at clinics and hospitals & 482 & 42.7 & 478 & 54.9 \\
Total & $\mathbf{1 1 2 8}$ & $\mathbf{1 0 0 . 0}$ & $\mathbf{8 7 2}$ & $\mathbf{1 0 0 . 0}$ \\
\hline
\end{tabular}

TB, tuberculosis.

(530 cases, 46.9\%) followed by Viet Nam (131 cases, $11.6 \%$ ) and Nepal (127 cases, 11.2\%) (Figure 1). Information on the countries of origin was unavailable in about $5 \%$ of the cases.

\section{TB notification rates}

The overall TB notification rates in foreign students are shown in Figure 2 with an increasing trend from 104 to 140 per 100000 population between 2011 and 2014. TB notification rates for foreign students were highest in students from the Philippines (675/100 000 person years [PYs], $95 \% \quad \mathrm{Cl}$ : 372-977/100 000 PYs) followed by Myanmar (617/100 000 PYs, 95\% Cl: 417-817/100 000 PYs) and Nepal (498/100 000 PYs, 95\% Cl: 385-611/100 000 PYs). TB notification rates in other countries were less than 400/100 000 PYs (Figure 3).

The TB notification rates in foreign students from seven countries were significantly higher than the average notification rate in their countries of origin: China (101 versus 65/100 000 PYs, Indonesia (361 versus 130/100 000 PYs), Mongolia (363 versus 166/100 000 PYs), Myanmar (617 versus 272/100 000 PYs), Nepal (498 versus 131/100 000 PYs), the Philippines (675 versus 234/100 000 PYs) and Viet Nam (231 versus 112/100 000 PYs). The notification rates in students from the Republic of Korea (38 versus 95/100 000 PYs) and Taiwan, China (27 versus $52 / 100000$ PYs) were significantly lower than that in their original countries and areas (Figure 3 ). In the other countries, the differences between the two notification rates were not statistically significant $(P>0.05)$.

\section{DISCUSSION}

To our knowledge, this is the first report on TB in an immigrant subpopulation in Japan. Almost all of the TB cases among foreign students were captured because most educational institutions in Japan conduct entry health screening with chest $X$-rays as required by law. Our results show that the overall TB notification rates in foreign students increased from 2010 to 2014. Increases in enrolment of foreign students from countries with higher notification rates of TB such as Viet Nam and Nepal in recent years may be the reason for the increase in the overall TB notification rate in foreign students in Japan. ${ }^{2,7}$

The national TB programmes of many countries might not capture all the TB cases either because of insufficient technical and managerial capacity or because TB patients seek health care from the private sector and are not reported to the programme ${ }^{4,5}$ unless special arrangements are made. ${ }^{6}$ Therefore their TB notification rates appear to be lower than in reality. This might explain the higher notification rates in foreign students than the overall TB notification rates in their original countries. This explanation is also supported by the findings of a previous study, which screened for TB in United States of America immigrants, that found a high prevalence of smear-negative TB (more than 500 per 100000 population) in those born in China, the Philippines and Viet Nam. ${ }^{13}$

Some of the student TB cases detected in Japan may not be incident cases but rather may be prevalent cases who had developed TB before they were screened 
Figure 1. Geographical distribution of countries and areas of origin of TB cases among foreign students who studied in Japan, 2010-2014*

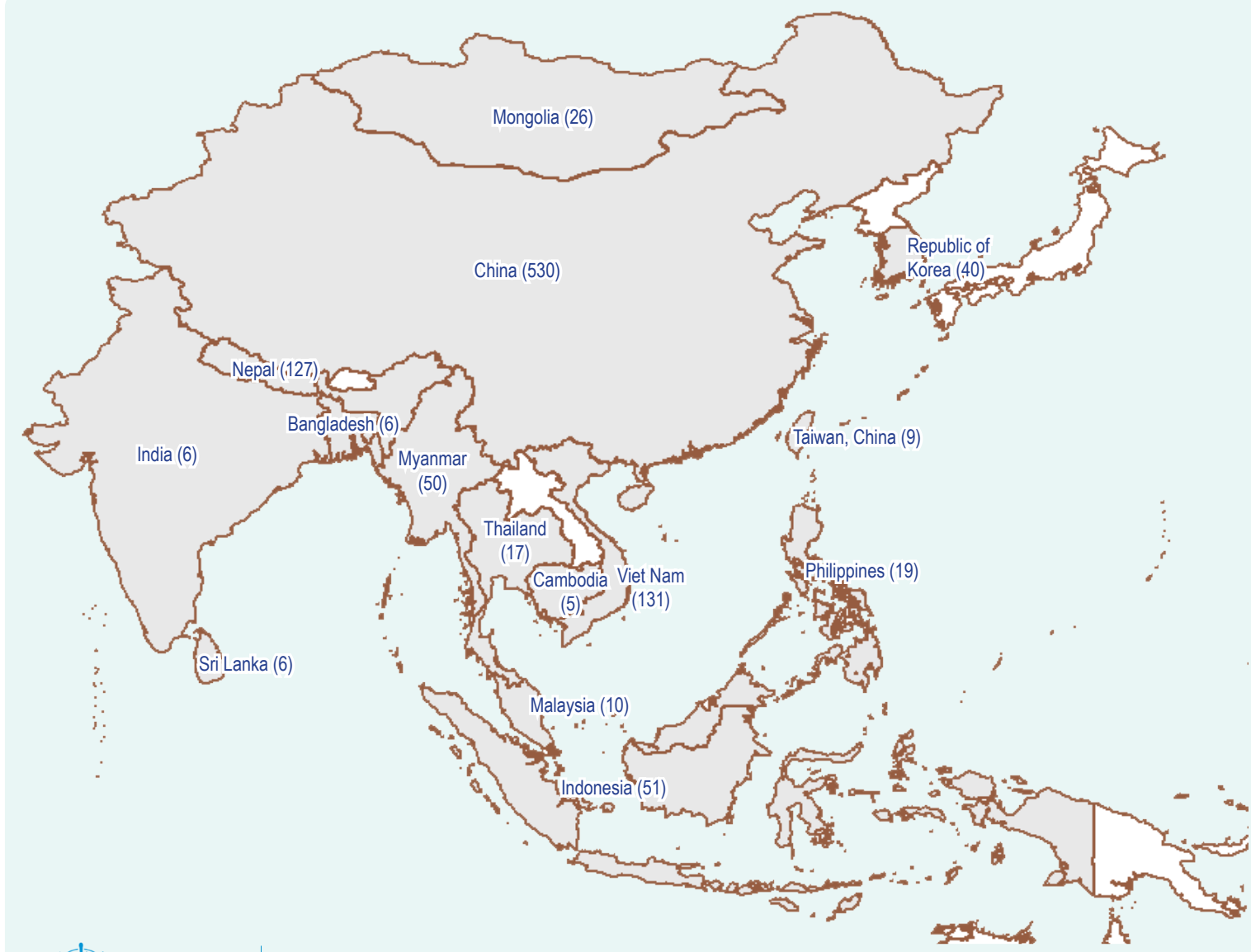

World Health Disclaimer: The boundaries shown and the designations used on this map do not imply the expression of any opinion 15 Organization whatsoever on the part of the World Health Organization concerning the legal status of any country, territory, city or area or of its authorities, or concerning the delimitation of its frontiers or boundaries. White lines on maps represent Western Pacific Region approximate border lines for which there may not yet be full agreement.

* Non-Asian countries and countries having fewer than four TB cases or fewer than 300 students are not shown.

TB, tuberculosis.

Figure 2. TB notification rates among foreign students, Japan, 2010-2014

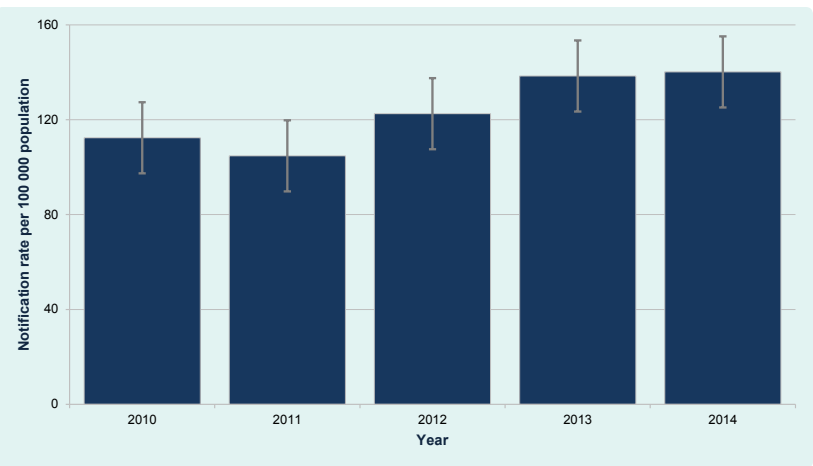

Error bars indicate $95 \%$ confidence intervals of the estimates. TB, tuberculosis. at the educational institutions. This might have made the student TB notification rates higher than the overall notification rate in their original countries and areas. However, about half of the TB patients sought health care only after they had arrived in Japan, suggesting they were incident cases. We believe the student TB notification rates mostly represent incidence of TB with some reflection of prevalence, although we do not know to what extent.

On the other hand, certain students may have come from regions with a higher TB notification rate than their national average. ${ }^{14}$ Also, students who had already developed TB may have transmitted the disease 
Figure 3. TB notification rates in foreign students in Japan and that of their countries and areas of origin, 2010-2014

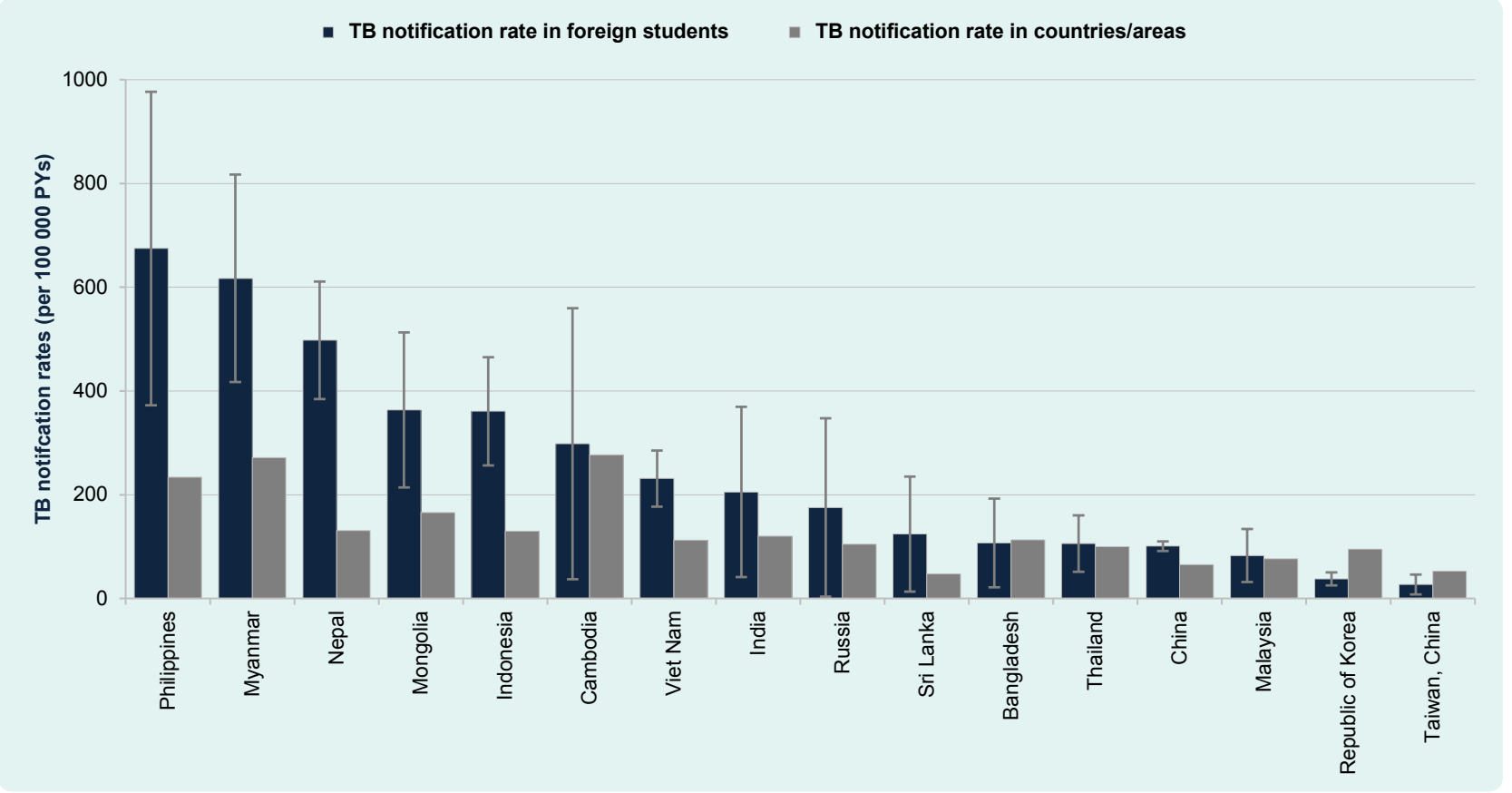

Error bars indicate $95 \%$ confidence intervals of the estimates.

PY, person years; TB, tuberculosis.

to other students after arriving in Japan. This could lead to a cluster of TB cases in the immigrant community and result in higher notification rates in this group than their national averages. In addition, in some countries and areas, TB burden is highest in the elderly population. Most of the foreign students from the Republic of Korea and Taiwan, China were aged 18 to 27 years, and the results show that their TB notification rates were lower than the national averages of their own countries and areas. $^{2,11}$

This study is based on routine surveillance data and has its limitations. First, the TB diagnostic data might have misclassifications or misdiagnoses. We were also unable to verify the occupational status data for each case. Second, about $5 \%$ of the foreign students with TB and information on their countries of origin were not available. The notification rates might be underestimated. Third, the survey conducted by JASSO might not capture all the students in Japan (nevertheless we were able to include short-term students who accounted for about $8 \%$ of the foreign students in this study). Furthermore, it is practically impossible to distinguish whether TB infections in the foreign students occurred before or after entering Japan. However, considering the low TB notification rate of Japanese residents, particularly young adults (less than 10 per 100000 population in 2014 for those aged 15 to 34 years) ${ }^{1}$ with whom foreign students are likely to socialize, the number of cases infected with TB after entering Japan is considered negligible.

We were unable to compare the case detection proportion between health screening at the education institutions (active screening) and self-health-care seeking at clinics and hospitals (passive screening) in this study as the total numbers of screened subjects in the two screening systems were not available. This should be addressed in future research.

Most countries with a low burden of TB in Europe, the Middle East, North America and Oceania have implemented systemic TB screening for immigrants, ${ }^{13,15}$ and such measures should be considered in Japan to further reduce the TB burden. ${ }^{16,17}$ In most South-East Asian countries, the peak age of developing TB is now shifting to the elderly (65 years or older). ${ }^{2}$ In assessing the risk of developing TB among immigrants who are mostly aged $20-50$ years, 
the TB notification rates in a subpopulation of immigrants may reflect the true TB rate better than the overall TB notification rate in their countries of origin especially when age-specific rates of these countries are not available. In future TB control programme management in Japan, the notification rates among foreign students can serve as a good reference to identify the immigrants' countries of origin with the necessity of pre-entry screening.

\section{Conflicts of interest}

None declared.

\section{Funding}

This study was supported through a Grant-in-Aid for Research Program on Emerging and Re-emerging Infectious Diseases (15fk0108004h001) by Japan Agency for Medical Research and Development and Ministry of Health, Labour, and Welfare.

\section{References}

1. Kekkaku no toukei 2015 (Statistics of TB 2015) [in Japanese]. Tokyo, Kekkaku Yobo kai (JATA), 2015.

2. Tuberculosis country profiles. Geneva, World Health Organization, 2015 (http://www.who.int/tb/country/data/profiles/en/, accessed 22 March 2016).

3. Tuberculosis Surveillance Center; RIT; JATA. [Tuberculosis annual report 2013-(1) Summary of tuberculosis notification statistics and foreign-born tuberculosis patients]. Kekkaku, 2015, 90:437443. pmid:26477115

4. Kumar M, Kumar S. Tuberculosis control in India: role of private doctors. Lancet, 1997, 350(9087):1329-1330. doi:10.1016/ S0140-6736(05)62497-X pmid:9357438

5. The burden of disease caused by TB. In: Global tuberculosis report 2014. Geneva, World Health Organization, 2014: 7-31 (http:// apps.who.int/iris/bitstream/10665/137094/1/9789241564809_ eng.pdf, accessed 22 March 2016).
6. Maung $\mathrm{M}$ et al. Private GPs contribute to TB control in Myanmar: evaluation of a PPM initiative in Mandalay Division. International Journal of Tuberculosis and Lung Diseases, 2006, 10(9):982987. pmid: 16964788

7. Result of an annual survey of international students in Japan, 2014 [in Japanese]. Tokyo, Japan Students Services Organization, 2014 (http://www.jasso.go.jp/about/statistics/intl_student_youryo/ index.html, accessed 22 March 2016).

8. Regulations related to the School Safety and Health Act of 1958 [in Japanese]. Tokyo, Ministry of Education, Culture, Sports, Science and Technology, 2008 (http://law.e-gov.go.jp/htmldata/ S33/S33F03501000018.html, accessed 22 March 2016).

9. National Standard of Tuberculosis Care (revised in 2016) [in Japanese]. Tokyo, Ministry of Health Labour and Welfare, 2016 (http://www.mhlw.go.jp/file/06-Seisakujouhou-10900000Kenkoukyoku/0000110838.pdf, accessed 22 March 2016).

10. Ohmori $\mathrm{M}$ et al. Computerized surveillance system of tuberculosis in Japan: its evolution, achievement and challenges. Kekkaku, 2012, 87(1):15-23. pmid:22416477

11. Centers for Disease Control annual report 2015. Taiwan, China, Ministry of Health and Welfare, 2015 (http://www.cdc gov.tw/uploads/files/201509/c9b61bbe-4a3b-40a9-8dceOf8b3d9cc2c7.pdf, accessed 22 March 2016).

12. Data query: Total population by sex (thousands). New York, United Nations Population Division, 2015 (http://esa.un.org/unpd/ wpp/DataQuery/, accessed 22 March 2016).

13. Liu $Y$ et al. Overseas screening for tuberculosis in U.S.-bound immigrants and refugees. New England Journal of Medicine, 2009, 360(23):2406-2415. doi:10.1056/NEJMoa0809497 pmid: 19494216

14. Wang $L$ et al. Tuberculosis prevalence in China, 1990-2010; a longitudinal analysis of national survey data. Lancet, 2014, 383(9934):2057-2064. doi:10.1016/S0140-6736(13)626392 pmid:24650955

15. Aldridge RW et al. Pre-entry screening programmes for tuberculosis in migrants to low-incidence countries: a systematic review and meta-analysis. Lancet Infectious Diseases, 2014 14(12):1240-1249. doi:10.1016/S1473-3099(14)70966-1 pmid:25455991

16. Ministry of Foreign Affairs et al. Stop TB Japan action plan. Tokyo, Stop TB Partnership Japan, 2014 (http:// www.stoptb.jp/dcms media/other/Action\%20PIan(F).pdf, accessed 5 April 2016).

17. Systematic screening for active tuberculosis: principles and recommendations. Geneva, World Health Organization, 2013 (http://www.who.int/tb/tbscreening/en/, accessed 22 March 2016). 


\title{
Profile of tuberculosis among the foreign- born population in Japan, 2007-2014
}

\author{
Lisa Kawatsu, ${ }^{a}$ Kazuhiro Uchimura, ${ }^{a}$ Kiyohiko Izumi, ab Akihiro Ohkadoab and Nobukatsu Ishikawa ${ }^{a}$ \\ Correspondence to Lisa Kawatsu (email: kawatsu@jata.or.jp).
}

The proportion of foreign-born people among the newly notified tuberculosis (TB) patients has been increasing in recent years and potentially poses a new challenge to TB control in Japan. In this report, we analysed the data from the Japan TB surveillance system between 2007 and 2014 to gain an overview of the trends and characteristics of foreign-born TB patients in Japan.

We found that the proportion of foreign-born TB patients was especially high among the younger age groups $-44.1 \%$ among the 20-29 years age group in 2014. The largest groups of foreign-born patients were from China and the Philippines; however, the number of those from Nepal and Viet Nam was on the rise. Students comprised the second largest professional category group for TB after regular workers, and its proportion increased over the study period. Compared to Japan-born TB patients, foreign-born patients were more likely to be diagnosed through routine medical check-ups. Treatment successes and patients still on treatment were significantly lower among foreign-born patients than their Japan-born counterparts; and transferred-out and unknown outcomes were higher. Our results indicated that distinctive subgroups within the foreignborn population in Japan, especially students and regular workers, might have a higher risk of developing TB. Measures to ensure early diagnosis and treatment adherence should be adapted to such populations.

$n$ many tuberculosis (TB) low-incidence countries, foreign-born people bear a disproportionate burden of the disease. Studies have indicated that these people often encounter various socioeconomic, cultural and behavioural challenges in their host countries that not only increase their risk of developing TB but also delay diagnosis and poor treatment outcomes. ${ }^{1,2}$ In Japan, a TB middle-burden country, the notification rate was 15.4 per 100000 population in 2014 with foreignborn TB patients contributing $5.8 \%$ to the total newly notified cases. ${ }^{3}$ The proportion has been increasing and potentially poses a new challenge to TB control in Japan. 4

Japan introduced its first nationwide computerized TB surveillance system, the Japan Tuberculosis Surveillance (JTBS), in 1987. TB is a notifiable disease and local public health centres (PHCs) are responsible for entering the data of notified patients into the system. The data are updated every month. Major findings are published annually and are available online. ${ }^{5}$ Data quality is ensured via the system's automatic verification programme as well as regular meetings at local levels attended by staff from hospitals and PHCs. Periodic refresher trainings on data entry are also provided to $\mathrm{PHC}$ nurses across the nation.
Sound policy-making should be informed by scientific evidence, and a detailed analysis of surveillance data can provide one such resource. In this report, we analysed the data from the JTBS between 2007 and 2014 to gain an overview of the burden of foreign-born TB patients in Japan.

\section{METHODS}

We conducted a cross-sectional study whereby aggregated data of newly registered TB cases in the JTBS between 1 January 2007 and 31 December 2014 were analysed. The years 2007 to 2014 were chosen as the study period as the information regarding nationality (either "Japanese" or "non-Japanese") was added to JTBS in 1998, and country name and year of entry (either "within five years," or "more than five years" or "unknown") were only added in 2007. In 2012, the category of nationality was changed to country of birth (either "Japan-born", "foreign-born" or "unknown"). Definitions of variables are described in detail in Table 1. Characteristics of foreign-born TB patients were summarized by number and proportion by sex and age groups; country of birth; professional status; mode of detection; treatment outcome; multidrug resistance (MDR); and status of HIV co-infection. Where appropriate, these characteristics

\footnotetext{
The Research Institute of Tuberculosis, Japan, Anti-Tuberculosis Association, Tokyo, Japan.

Graduate School of Biomedical Sciences, Nagasaki University, Nagasaki, Japan.

Submitted: 30 March 2016; Published: 15 June 2016

doi: 10.5365/wpsar.2016.7.1.008
} 


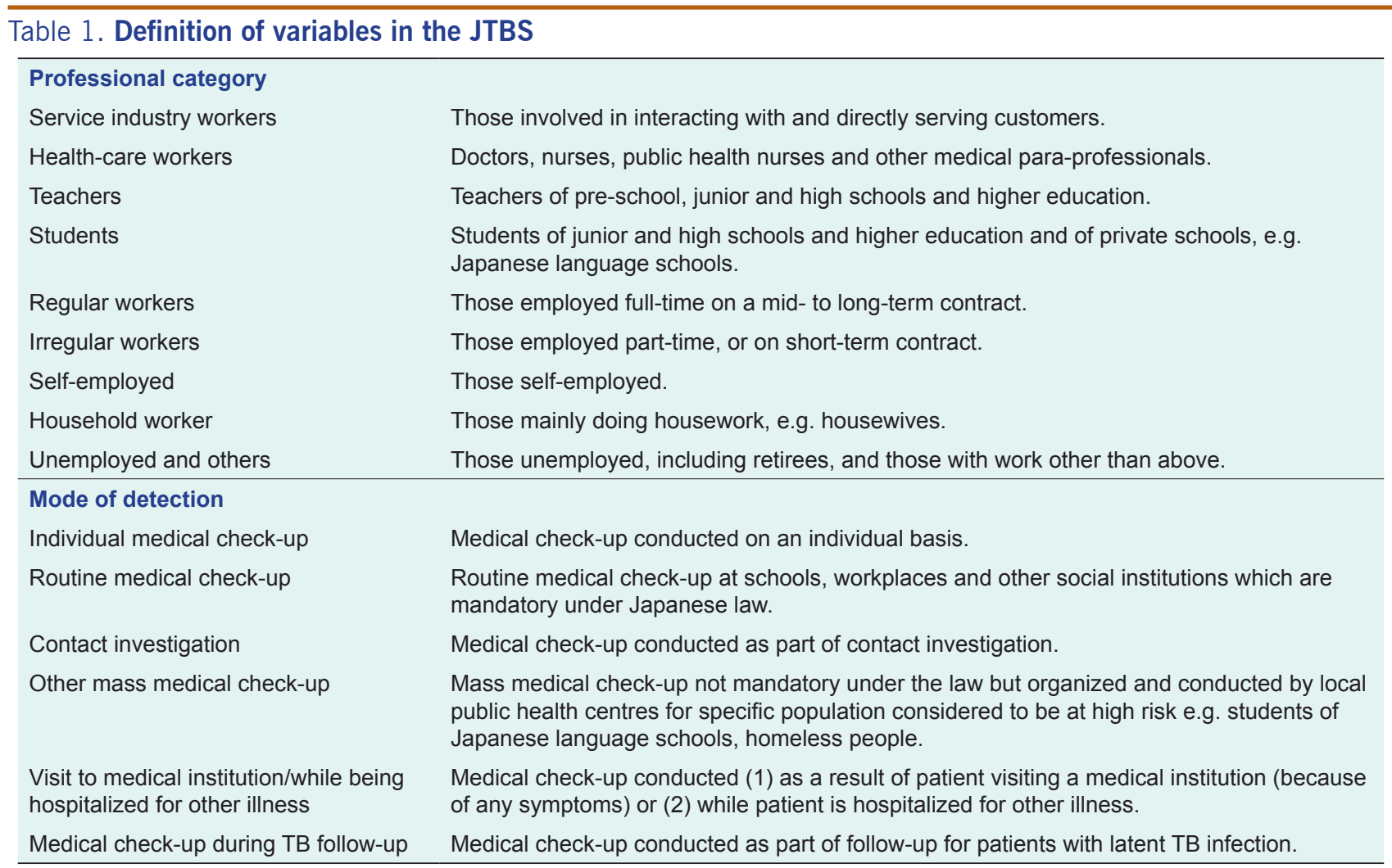

were compared with those of the Japan-born patients. Data of those whose country of birth was "unknown" were excluded from the analysis.

Chi-square test was conducted to compare proportions for the modes of detection and treatment outcomes among Japan- and foreign-born patients. Ageadjusted rate for treatment outcomes of the two groups were calculated using the 2010 population census data. ${ }^{6}$ Data trend was evaluated by the Cochran-Armitage test for trend. A $P$-value $<0.05$ was considered statistically significant. R version 3.1.3 (R Development Core Team, Vienna, Austria) was used for all statistical analyses.

Ethical clearance was not required as the JTBS data do not include case identifiers, as according to the Ethical Guidelines for Epidemiological Research established by Ministry of Education, Culture, Sports, Science and Technology and Ministry of Health, Labour and Welfare of Japan.

\section{RESULTS}

\section{General trend}

Between 2007 and 2014, of a cumulative total of 181576 newly notified TB cases, 7832 were foreignborn $(4.3 \%)$. The number of newly notified foreignborn TB patients has steadily increased from 842 in 2007 to 1101 in 2014. The proportion of foreign-born patients among the newly notified TB patients has also steadily increased (Figure 1a) with the most prominent rise among 20-29 years olds (Figure 1b). In 2014, $44.1 \%$ of TB cases among those aged 20-29 were foreign-born.

\section{Country of birth}

Major countries of birth (or nationality, before 2012) among the foreign-born patients who entered Japan within the past five years and those who entered Japan 
Figure 1a. Foreign-born TB cases among newly notified TB patients, Japan, 2007-2014

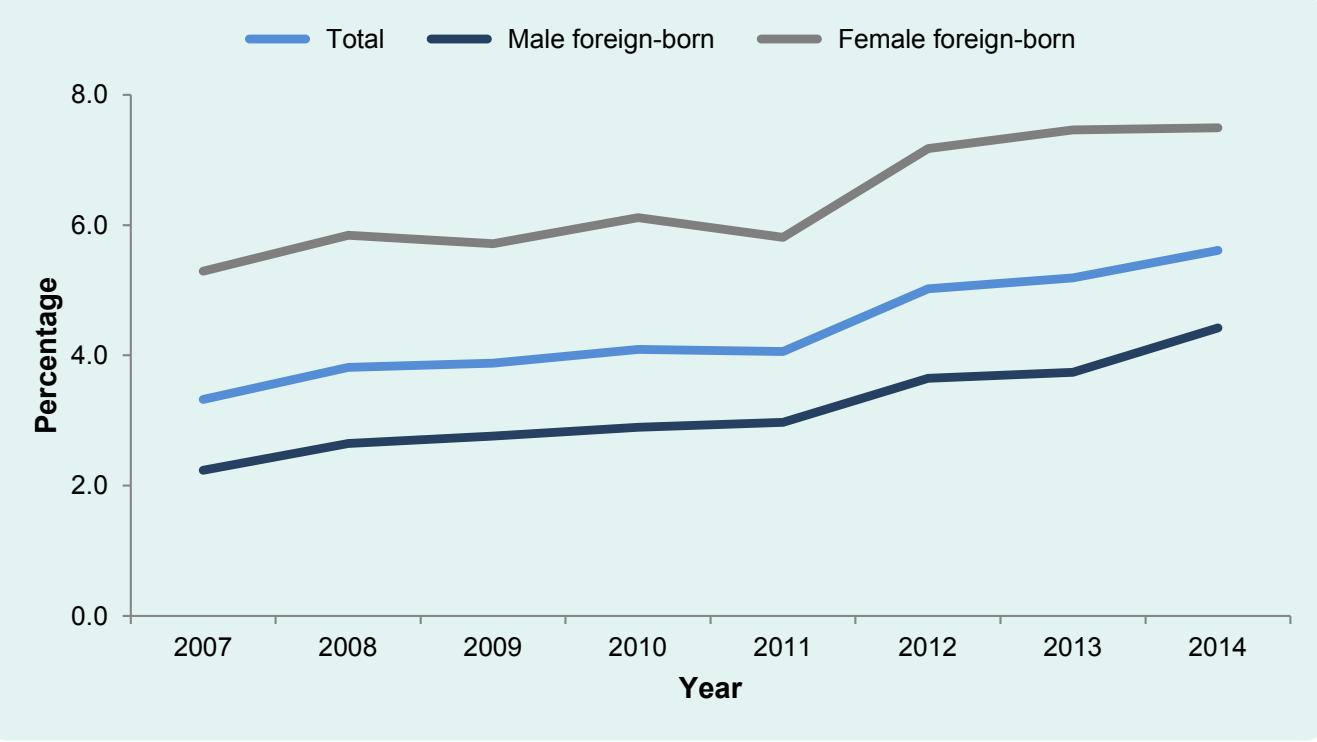

Figure 1b. Foreign-born TB cases among newly notified TB patients by age group, Japan, 2007-2014

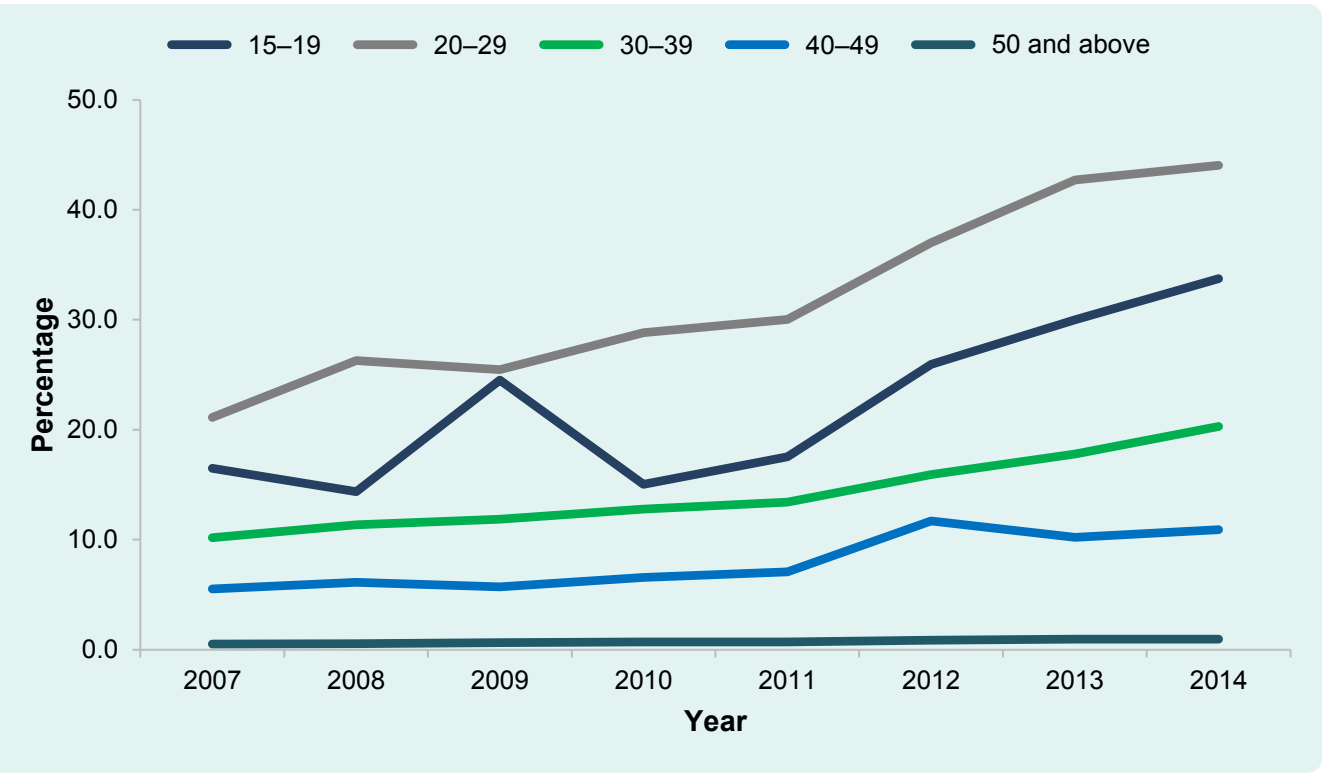

more than five years ago are summarized in Figures 2a and $\mathbf{2 b}$. The largest two groups have consistently been those from China and the Philippines. China occupied a greater share among the recently arrived TB patients (China, 32.7\%; the Philippines, 15.2\%; Figure 2a), while those from the Philippines occupied a greater share among those who have entered Japan more than five years ago (China, 18.3\%; the Philippines, $31.6 \%$; Figure $2 \mathrm{~b}$ ). The proportions of those from Nepal and Viet Nam have significantly increased among the recently arrived TB patients (Nepal; $P<0.01, \chi^{2}=45.9$, Viet Nam; $P<0.01, \chi^{2}=42.6$ ).

\section{Professional category}

Of the cumulative total of 7832 foreign-born patients between 2007 and 2014, 26.3\% of them were regular workers and $21.4 \%$ were students (Table 2). The proportions of foreign-born TB patients among students and health-care workers have significantly increased (students, $P<0.01, \chi^{2}=21.7$; health-care workers, $P<0.01, \chi^{2}=11.2$ ), while those of irregular and day workers, and household workers have significantly decreased (irregular and day workers, $P<0.01$, $\chi^{2}=12.4 ;$ household workers; $P<0.01, \chi^{2}=17.0$ ) 
Figure 2a. Countries of birth among foreign-born TB patients who entered Japan within five years, 2007-2014

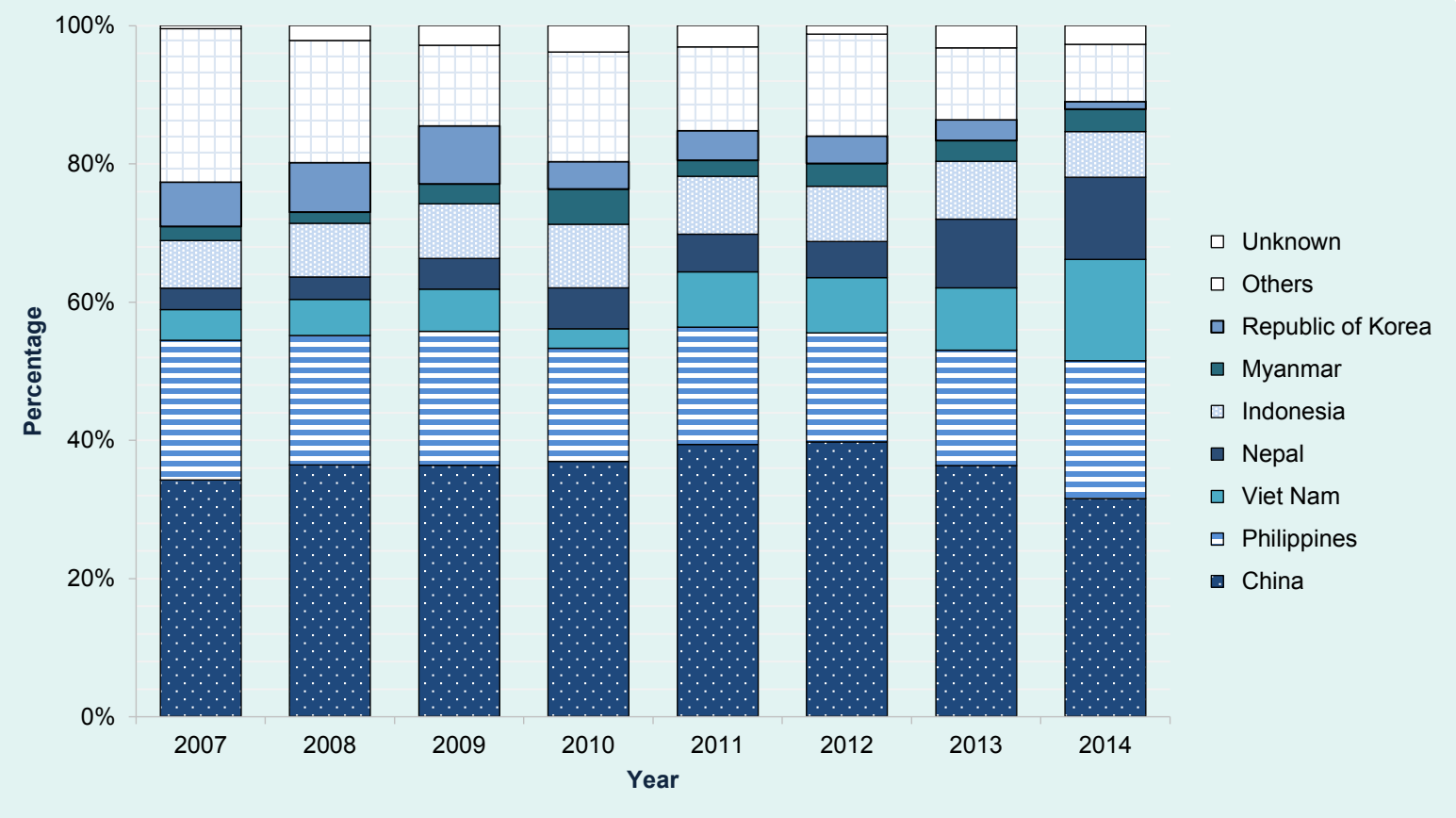

Figure 2b. Countries of birth among foreign-born TB patients who entered Japan more than five years ago, 2007-2014

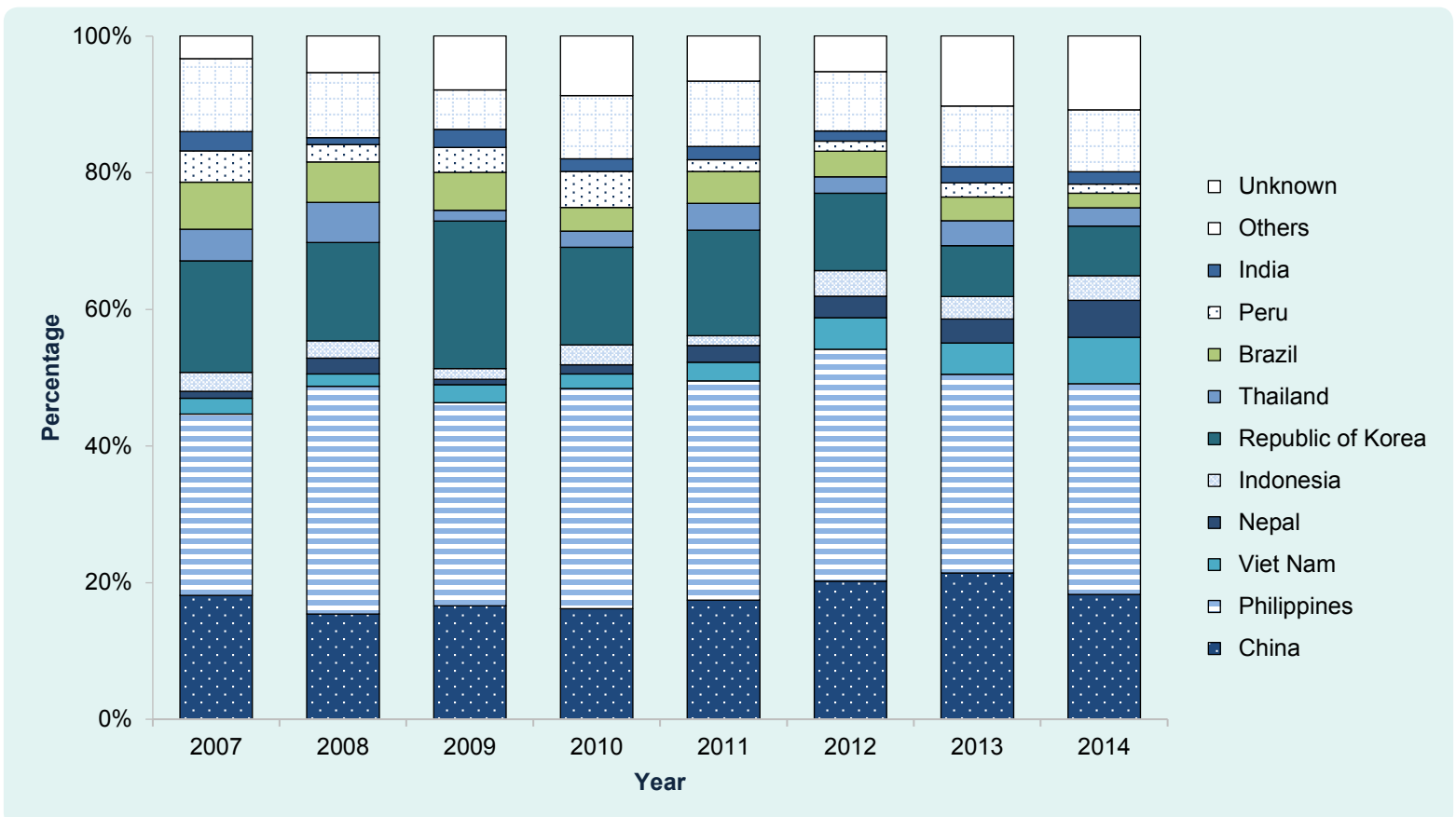


Figure 3. Proportion of selected professional categories among foreign-born TB patients, Japan, 2007-2014

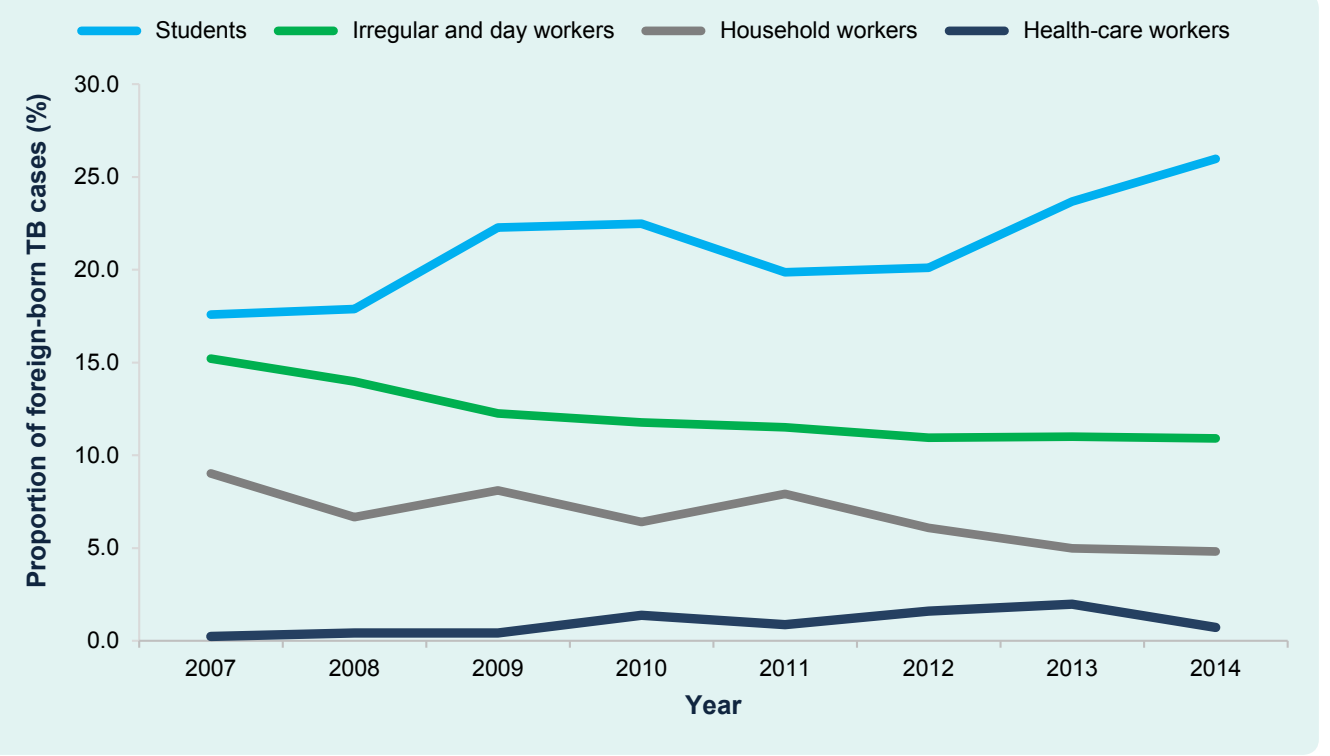

(Figure 3). Proportions of other professional categories remained constant.

\section{Mode of detection}

Of the cumulative total of 7832 foreign-born TB patients, $67.2 \%$ were diagnosed while visiting medical institution with TB or other symptoms or during hospitalization for other diseases; whereas $22.3 \%$ were diagnosed through routine medical check-up (Table 3 ).

Stratified by students and regular workers, a significantly higher proportion of foreign-born students was diagnosed through routine or other mass medical check-ups (ad hoc medical check-up usually organized by PHCs) than the Japan-born students. On the other hand, a significantly lower proportion of foreignborn regular workers was diagnosed through routine medical check-up than their Japan-born counterparts (Table 4). However, as shown in Figure 4, the proportion of foreign-born students diagnosed through routine medical check-up had significantly decreased throughout the study years $\left(P=0.01, \chi^{2}=6.1\right)$, while the proportion of those diagnosed through other mass medical checkups had significantly increased $\left(P<0.01, \chi^{2}=23.9\right)$. The proportion of foreign-born regular workers diagnosed through routine medical check-up had significantly increased $\left(P<0.01, \chi^{2}=8.2\right)$ while the proportion of those diagnosed while visiting medical institution had significantly decreased $\left(P<0.01, \chi^{2}=12.8\right)$.

\section{Treatment outcome}

Of the cumulative total of 5353 foreign-born patients between 2007 and 2013, 53.4\% had successfully completed treatment while $11.5 \%$ had transferred out. Compared with the Japan-born patients, after adjusting for age, the proportion of "success" and "treatment exceeding 12 months" was significantly lower, and "transferred-out" and "unknown" significantly higher among the foreign-born patients (Table 5).

\section{Multidrug-resistant (MDR)-TB and HIV co-infection}

The proportion of MDR-TB among the foreign-born TB patients was significantly higher than that among the Japan-born patients (3.2\% versus $0.2 \%$ ) over the years 2007-2014. The number of TB cases was also on the increase (Figure 5 ). Of the cumulative total of 99 foreign-born MDR-TB patients, 44.4\% $(n=44)$ were from China and $13.1 \%(n=13)$ from the Philippines.

The proportion of HIV co-infected cases also had been significantly higher among the foreign-born patients than among the Japan-born TB patients ( $1.2 \%$ versus $0.2 \%$ ) between 2007 and 2014; however no obvious increase was observed in the proportion both among the foreign- and Japan-born patients during the study period (Figure 6). Of the cumulative total of 96 foreign-born HIV co-infected patients, $16.7 \%(n=16)$ were from 
Thailand, $11.5 \%(n=11)$ from Myanmar and $10.4 \%$ ( $n=10)$ from Brazil.

\section{DISCUSSION}

Compared to many other low TB incidence countries, the current burden of foreign-born TB patients was relatively low in Japan. However, this proportion has been increasing steadily, especially among the younger age groups. This may partially be explained by the drastic increase in the number of foreign-born people entering Japan to study at Japanese language schools, many of whom are young and from TB high-burden countries. According to one study, the number of foreignborn people travelling to Japan to study at language schools increased from 25622 in 2011 to 44970 in 2014 - an increase of $37.8 \% .^{7}$ In 2015 , students from
Table 2. Professional categories of foreign-born TB patients, Japan, 2007-2014

\begin{tabular}{lrr}
\hline \multicolumn{1}{c}{ Professional categories } & \multicolumn{1}{c}{$\boldsymbol{n}$} & \multicolumn{1}{c}{$\%$} \\
\hline Regular workers & 2062 & 26.3 \\
Students & 1676 & 21.4 \\
Irregular and day workers & 947 & 12.1 \\
Household workers & 520 & 6.6 \\
Service industry workers & 466 & 5.9 \\
Self-employed & 146 & 1.9 \\
Health-care workers & 77 & 1.0 \\
Infants and pre-school children & 66 & 0.8 \\
Teachers & 30 & 0.4 \\
Unemployed and others & 1551 & 19.8 \\
Unknown & 291 & 3.7 \\
Total & 7832 & 100.0 \\
\hline
\end{tabular}

Table 3. Mode of TB case detection of Japan- and foreign-born TB patients, Japan, 2007-2014

\begin{tabular}{|c|c|c|c|c|}
\hline \multirow{2}{*}{ Mode of detection } & \multicolumn{2}{|c|}{ Japan-born } & \multicolumn{2}{|c|}{ Foreign-born } \\
\hline & $n$ & $\%$ & $n$ & $\%$ \\
\hline Visit to medical institution/while being hospitalized for other illness & 139506 & 82.7 & 5264 & 67.2 \\
\hline Routine medical check-up & 17061 & 10.1 & 1747 & 22.3 \\
\hline Contact investigation & 5086 & 3.0 & 333 & 4.3 \\
\hline Individual medical check-up & 3657 & 2.2 & 185 & 2.4 \\
\hline Medical check-up during TB follow-up & 629 & 0.4 & 26 & 0.3 \\
\hline Other mass medical check-up & 522 & 0.3 & 147 & 1.9 \\
\hline Others & 1159 & 0.7 & 62 & 0.8 \\
\hline Unknown & 1021 & 0.6 & 68 & 0.9 \\
\hline Total & 168641 & 100.0 & 7832 & 100.0 \\
\hline
\end{tabular}

Table 4. Mode of TB case detection among Japan- and foreign-born TB patients by selected professional categories, Japan, 2007-2014

\begin{tabular}{|c|c|c|c|c|c|c|}
\hline \multirow{2}{*}{ Mode of detection } & \multicolumn{3}{|c|}{ Students } & \multicolumn{3}{|c|}{ Regular workers } \\
\hline & Japan-born (\%) & Foreign-born (\%) & $p$-value* & Japan-born (\%) & Foreign-born (\%) & $p$-value* \\
\hline Individual medical check-up & 3.8 & 2.4 & $<0.05$ & 2.7 & 1.7 & $<0.05$ \\
\hline Routine medical check-up & 37.1 & 47.5 & $<0.01$ & 29.4 & 25.5 & $<0.05$ \\
\hline Contact investigation & 11.5 & 3.9 & $<0.01$ & 5.7 & 5.1 & 0.16 \\
\hline Other mass medical check-up & 1.0 & 7.0 & $<0.05$ & 0.3 & 0.3 & 0.98 \\
\hline $\begin{array}{l}\text { Visit to medical institution/while } \\
\text { being hospitalized for other } \\
\text { illness }\end{array}$ & 44.3 & 37.4 & $<0.01$ & 60.4 & 66.3 & $<0.05$ \\
\hline $\begin{array}{l}\text { Medical check-up during TB } \\
\text { follow-up }\end{array}$ & 1.0 & 0.2 & $<0.05$ & 0.5 & 0.4 & 0.53 \\
\hline Others & 0.4 & 0.6 & 0.44 & 0.4 & 0.3 & 0.55 \\
\hline Unknown & 0.9 & 1.0 & 0.18 & 0.5 & 0.4 & 0.29 \\
\hline Total & 100.0 & 100.0 & & 100.0 & 100.0 & \\
\hline
\end{tabular}

* By Chi-square test. 
Figure 4. Mode of TB case detection among foreign-born TB patients by selected professional categories, Japan, 2007-2014

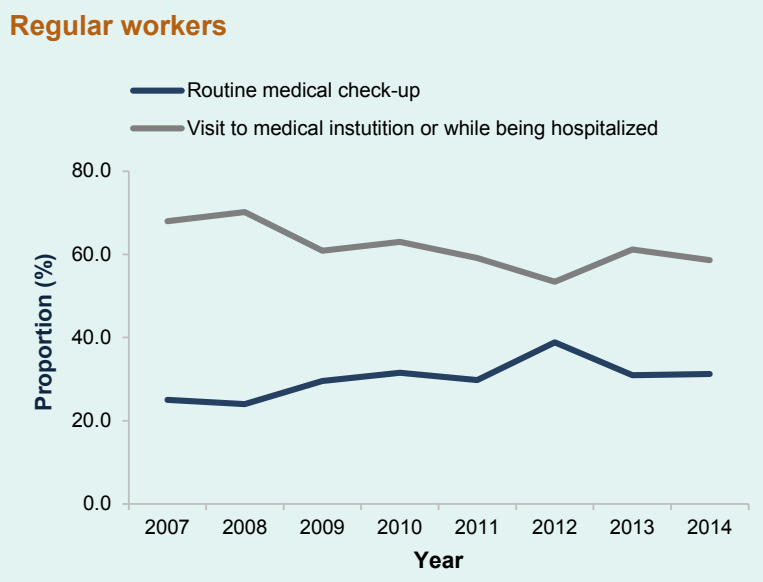

Students

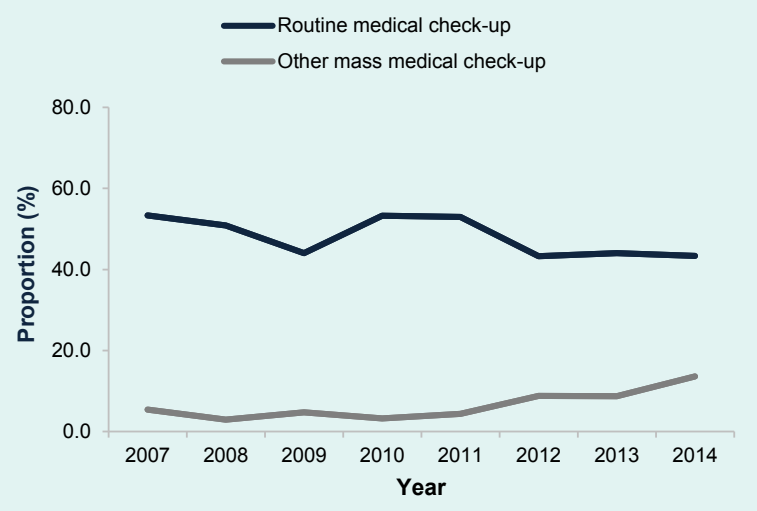

Table 5. Treatment outcomes of Japan- and foreign-born TB patients, Japan, 2007-2013*

\begin{tabular}{|c|c|c|c|c|c|}
\hline \multirow{2}{*}{ Treatment outcome } & \multirow{2}{*}{$\begin{array}{c}\text { Japan-born } \\
n\end{array}$} & \multicolumn{3}{|c|}{ Foreign-born } & \multirow{2}{*}{ Adjusted rate ratio $(95 \% \mathrm{Cl})$} \\
\hline & & $\%^{\dagger}$ & $n$ & $\%^{\dagger}$ & \\
\hline Success & 63334 & 62.6 & 3091 & 53.4 & $0.85(0.81-0.90)$ \\
\hline Died & 18856 & 6.1 & 89 & 5.2 & $0.86(0.70-1.06)$ \\
\hline Treatment failed & 815 & 0.7 & 30 & 0.7 & $1.05(0.59-1.87)$ \\
\hline Lost to follow-up & 8645 & 7.7 & 402 & 6.9 & $0.90(0.77-1.06)$ \\
\hline Transferred out & 2795 & 3.4 & 706 & 11.5 & $3.40(2.88-4.01)$ \\
\hline Treatment exceeding 12 months & 11545 & 8.5 & 349 & 7.2 & $0.84(0.71-0.98)$ \\
\hline Unknown & 14462 & 11.0 & 686 & 15.1 & $1.37(1.17-1.60)$ \\
\hline Total & 120452 & 100.0 & 5353 & 100.0 & \\
\hline
\end{tabular}

* The cohort data were only available until 2013.

${ }^{\dagger}$ Adjusted by age, using the population census of $2010 .{ }^{6}$

$\mathrm{Cl}$, confidence interval.

China consisted the largest group (36.4\%), followed by Viet Nam (30.9\%) and Nepal (12.4\%). However, over the past decade, the proportion of students from China has steadily declined while those from Viet Nam and Nepal have increased eleven-fold and fivefold, respectively. ${ }^{8}$ These recent trends among Japanese language school students were clearly reflected in the countries of birth and the professional categories of foreign-born TB patients in this study. An increase in the number of Japanese language school students also explains the rising proportion of students diagnosed through other mass medical check-ups. While routine medical check-ups at universities and vocational schools are mandatory under Japanese law, check-ups at Japanese language schools are optional and often entrust the planning and implementation of medical check-ups to local PHCs.
To our knowledge, although no study has yet examined the risk factors for TB of foreign-born students in Japan, several studies have indicated that foreignborn students are prone to poor socioeconomic status and physical and mental stress after arriving in Japan. For example, a study on the health and welfare of Japanese language school students reported that $66.5 \%$ of the respondents had experienced sickness or injury since their arrival in Japan, and $10.1 \%$ were not covered by any medical insurance. Furthermore, $73.4 \%$ of them had part-time jobs; $59.5 \%$ had answered that they were working for economic reasons. ${ }^{9}$ Others have reported that foreign-born students living in Japan suffer from various psychological stress and depression. ${ }^{10,11}$

The number of registered foreign-born workers in Japan has also increased from 486000 in 2008 to 
Figure 5. MDR-TB cases among Japan- and foreign-born TB patients, 2007-2014

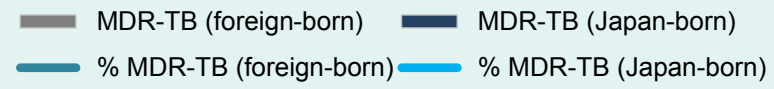

60

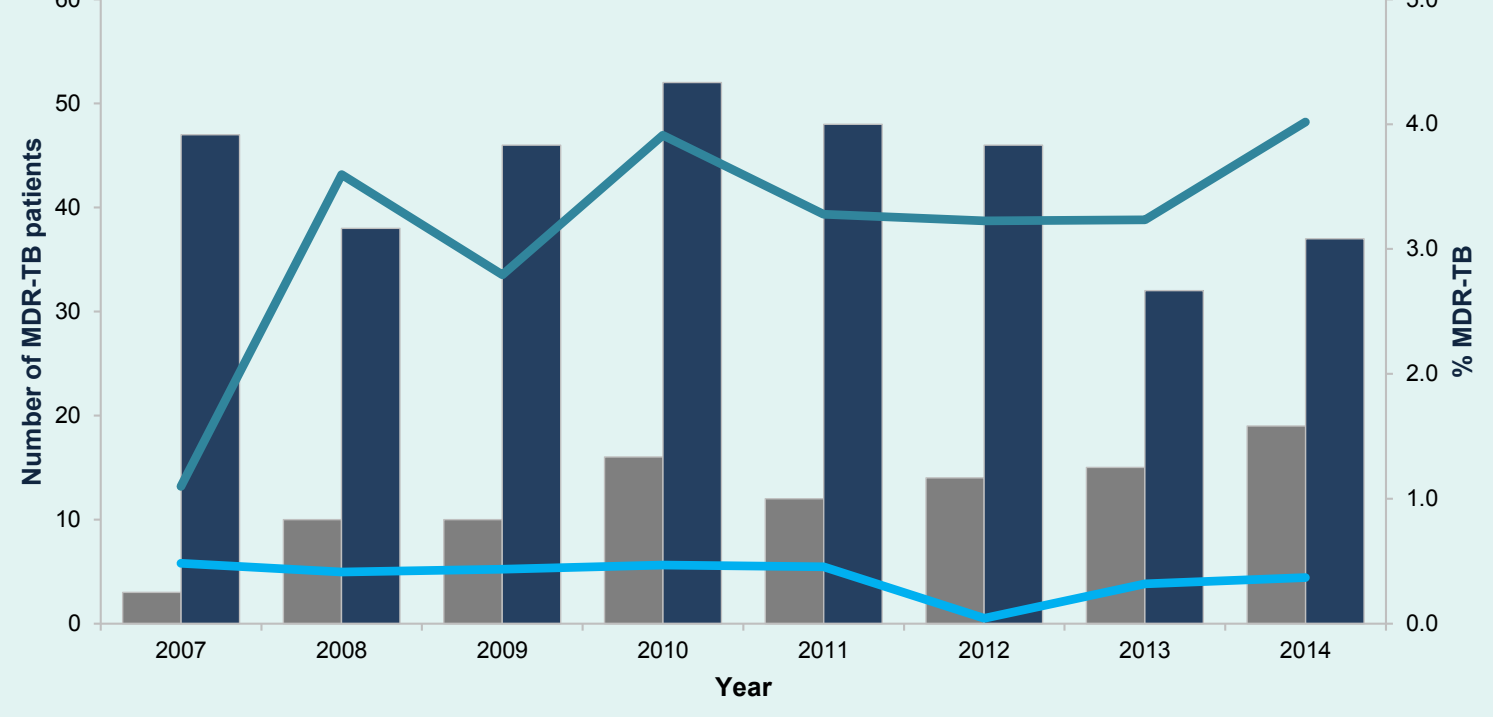

MDR-TB, multidrug-resistant tuberculosis.

Figure 6. HIV co-infected cases among Japan- and foreign-born TB patients, Japan, 2007-2014

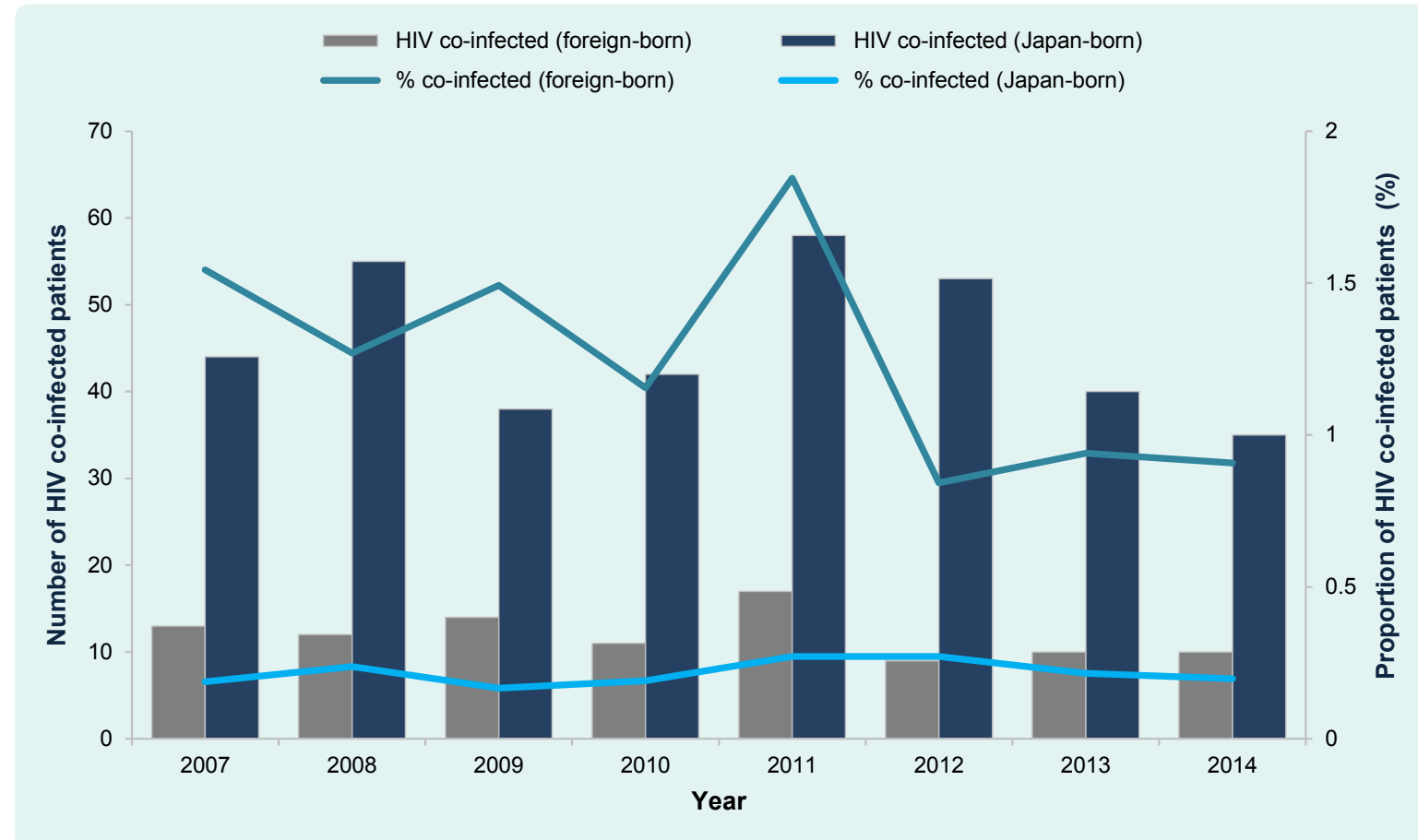

HIV, human immunodeficiency virus. 
787627 in $2014 .{ }^{12}$ However, as of 2014, we did not observe a clear increase in the proportion of regular workers among the foreign-born TB patients. This is partially due to the rise in the number of foreign-born workers on "conditional work permits" (i.e. students working part-time). When they are diagnosed with TB, however, they are registered as "students" under the JTBS. Foreign-born workers who work under the "technical internship permit" should also be noted. This work permit, introduced in 1993, and officially designed to support mainly those from developing countries to acquire skills and knowledge of Japanese advanced technology, has been criticized from various domestic and international communities as a means for Japanese companies to secure a cheap foreign labour force. ${ }^{13,14}$ It has also been reported that those on "technical internship permits" often live in poor social and economic conditions and with limited access to social and health care services in Japan. ${ }^{15}$ In 2015, 41.9\% of such workers came from Viet Nam, 29.6\% from China and $11.8 \%$ from the Philippines. ${ }^{16}$ The JTBS does not differentiate those workers on "technical internship permit" from other "regular" workers, and we cannot quantify the burden of TB among workers under this permit. However, considering the high TB burden in their home countries, and the socioeconomic vulnerability which they face in Japan, those on "technical internship permits" should be recognized as having a higher TB risk than other foreign-born people in Japan.

Treatment costs for most TB patients who require hospitalization, including those foreign-born, are subsidized by the Japanese government. Outpatients are requested to pay only $5 \%$ of their treatment cost and it is usually covered by their health insurance. The main barrier to TB treatment success is the high proportion of those who transfer out. Among the foreign-born patients, transferred-out cases mostly refer to those who have returned to their home country while they are still on treatment. Unlike "lost to follow-up" cases, whereby patients terminate treatment in Japan without informing the local PHC, "transferred-out" indicates that at least an effort was made to organize the transfer of patient from a medical institution in Japan to a relevant counterpart in the patients' home country. However, as of today, no systematic arrangement exists to enable local PHCs in Japan to confirm treatment results of foreign-born patients who have transferred out of the country.
A significantly higher proportion of MDR-TB among the foreign-born patients was expected considering the high burden of MDR-TB in the home countries of those patients. On the other hand, the proportion of HIV coinfected among the foreign-born TB patients in Japan was low, reflecting the relatively low prevalence of HIV in Asia.

The limitations of our study reflect those inherent in the JTBS. Despite TB being a notifiable disease and the various mechanisms to ensure quality control of TB surveillance data, anecdotal evidence suggests underreporting as well as inaccurate or incomplete data entry in the system. For example, Uchimura has estimated the underreporting rate of the JTBS was approximately $5 \% .{ }^{16}$ Improvements to the system in the next few years may hopefully minimize these errors.

\section{CONCLUSION}

A detailed analysis of surveillance data revealed that distinct subgroups within foreign-born populations in Japan, namely students and certain types of workers, were at a higher risk of developing TB. Measures to ensure early access to diagnosis and treatment, regardless of whether they choose to return to their home country, should be adapted to such populations for TB control and prevention.

\section{Conflicts of interest}

None declared.

\section{Funding}

This research was partially supported by the GrantIn-Aid for Research Program on Emerging and Reemerging Infectious Diseases (16fk0108301h0003) by Japan Agency for Medical Research and Development, Japan.

\section{Acknowledgements}

The authors would like to thank Ms $Y$ Yamamoto and Mr K Otake of the Department of Epidemiology and Clinical Research, RIT-JATA for their kind assistance in preparing the data. 


\section{References}

1. Wörmann T, Krämer A. Communicable diseases. In: Rechel B Mladovsky P, Devillé W, Rijks B, Petrova-Benedict R, McKee $\mathrm{M}$, editors. Migration and Health in the European Union. Maidenhead, Open University Press, 2011 (http://www.euro.who. int/ data/assets/pdf file/0019/161560/e96458.pdf, accessed 26 May 2016)

2. Migrant Health: Background Note to the ECDC Report on Migration and Infectious Diseases in the EU. Stockholm, European Center for Disease Prevention and Control, 2009 (http:// ecdc.europa.eu/en/publications/Publications/0907 TER Migrant health_Background_note.pdf, accessed 26 May 2016).

3. The Research Institute of Tuberculosis. JATA: Annual Reports. Tokyo, The Tuberculosis Surveillance Center, 2016 (http:// www.jata.or.jp/rit/ekigaku/en/annual-reports/, accessed 26 May 2016)

4. Ota M, Uchimura K, Kato S. Tuberculosis in foreign students in Japan, 2010-2014: a comparison with the notification rates in their countries of origin. Western Pacific Surveillance and Response Journal, 2016, 7(2). doi: 10.5365/wpsar.2015.6.4.009

5. The Research Institute of Tuberculosis, JATA [in Japanese]. Tokyo, The Tuberculosis Surveillance Center, 2016 (http://www.jata.or.jp/ rit/ekigaku/, accessed 26 May 2016).

6. Population Census of Japan, 2010. Tokyo, Ministry of Internal Affairs and Communications, 2016 (http://www.stat.go.jp/data/ kokusei/2010/, accessed 26 May 2016).

7. Survey on foreign-born students in Japan - 2014 [in Japanese] (Gaikokujin ryugakusei zaiseki joukyo chousa). Tokyo, Japan Student Services Organization, 2016 (http://www.jasso. go.jp/about/statistics/intl_student_e/2014/index.html, accessed 26 May 2016).

8. Japanese language schools in Japan - 1989-2015 [in Japanese] (Nihongo kyoiku kikan no gaikyo). Tokyo, Association for the Promotion of Japanese Language Education, 2016 (http:// www.nisshinkyo.org/article/pdf/20160209s.gaikyo.pdf, accessed 26 May 2016).

9. Survey on the Japanese language school students in Japan 2009 [in Japanese] (Nihongo kyouiiku kikan gakusei seikatsu jittai chousa). Tokyo, Association for the Promotion of Japanese Language Education, 2016 (http://www.nisshinkyo.org/article/pdf/ overview03.pdf, accessed 26 May 2016).

10. Lee K, Kawanishi T. Mental health issues in international students: suicidal ideation, suicide-related behaviors, depression, and alcohol dependence [in Japanese]. Suicide prevention and crisis intervention, 2011, 31: 65-73.

11. Ozeki N, Knowles A, Asada Y. Analyses of Stress and Adaptation of Foreign University Students in Japan [in Japanese]. Japanese Academy of Human Care Science, 2010, 3:25-39.

12. Status of reporting on the employment of foreign workers by employers (press release) [in Japanese]. Tokyo, Ministry of Health, Labour and Welfare, 2016 (http://www.mhlw.go.jp/stf/ houdou/0000072426.html, accessed 26 May 2016).

13. Opinion on the revision of technical internship [in Japanese]. Tokyo, Japanese Trade Union Confederation, 2016 (http://www. jtuc-rengo.or.jp/roudou/gaikokujin/minaoshi.html, accessed 26 May 2016).

14. Opinion on the possible abolition of technical internship [in Japanese]. Japan Bar Federation, 2011 (http://www. nichibenren.or.jp/library/ja/opinion/report/data/110415_4.pdf, accessed 26 May 2016).

15. Trafficking in Persons Report 2015. Washington, DC, US Department of State, 2015 (http://www.state.gov/j/tip/rls/ tiprpt/2015/index.htm, accessed 26 May 2016).

16. Uchimura K. Evaluation of the quality of Japan TB Surveillance System using TB mortality data [in Japanese] (Kekkaku shibou kara no kekkaku sabeiransu touroku no seidokenshou oyobi kekkaku rikanritusuitei no kokoromi). Kekkaku, 2013, 88:197. 


\title{
Assessment of the risk posed to Singapore by the 2015 Middle East respiratory syndrome outbreak in the Republic of Korea
}

\author{
Emma Xuxiao Zhang, ${ }^{a}$ Olivia Seen Huey Oh, ${ }^{a}$ Wanhan See, ${ }^{a}$ Pream Raj, ${ }^{a}$ Lyn James, ${ }^{a}$ Kamran Khan ${ }^{b c}$ and \\ Jeannie Su Hui Tey ${ }^{a}$ \\ Correspondence to Jeannie Su Hui Tey (email: Jeannie_tey@moh.gov.sg).
}

Objective: To assess the public health risk to Singapore posed by the Middle East respiratory syndrome (MERS) outbreak in the Republic of Korea in 2015.

Methods: The likelihood of importation of MERS cases and the magnitude of the public health impact in Singapore were assessed to determine overall risk. Literature on the epidemiology and contextual factors associated with MERS coronavirus infection was collected and reviewed. Connectivity between the Republic of Korea and Singapore was analysed. Public health measures implemented by the two countries were reviewed.

Results: The epidemiology of the 2015 MERS outbreak in the Republic of Korea remained similar to the MERS outbreaks in Saudi Arabia. In addition, strong infection control and response measures were effective in controlling the outbreak. In view of the air traffic between Singapore and MERS-affected areas, importation of MERS cases into Singapore is possible. Nonetheless, the risk of a serious public health impact to Singapore in the event of an imported case of MERS would be mitigated by its strong health-care system and established infection control practices.

Discussion: The MERS outbreak was sparked by an exported case from the Middle East, which remains a concern as the reservoir of infection (thought to be camels) continues to exist in the Middle East, and sporadic cases in the community and outbreaks in health-care settings continue to occur there. This risk assessment highlights the need for Singapore to stay vigilant and to continue enhancing core public health capacities to detect and respond to MERS coronavirus.

O n 20 May 2015, the International Health Regulations National Focal Point of the Republic of Korea notified the World Health Organization (WHO) of the first laboratory-confirmed imported case of Middle East respiratory syndrome coronavirus (MERS-CoV) infection in a 68-year-old man with a recent history of travel to the Middle East. ${ }^{1}$ Subsequent human-to-human transmission of the virus occurred in 16 health-care facilities in the Republic of Korea among close family contacts; patients who shared the same room or ward with infected patients; their visitors; and health-care workers who provided care to the patients, resulting in the largest nosocomial outbreak outside the Middle East. In addition, one case was exported to China. The last case of MERS-CoV associated with the outbreak was reported on 5 July 2015, leading to a total of 186 cases including 36 deaths reported in the Republic of Korea. ${ }^{1}$
To assess the risk posed by the MERS-CoV outbreak in the Republic of Korea to Singapore, we carried out an analysis to estimate the likelihood of importation of MERS-CoV cases into Singapore from the Republic of Korea and to assess the public health impact should a case be imported.

\section{METHODS}

The likelihood of MERS-CoV spreading from the Republic of Korea and its impact on public health in Singapore were assessed following WHO guidance on the risk assessment of acute public health events. ${ }^{2}$ The process of risk assessment included literature review, epidemiological analysis of the MERS-CoV outbreak in the Republic of Korea, analysis of air travel volume between the Republic of Korea and Singapore, assessment of public health control measures taken by the Republic

Epidemiology and Disease Control Division, Public Health Group, Ministry of Health, Singapore.

Li Ka Shing Knowledge Institute, St. Michael's Hospital, Toronto, Canada.

Department of Medicine, Division of Infectious Diseases, University of Toronto, Toronto, Canada

Submitted: 7 December 2015; Published: 10 May 2015

doi: 10.5365/wpsar.2015.6.4.008 
of Korea and preparedness of the Singapore health authorities. The risk assessment was conducted by a core group of five public health officers specializing in public health surveillance, epidemiology and risk analysis of infectious diseases. Their findings were reviewed by a broader group of experts from the Singapore Ministry of Health in the areas of public health, laboratory medicine, epidemiology, infectious diseases, risk communication, as well as emergency preparedness and response.

The epidemiology of MERS-CoV and the 2015 MERS outbreak in the Republic of Korea was analysed based on information obtained from scientific literature review using PubMed, WHO situation reports and official information released by the Republic of Korea Ministry of Health and Welfare. A qualitative review of the public health measures taken by the Republic of Korea and Singapore in response to this outbreak was conducted based on information released by the Republic of Korea Ministry of Health and Welfare and the Singapore Ministry of Health. The volume of travellers initiating trips on commercial flights originating from the Republic of Korea with final destinations in Singapore between January and November 2015 was analysed using data from the International Air Transport Association (IATA). These data include worldwide, anonymized, passenger-level flight itineraries capturing an estimated $90 \%$ of the world's air traffic with the remainder being imputed using market intelligence. Each itinerary includes information on the travellers' point of origin, final destination, and where applicable, connecting flights. (IATA data have been used previously to predict the epidemic wave-front of emerging pathogens, to support risk assessments for mass gatherings and to evaluate policies around screening of travellers at commercial airports. $)^{3}$

\section{RESULTS}

\section{Hazard assessment}

MERS is a viral respiratory illness caused by a novel coronavirus that was first detected in Saudi Arabia in 2012. ${ }^{4}$ The clinical presentation of MERS-CoV infection ranges from asymptomatic infection to severe pneumonia with acute respiratory distress syndrome, septic shock and multiorgan failure resulting in death. ${ }^{4}$ Poor prognosis is associated with increasing age or medical co-morbidities. ${ }^{4}$ The median incubation period for human-to-human secondary cases was estimated to be just over five days but could be as long as two weeks. ${ }^{5}$

The source of MERS-CoV and the mode of transmission have yet to be determined. Current evidence suggests that camels are an important source of MERS$\mathrm{CoV}$ in the community, and the pattern of disease reported in humans appear to be the result of repeated introductions of the virus from camels to humans. ${ }^{6,7}$ Although no sustained community transmission has been reported thus far, human-to-human transmission has been documented in several clusters associated with health-care facilities, households and workplaces. ${ }^{8,9}$ The overall basic reproduction number of MERS is less than one but can be higher in crowded healthcare settings where infection prevention and control measures are inadequate. ${ }^{10,11}$ Visits to multiple healthcare facilities with increasing number of contacts has also been identified as a common feature of clustering events in the outbreak in the Republic of Korea. ${ }^{12}$ Thus far, the possibility of transmission from asymptomatic polymerase chain reaction- (PCR) positive cases cannot be excluded, necessitating the need for close monitoring and investigation of all contacts, including asymptomatic contacts. ${ }^{13}$ There has been no reported transmission during air travel, and the incidence of infection associated with large gatherings such as umrah and hajj was very low. ${ }^{14}$

The largest MERS outbreak outside the Saudi Arabia occurred in 2015 in the Republic of Korea. The index case travelled to the Middle East and developed symptoms one week after returning to the Republic of Korea. By the time the diagnosis of MERS-CoV infection was established, the index case had transmitted the infection to his wife, other patients and visitors in the same room/ ward and health-care workers who had provided care to him. These secondary cases subsequently went on to infect relatives, patients and health-care workers in a similar pattern and largely in health-care settings, resulting in four generations of cases. Among them, 83\% appeared to be linked to five clustering events. An event was arbitrarily defined by the Korea Centers for Disease Control and Prevention as one patient transmitting the infection to more than four patients. ${ }^{1}$ There was no evidence of sustained human-to-human transmission in the community or airborne transmission. The pattern of transmission in the Republic of Korea was similar to that of the outbreaks in Saudi Arabia. In addition, poor outcomes were associated with increasing age or medical 
co-morbidities, similar to that observed in the previous outbreaks in Saudi Arabia. ${ }^{1}$ The epidemiological patterns observed were in line with the close resemblance of genetic sequences of the viruses isolated from the Republic of Korea and Saudi Arabia, ${ }^{1}$ which suggested that the viruses were likely to demonstrate similar virulence and transmissibility.

\section{Exposure assessment}

The MERS outbreak was contained in the Republic of Korea with only one case exported to China via transit in the Hong Kong Special Administrative Region (SAR). ${ }^{1}$ The case did not transmit the infection to any of his contacts during travel. Among the top 15 global final destination cities for travellers from the Republic of Korea in 2015, Hong Kong SAR received the third highest number of travellers from the Republic of Korea after Tokyo and Shanghai. Singapore ranked $11^{\text {th }}$ with an average of 42283 travellers coming from the Republic of Korea per month (Figure 1). In view of the close connectivity between the two countries and the relatively long incubation time of MERS-CoV infection (up to 14 days), the importation of the MERS-CoV infection from the Republic of Korea to Singapore is possible.

\section{Context assessment}

This context assessment considers both the capabilities of the Republic of Korea health authorities to control the outbreak and to reduce the risk of exportation of cases, as well as the preparedness and response measures in Singapore to evaluate the risk of this outbreak to the Singapore local population.

\section{Measures taken by the Republic of Korea}

The majority of the MERS cases in the Republic of Korea had been infected before adequate infection prevention and control procedures were applied, suggesting lapses in the preventive and control measures, including contact tracing and quarantine at the beginning of the outbreak. In response to the surge in cases, the Republic of Korea authorities subsequently implemented intense case and contact management measures. ${ }^{15}$ Upon detection of the first tertiary case on 2 June, the definition of contacts (initially health-care workers who directly cared for the index case and people who were in the same hospital room as the index case) was expanded to include anyone in the same room/ward as confirmed cases or those who had contact with the respiratory secretions of the cases. ${ }^{1}$ As a result, the number of contacts placed under quarantine increased rapidly (Figure 2). The authorities also expanded their contact-tracing and search activities to include the entire hospital when deemed necessary. For instance, the authorities had attempted to contact every individual who had visited two severely MERS-infected hospitals during the implicated period. The authorities also sealed off several hospitals and quarantined all patients and staff at the hospitals, resulting in a further increase in the number of contacts under quarantine between 10 and 18 June. More than 16000 contacts were monitored during the entire outbreak with a peak of more than 1000 new contacts put under quarantine daily (Figure 2 ). The increase in the number of contacts under quarantine corresponded with the decrease in the number of new cases reported.

For hospital management, the Republic of Korea authorities closed down several affected hospitals, which were deemed to be epicentres of the outbreak, to prevent further transmission of the disease. The authorities also designated referral hospitals for managing confirmed cases. A National Safe Hospital Program was implemented to control MERS-CoV transmission within hospitals by providing care for patients with respiratory diseases in secured areas separate from outpatient or emergency department. ${ }^{16}$ Infection prevention and control measures were also strengthened in all healthcare facilities.

The Republic of Korea used the real-time reverse transcription PCR protocol recommended by $\mathrm{WHO}^{17}$ and was able to confirm the majority of the cases in the first test. Repeat testing was required on 27 of 186 cases $(15 \%)$. It remains unclear if these cases had low viral loads, although their symptoms were not milder than those who tested positive in the first test.

In response to the exported case to China and reports of contacts of confirmed cases travelling within the Republic of Korea while under quarantine, a travel ban was imposed on quarantined people from travelling on both international and domestic flights. ${ }^{18}$ Such extensive efforts to enhance contact tracing and stronger monitoring and quarantine measures contributed to the subsequent decline in new cases and the eventual end of the outbreak. 


\section{Figure 1. Top final destinations of travellers from the Republic of Korea, January to November 2015}

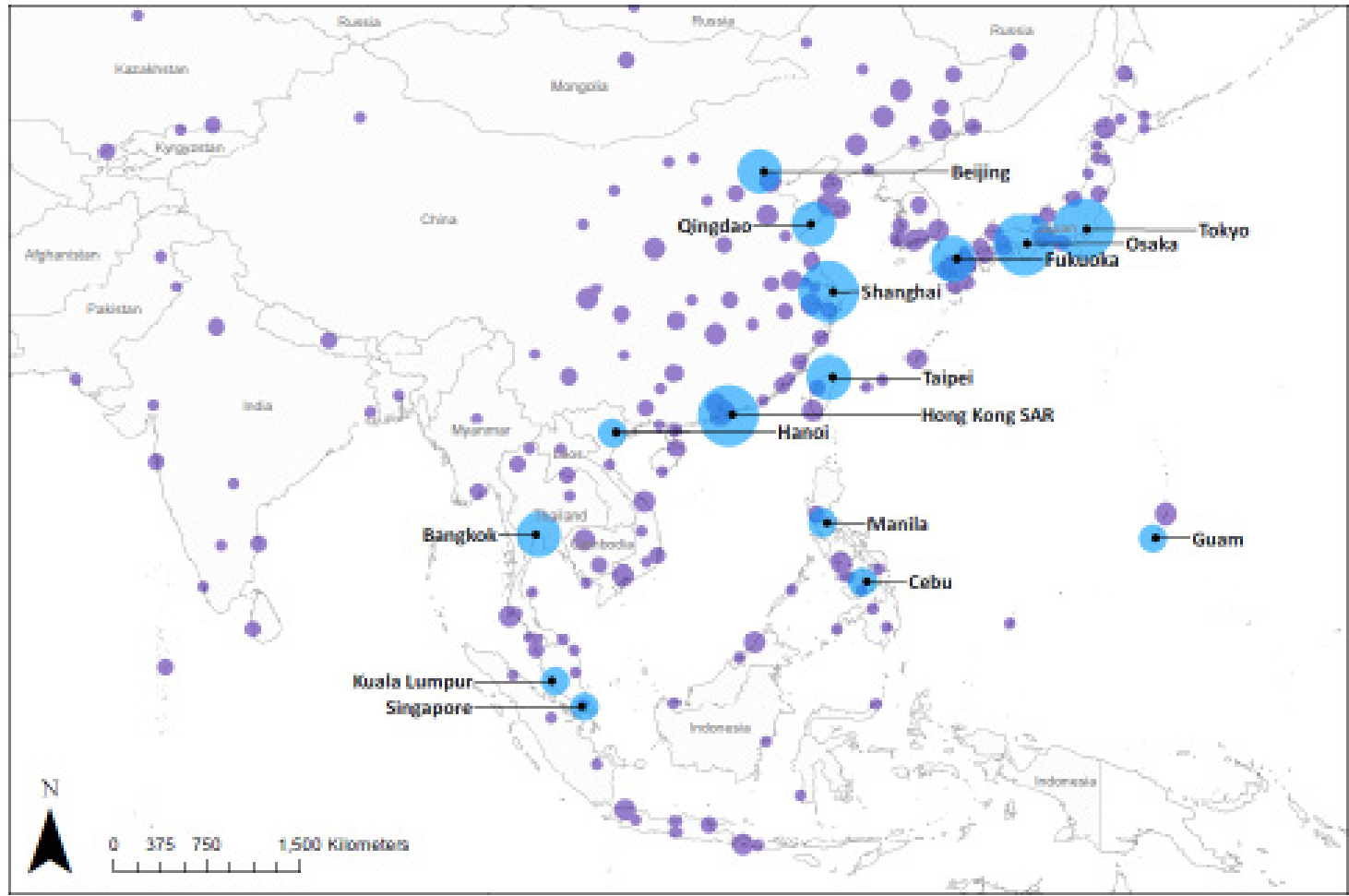

Volume of Travellers

- $500-10 K-10 K-100 K-100 K-300 K-500 K-500 K$

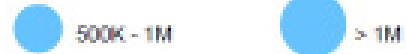

\begin{tabular}{clcc}
\hline Rank & Final destination/city/country or area & Volume of travellers from the Republic of Korea & \% of total traveller volume \\
\hline 1 & Tokyo, Japan & 1550700 & 6.63 \\
2 & Shanghai, China & 1453782 & 6.22 \\
3 & Hong Kong SAR, China & 1303316 & 5.57 \\
4 & Osaka, Japan & 1263645 & 5.40 \\
5 & Bangkok, Thailand & 984774 & 4.21 \\
6 & Taipei, Taiwan, China & 900658 & 3.85 \\
7 & Beijing, China & 884945 & 3.78 \\
8 & Qingdao, China & 701208 & 3.00 \\
9 & Fukuoka, Japan & 676139 & 2.89 \\
10 & Manila, Philippines & 485194 & 2.07 \\
11 & Singapore & 465111 & 1.99 \\
12 & Hanoi, Viet Nam & 432055 & 1.85 \\
13 & Cebu, Philippines & 388265 & 1.66 \\
14 & Guam & 360970 & 1.54 \\
15 & Kuala Lumpur, Malaysia & 317946 & 1.36 \\
\hline
\end{tabular}

The light blue graduated circles reflect the top 15 final destinations identified. Final destinations receiving fewer than 500 travellers were excluded. Source: Data were obtained from the International Air Transport Association. 
Figure 2. Cumulative and daily number of contacts of MERS cases under quarantine in the Republic of Korea, 2015*

\section{A. Cumulative contacts}
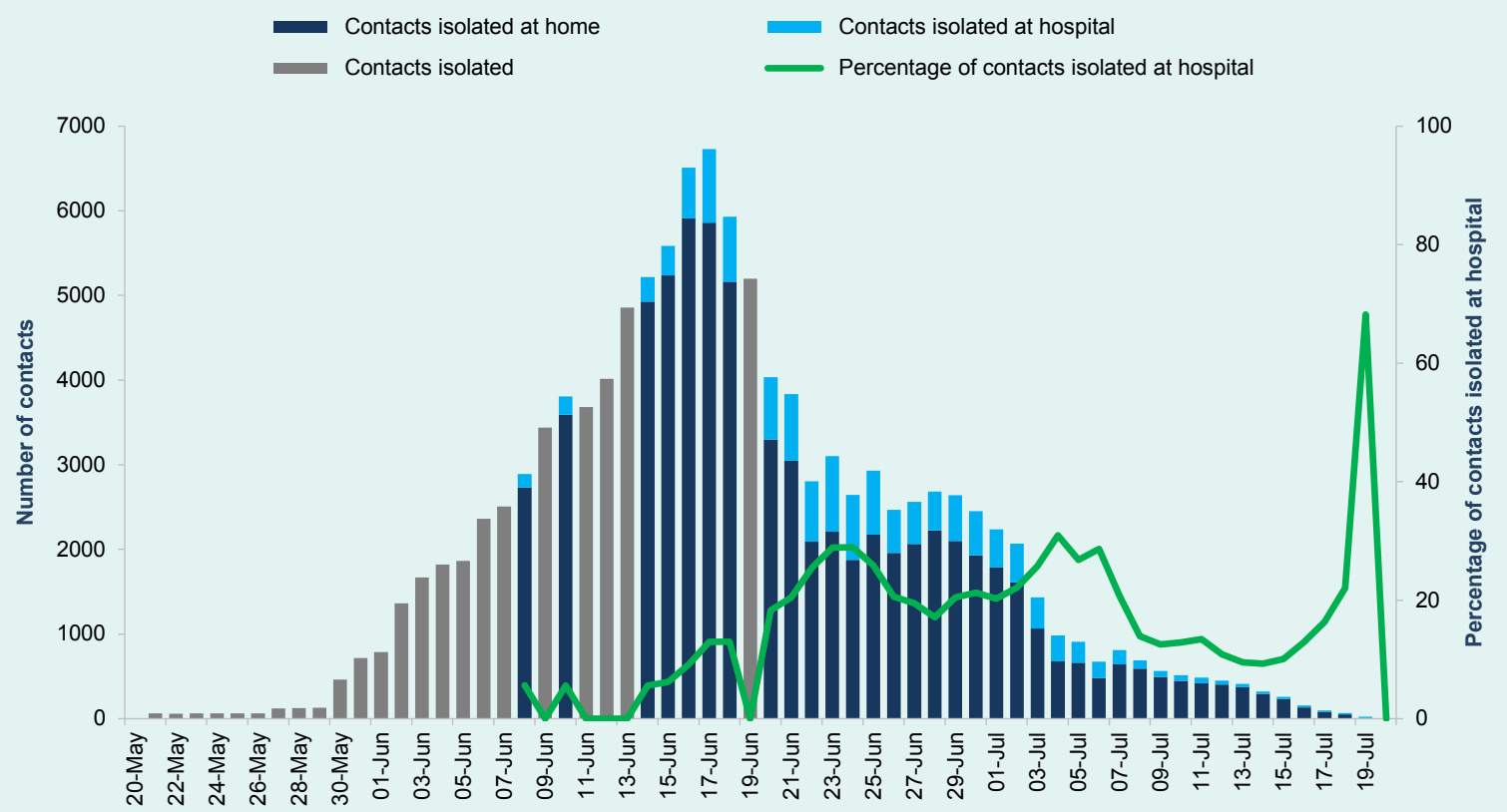

Note: Contacts isolated at hospitals are represented by a light blue bar, and contacts isolated at home are represented by a dark blue bar. When the numbers were not separately reported, the total number of contacts isolated is represented by a gray bar. Percentage of contacts isolated at hospital is represented by a green line.

\section{B. Daily contacts}

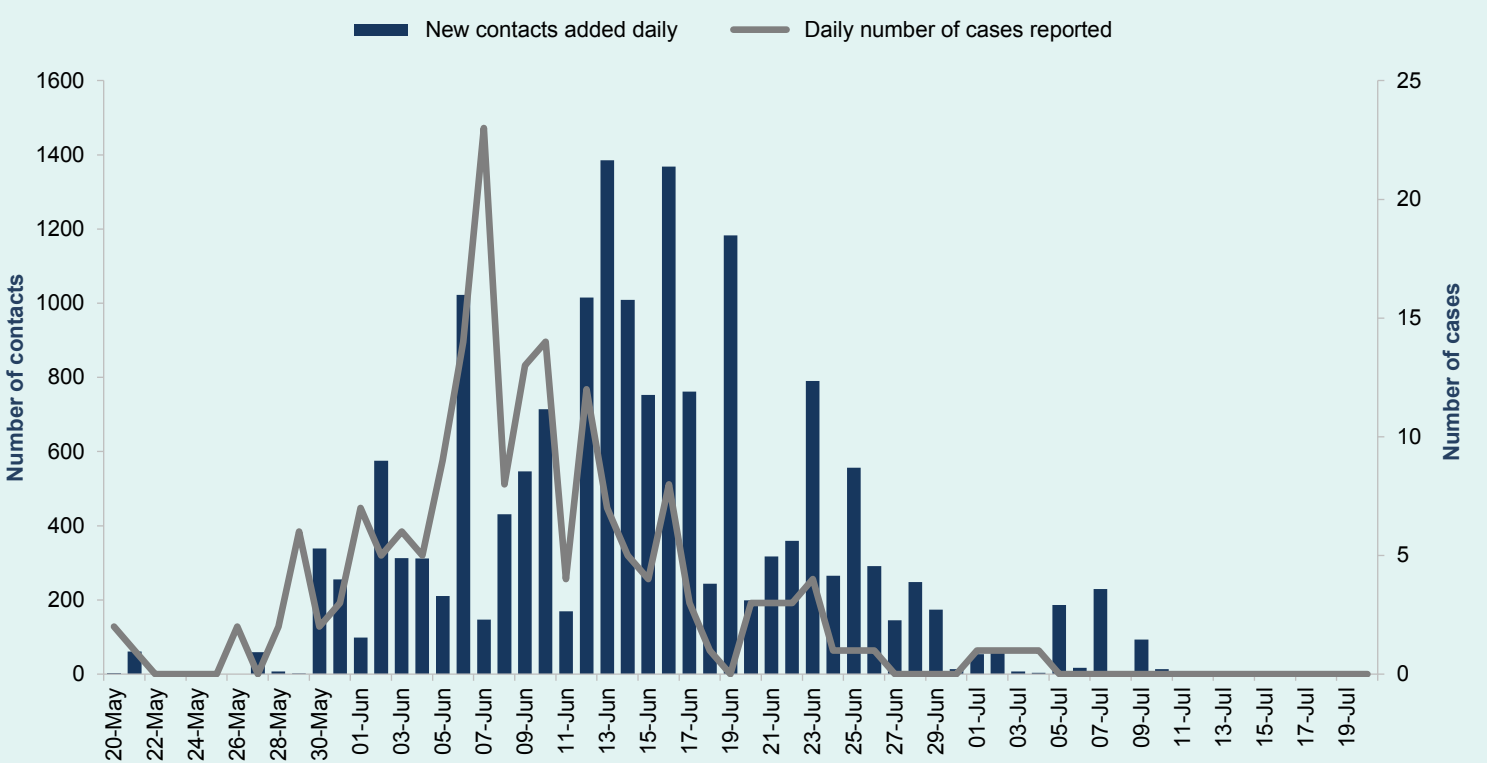

\footnotetext{
* The information is summarized based on the line listing reported by the Republic of Korea Ministry of Health and Welfare from 20 May to 20 July 2015.
} 


\section{Preparedness and response in Singapore}

The Singapore Ministry of Health has been closely watching the developments of MERS-CoV infections since its first emergence in the Arabian Peninsula in 2012. As a precautionary measure for the early detection of MERS cases, temperature screening at air checkpoints has been in place since 18 May 2014 for passengers arriving from affected countries in the Middle East. ${ }^{19}$ In view of the surge in the number of MERS-CoV cases in the Republic of Korea, and continued news of reported breaches in containment and quarantine measures there, temperature screening at air checkpoints for passengers arriving from the Republic of Korea commenced on 9 June $2015 .^{20}$ Health advisories were also distributed at border checkpoints for travellers coming from and going to areas affected by MERS-CoV. ${ }^{21}$ Temperature screening and other border health measures for passengers arriving from the Republic of Korea ended on 6 August 2015 in view of the stabilized situation in the Republic of Korea. ${ }^{22}$

Temperature screening may not pick up all imported cases due to the long incubation period of MERS-CoV and the presence of mild and asymptomatic cases. Therefore, all hospitals and doctors have been reminded to remain vigilant and to step up their operational readiness in the event of an imported case. ${ }^{20}$ Patients with clinical signs/symptoms of pneumonia or severe respiratory infection with breathlessness and a travel history to the Middle East and the Republic of Korea in the two weeks before onset will be evaluated to exclude MERS-CoV infection. In addition, people with a fever and respiratory illness of any severity who had recently visited a healthcare facility while travelling in the Middle East will also be similarly evaluated. (This measure was similarly applied for the Republic of Korea during the outbreak there. All suspected and confirmed cases will be isolated and managed under strict airborne infection control precautions.) Infection control precautions and practices have been strengthened in all health-care institutions. Guidance to health-care workers on the management of any suspected MERS cases has also been provided. The National Public Health Laboratory and the public hospital laboratories have the capabilities to test for MERS-CoV following the protocol recommended by
WHO. ${ }^{17}$

If a confirmed MERS case is detected, Singapore Ministry of Health will conduct contact tracing when appropriate and all close contacts will be placed under quarantine. A designated quarantine housing will be on standby and can be deployed at short notice to safeguard public health. ${ }^{23} \mathrm{~A}$ coordinated national response plan against disease threats, including MERS-CoV, has been developed. The Disease Outbreak Response System Condition is a colour-coded framework that provides a quick reference to agencies and the public on the current disease situation and what needs to be done to respond to and prevent infections and reduce the impact. ${ }^{24}$ In response to the MERS outbreak, the Ministry of Manpower issued a tripartite advisory on 7 July 2015 to help employers prepare and implement precautionary measures at the workplace. ${ }^{25}$

\section{Risk characterization}

The risk imposed to Singapore by the 2015 MERS outbreak in the Republic of Korea was characterized using the information collected with key factors considered to assess the likelihood of exportation of cases to Singapore and the impact on public health (Table 1).

The risk characterization suggests that the likelihood of MERS-CoV importation into Singapore is possible in view of air traffic between Singapore and the Republic of Korea. The review of the Republic of Korea outbreak demonstrated that notwithstanding the initial surge in cases due to weaknesses in outbreak management and response at the early stage, MERS outbreaks can be effectively contained with the implementation of strict infection control and outbreak response measures. This is reminiscent of our experience with severe acute respiratory syndrome (SARS) in 2003. The lessons learnt from the MERS outbreak in the Republic of Korea and our past experience in the management of the SARS outbreak have been referenced in the planning of Singapore's response against MERS, and the measures have been implemented accordingly. The risk of serious public health impact to Singapore in the event of an imported case of MERS-CoV infection would be 
Table 1. Risk characterization matrix for the public health risk posed to Singapore by the 2015 MERS outbreak in the Republic of Korea

\begin{tabular}{|c|c|c|c|}
\hline & Hazard & Exposure & Context \\
\hline $\begin{array}{l}\text { Potential for } \\
\text { exportation from the } \\
\text { Republic of Korea } \\
\text { to Singapore }\end{array}$ & $\begin{array}{l}\text { A novel coronavirus first detected in } \\
2012 . \\
\text { The Republic of Korea outbreak was } \\
\text { the largest outbreak outside Saudi } \\
\text { Arabia. } \\
\text { No evidence of sustained } \\
\text { community transmission or airborne } \\
\text { transmission. } \\
\text { Nosocomial transmission is a distinct } \\
\text { hallmark in MERS-CoV transmission; } \\
\text { majority of the cases in the Republic } \\
\text { of Korea were linked to five } \\
\text { clustering events. } \\
\text { Human-to-human transmission had } \\
\text { been observed to a limited extent in } \\
\text { households. } \\
\text { Possibility of transmission from } \\
\text { asymptomatic PCR-positive cases } \\
\text { cannot be excluded. }\end{array}$ & $\begin{array}{l}\text { The outbreak was largely } \\
\text { contained in the Republic } \\
\text { of Korea with one case } \\
\text { exported to China. } \\
\text { A long incubation period of } \\
\text { MERS-CoV of up to } 14 \text { days } \\
\text { means that international } \\
\text { travel of asymptomatic } \\
\text { cases is possible. } \\
\text { No reported transmission } \\
\text { during air travel. } \\
\text { Close connectivity between } \\
\text { the Republic of Korea and } \\
\text { Singapore, with an average } \\
\text { of } 42283 \text { travellers coming } \\
\text { from the Republic of Korea } \\
\text { per month. }\end{array}$ & $\begin{array}{l}\text { Majority of the cases in the } \\
\text { Republic of Korea had occurred } \\
\text { before adequate infection prevention } \\
\text { and control procedures were applied; } \\
\text { the Republic of Korea authority } \\
\text { subsequently implemented intense case } \\
\text { and contact management measures. } \\
\text { Capable laboratory testing in the } \\
\text { Republic of Korea was able to confirm } \\
\text { majority of the cases at the first } \\
\text { instance. } \\
\text { A travel ban was imposed on } \\
\text { quarantined persons from travelling } \\
\text { within and out of the Republic of Korea. } \\
\text { Temperature screening at air } \\
\text { checkpoints and other border health } \\
\text { measures for passengers arriving } \\
\text { from the Republic of Korea were } \\
\text { implemented in Singapore. }\end{array}$ \\
\hline $\begin{array}{l}\text { Potential public } \\
\text { health impact to } \\
\text { Singapore }\end{array}$ & $\begin{array}{l}\text { Infection results in severe pneumonia } \\
\text { with acute respiratory distress } \\
\text { syndrome, septic shock and multi- } \\
\text { organ failure leading to death. } \\
\text { High hospitalization and case fatality } \\
\text { rates. } \\
\text { Possible negative implications for } \\
\text { the extended use of public health } \\
\text { resources; high level infrastructure } \\
\text { and personnel requirement for case } \\
\text { and contact management. }\end{array}$ & $\begin{array}{l}\text { The elderly people and } \\
\text { people with underlying co- } \\
\text { morbidities seem to be at } \\
\text { higher risk of infection and } \\
\text { death. } \\
\text { Health-care workers that } \\
\text { come into close contact with } \\
\text { cases are at higher risk of } \\
\text { infection. }\end{array}$ & $\begin{array}{l}\text { Key preparedness areas include } \\
\text { laboratory testing capabilities, infection } \\
\text { control precautions and practices, } \\
\text { contact and case management, risk } \\
\text { communication and strengthening of the } \\
\text { national response plan in Singapore. }\end{array}$ \\
\hline
\end{tabular}

PCR, polymerase chain reaction.

mitigated by a strong health-care system and established infection control practices in the local health-care settings.

\section{DISCUSSION}

This 2015 MERS outbreak in the Republic of Korea was the largest nosocomial MERS outbreak outside of the Middle East and the first MERS outbreak that resulted in further exportation to a third country. The spread of the disease in the Republic of Korea was less likely due to any intrinsic changes in virus but was more likely attributed to lapses in the infection and control measures in health-care facilities and weak enforcement of quarantine of contacts. Also responsible for the spread of the disease were the health-seeking behaviours that were typical in the Republic of Korea, including seeking medical assistance at several health-care facilities (doctor shopping), transferring sick patients to multiple health-care facilities and family members staying for long durations in the overcrowded wards to provide care to their hospitalized relatives. ${ }^{26}$ The subsequent intense case and contact management implemented by the Republic of Korea government was effective in bringing down the case incidence. The analysis of the number of contacts under quarantine in the Republic of Korea provided insights into the surge capacity required from public health authorities to deal with such an outbreak.

This risk assessment has some limitations. The assessment is based on limited data as only one case had been exported from the Republic of Korea and no cases had been imported into Singapore. As the risk characterization was defined by the epidemiological and contextual knowledge available currently, conclusions could change as new information emerges. A better understanding of the variation in individual infectiousness and the environmental impact could provide key information on epidemic spread and facilitate the design of control measures. Major gaps in information including source of infection, transmission mode and factors 
contributing to clustering events need to be filled to better assess the risk to public health. In addition, the analysis of contact management is based on the best available data reported by the Republic of Korea Ministry of Health and Welfare during the outbreak.

To conclude, this 2015 MERS outbreak in the Republic of Korea was initiated by an exported case from the Middle East. It remains a concern as the reservoir of infection (thought to be camels) continues to exist in the region, and sporadic cases in the community and outbreaks in health-care settings continue to occur there. In view of air traffic between Singapore and the MERSaffected areas, the importation of MERS-CoV infections into Singapore is possible. This risk assessment highlights the need for Singapore to stay vigilant and to continue enhancing core public health capacities to detect and respond to MERS-CoV. To date, there have been no MERS cases reported in Singapore.

\section{Conflict of interests}

None declared.

Funding

None.

\section{Acknowledgements}

The authors are grateful to Dr Marisa Creatore of Bluedot, as well as Dr Derrick Heng (Group Director of the Public Health Group) of the Singapore Ministry of Health for helpful discussion.

\section{References}

1. Korea Centers for Disease Control and Prevention. Middle East Respiratory Syndrome Coronavirus Outbreak in the Republic of Korea, 2015. Osong Public Health Research Perspective, 2015, 6(4):269-278. doi:10.1016/j.phrp.2015.08.006 pmid:26473095

2. Rapid risk assessment of acute public health events. Geneva, World Health Organization, 2012 (http://whqlibdoc.who.int/cgibin/repository.pl?url=/hq/2012/WHO_HSE_GAR_ARO_2012.1_ eng.pdf, accessed 25 January 2016).

3. Bogoch II et al. Assessment of the potential for international dissemination of Ebola virus via commercial air travel during the 2014 west African outbreak. Lancet, 2015, 3, 385(9962):29-35. doi:10.1016/S0140-6736(14)61828-6 pmid:25458732

4. The WHO MERS-CoV Research Group. State of knowledge and data gaps of Middle East Respiratory Syndrome Coronavirus (MERS-CoV) in humans. PLoS Current, 2013, 12:5. doi:10.1371/currents.outbreaks.0bf719e352e7478f8ad85fa30 $127 \mathrm{ddb} 8$
5. Cowling BJ et al. Preliminary epidemiological assessment of MERS-CoV outbreak in South Korea, May to June 2015. Eurosurveillance: European Communicable Disease Bulletin, 2015, 20(25):7-13. pmid:26132767

6. Müller MA et al. Presence of Middle East respiratory syndrome coronavirus antibodies in Saudi Arabia: a nationwide, crosssectional, serological study. Lancet Infectious Diseases, 2015, 15(5):559-564. doi:10.1016/S1473-3099(15)70090-3 pmid:25863564

7. Reusken $\mathrm{CB}$ et al. Occupational exposure to dromedaries and risk for MERS-CoV infection, Qatar, 2013-2014. Emerging Infectious Diseases, 2015, 21(8):1422-1425. doi:10.3201/ eid2108.150481 pmid:26196891

8. Assiri A et al. Hospital outbreak of Middle East respiratory syndrome coronavirus. New England Journal of Medicine, 2013, 369(5):407-416. doi:10.1056/NEJMoa1306742

9. Bermingham A et al. Severe respiratory illness caused by a novel coronavirus, in a patient transferred to the United Kingdom from the Middle East, September 2012. Eurosurveillance: European Communicable Disease Bulletin, 2012, 17(40):20290. pmid:23078799

10. Cauchemez S et al. Middle East respiratory syndrome coronavirus: quantification of the extent of the epidemic, surveillance biases, and transmissibility. Lancet Infectious Diseases, 2014, 14(1):50-56. doi:10.1016/S1473-3099(13)70304-9 pmid:24239323

11. Breban R et al. Interhuman transmissibility of Middle East respiratory syndrome coronavirus: estimation of pandemic risk. Lancet, 2013, 24; 382(9893):694-699. doi:10.1016/S01406736(13)61492-0 pmid:23831141

12. Nishiura $\mathrm{H}$ et al. Identifying determinants of heterogeneous transmission dynamics of the Middle East respiratory syndrome (MERS) outbreak in the Republic of Korea, 2015: a retrospective epidemiological analysis. BMJ Open, 2016, 6(2):e009936. doi:10.1136/bmjopen-2015-009936 pmid:26908522

13. Al Hammadi ZM et al. Asymptomatic MERS-CoV Infection in Humans Possibly Linked to Infected Dromedaries Imported from Oman to United Arab Emirates, May 2015. Emerging Infectious Diseases, 2015, 21(12):2197-2200. doi:10.3201/ eid2112.151132 pmid:26584223

14. Gautret $P$ et al. Hajj-associated viral respiratory infections: A systematic review. Travel Medicine and Infectious Disease, 2015, 13(1):106-109. doi:10.1016/tmaid.2015.12.008

15. Kim JY et al. Middle East Respiratory Syndrome Infection Control and Prevention Guideline for Healthcare Facilities. Journal of Infection and Chemotherapy, 2015, 47(4):278-302. doi:10.3947/ic.2015.47.4.278 pmid:26788414

16. Press Release: 87 hospitals would begin operations as National Safe Hospitals (12 June 2016). Sejong, Korea Centers for Disease Control and Prevention, 2015 (http://www.mers.go.kr/mers/html/ jsp/Menu_C/list_C1.jsp? menulds $=\&$ fid $=21 \&$ \&_type $=\& q \_$value $=$ \&cid $=63431$ \&pageNum $=1$, accessed 7 April 2016).

17. Laboratory testing for Middle East Respiratory Syndrome Coronavirus: interim recommendations (revised). Geneva, World Health Organization, 2014 (http://www.who.int/csr/disease/ coronavirus_infections/WHO_interim_recommendations_lab_ detection_MËRSCoV_092014.pdf, accessed 7 April 2016).

18. S. Korea reports 3 new MERS cases with no additional deaths. The Korea Herald, 23 June 2015 (http://www.koreaherald.com/ view.php?ud=20150623000200, accessed 7 April 2016)

19. Additional measure for early detection of MERS-CoV. Singapore, Ministry of Health, 2014 (https:/www.moh.gov.sg/content/ moh web/home/pressRoom/pressRoomItemRelease/2014/ additional-measure-for-early-detection-of-mers-cov.html, accessed 7 April 2016). 
20. Additional precautionary measures against MERS-CoV situation in South Korea. Singapore, Ministry of Health, 2015 (https://www.moh.gov.sg/content/moh_web/home/pressRoom/ pressRoomltemRelease/2015/additional-precautionary-measuresagainst-mers-cov-situation-in-.html, accessed 7 April 2016).

21. MERS-CoV: Health Advisory (October 2015). Singapore, Ministry of Health, 2015 (https://www.moh.gov.sg/content/moh_web/ home/pressRoom/pressRoomltemRelease/2015/additionalprecautionary-measures-against-mers-cov-situation-in-.html, accessed 7 April 2016).

22. Cessation of MERS-CoV measures for South Korea. Singapore, Ministry of Health, 2015 (https://www.moh.gov.sg/content/ moh web/home/pressRoom/pressRoomltemRelease/ 2015/cessation-of-mers-measures-for-south-korea.html, accessed 7 April 2016).

23. Strengthening preparedness for emerging infectious diseases. Singapore, Ministry of Health, 2013 (https://www. moh.gov.sg/content/moh web/home/pressRoom/ pressRoomltemRelease/2013/strengthening-preparedness-foremerging-infectious-diseases.html, accessed 7 April 2016).

24. Pandemic preparedness. Singapore, Ministry of Health, 2014 (https://www.moh.gov.sg/content/moh_web/home/ diseases and conditions/pandemic-preparedness.html, accessed 7 April 2016).

25. Tripartite advisory on workplace measures to tackle Middle East Respiratory syndrome coronavirus (MERS-CoV). Singapore, Ministry of Manpower, 2015 (http://www.mom.gov.sg/ / media/mom/documents/employment-practices/guidelines/ tripartite-advisory-workplace-measures-mers.pdf?la=en, accessed 7 April 2016).

26. WHO statement on the ninth meeting of the IHR Emergency Committee regarding MERS-CoV. Geneva, World Health Organization, 2015. (http://www.who.int/mediacentre/news/ statements/2015/ihr-ec-mers/en/, accessed 7 April 2016). 


\title{
External quality assessment of dengue and chikungunya diagnostics in the Asia Pacific region, 2015
}

\author{
Li Ting Soh, ${ }^{a *}$ Raynal C Squires, ${ }^{, *}$ Li Kiang Tan, ${ }^{a}$ Kwoon Yong Pok, ${ }^{a}$ HuiTing Yang, ${ }^{a}$ Christina Liew, ${ }^{a}$ \\ Aparna Singh Shah, ${ }^{c}$ John Aaskov, ${ }^{a}$ Sazaly Abubakar, ${ }^{d}$ Futoshi Hasabe, ${ }^{e}$ Lee Ching Ng ${ }^{a}$ and Frank Konings ${ }^{b}$ \\ Correspondence to Frank Konings (email: koningsf@wpro.who.int).
}

Objective: To conduct an external quality assessment (EQA) of dengue and chikungunya diagnostics among national-level public health laboratories in the Asia Pacific region following the first round of EQA for dengue diagnostics in 2013.

Methods: Twenty-four national-level public health laboratories performed routine diagnostic assays on a proficiency testing panel consisting of two modules. Module A contained serum samples spiked with cultured dengue virus (DENV) or chikungunya virus (CHIKV) for the detection of nucleic acid and DENV non-structural protein 1 (NS1) antigen. Module B contained human serum samples for the detection of anti-DENV antibodies.

Results: Among 20 laboratories testing Module A, 17 (85\%) correctly detected DENV RNA by reverse transcription polymerase chain reaction (RT-PCR), 18 (90\%) correctly determined serotype and 19 (95\%) correctly identified CHIKV by RT-PCR. Ten of 15 (66.7\%) laboratories performing NS1 antigen assays obtained the correct results. In Module B, $18 / 23(78.3 \%)$ and $20 / 20(100 \%)$ of laboratories correctly detected anti-DENV IgM and IgG, respectively. Detection of acute/recent DENV infection by both molecular (RT-PCR) and serological methods (IgM) was available in 19/24 (79.2\%) participating laboratories.

Discussion: Accurate laboratory testing is a critical component of dengue and chikungunya surveillance and control. This second round of EQA reveals good proficiency in molecular and serological diagnostics of these diseases in the Asia Pacific region. Further comprehensive diagnostic testing, including testing for Zika virus, should comprise future iterations of the EQA.

G lobal dengue incidence has increased in recent decades, though the actual numbers of dengue cases are masked by underreporting. Bhatt et al. suggested that there are 390 million dengue virus (DENV) infections per year, of which 96 million manifest clinically. ${ }^{1}$ Estimated to bear around $70 \%$ of the global burden, the Asia Pacific region (comprising the World Health Organization [WHO] South-East Asia and Western Pacific Regions) is an area of high dengue activity with multiple and large outbreaks occurring yearly. In the Western Pacific Region in 2014 alone, there were outbreaks involving 1513 dengue cases in Solomon Islands, ${ }^{2} 45171$ cases in China and 108698 cases in Malaysia. ${ }^{3}$ Japan reported its first autochthonous outbreak in over 70 years ${ }^{4,5}$ and DENVserotype 3 was found to be circulating in the Pacific after an absence of 18 years. ${ }^{6}$

Chikungunya is an emerging threat to the Asia Pacific region. The disease is caused by the chikungunya virus (CHIKV), an alphavirus spread by some of the same mosquito vectors as DENV (Aedes aegypti and Ae. albopictus, among others). Clinical symptoms resemble dengue, and while chikungunya is a generally milder disease, debilitating sequelae such as persistent arthralgia have been reported in $36-64 \%$ of cases. ${ }^{7}$ CHIKV has probably had an unappreciated circulation in the region due to its disease presentation and

\footnotetext{
WHO Collaborating Centre for Reference and Research of Arbovirus and their Associated Vectors, Environmental Health Institute, National Environment Agency, Singapore.

Emerging Disease Surveillance and Response, Division of Health Security and Emergencies, World Health Organization Regional Office for the Western Pacific, Manila, Philippines.

Blood Safety and Laboratory Technology, Communicable Diseases Department, World Health Organization Regional Office for the South East-Asia, New Delhi, India.

WHO Collaborating Centre for Arbovirus Reference and Research (Dengue/Severe Dengue), Tropical Infectious Diseases Research and Education Centre, Department of Medical Microbiology, Faculty of Medicine, University of Malaya, Kuala Lumpur, Malaysia.

WHO Collaborating Centre for Reference and Research on Tropical and Emerging Virus Diseases, Nagasaki University, Nagasaki, Japan. Both authors contributed equally in the writing of this paper.

Submitted: 16 February 2016; Published: 22 April 2016

doi: 10.5365/wpsar.2016.7.1.002
} 
co-circulation with DENV. ${ }^{7,8}$ That may also be the case for Zika virus (ZIKV), a flavivirus that was detected in Asia in the 1960 s but has recently emerged in the Pacific and the Americas. ${ }^{9}$ ZIKV has been linked to clusters of microcephaly and other neurological disorders that WHO declared on 1 February 2016 to constitute a public health emergency of international concern. ${ }^{10}$

Accurate laboratory diagnosis is a critical component of surveillance and response. The similarity of dengue and chikungunya symptoms makes differential diagnosis difficult without laboratory confirmation, especially in dengue-endemic areas. This impacts public health response as the Ae. aegypti and Ae. albopictus mosquito vectors require different control strategies, ${ }^{11}$ and clinicians require specialized training to treat severe dengue cases. ${ }^{12}$ Diagnostics for dengue and chikungunya are comparable. During the acute phase of infection, diagnosis focuses on detection of viral RNA (or DENV non-structural protein 1 [NS1]); immunoglobulin M (IgM) and/or high titre immunoglobulin G (IgG) antibodies are the diagnostic targets in the convalescent phase. ${ }^{7,13}$ Despite the high initial cost, technical expertise and well-equipped facilities required for RNA detection using reverse transcription polymerase chain reaction (RT-PCR), this platform permits simultaneous detection of multiple pathogens and generates serotype (DENV) and genotype data useful for tracking the movement of viruses and for risk assessment. ${ }^{14}$ There are several commercial diagnostic tests for the detection of DENV and CHIKV by RT-PCR or for the detection of IgG and IgM antibodies against the viruses. However, while point-of-care tests for dengue diagnosis in nonclinical settings are well established, similar, reliable rapid diagnostic tests (RDTs) for chikungunya are not available. ${ }^{15}$

We recently reported the results of the first regional external quality assessment (EQA) for dengue in national-level public health laboratories in the WHO Western Pacific Region ${ }^{13}$ that was initiated under the Asia Pacific Strategy for Emerging Diseases (APSED). ${ }^{16}$ That 2013 study, based on the WHO existing influenza EQA programme ${ }^{17}$ and using a small panel containing inactivated DENV and convalescent patient serum provided an initial overview of dengue diagnostic testing in the Region, revealing good proficiency in molecular and serological diagnostics. The current study reflects an expansion of the panel to comprise more samples for dengue diagnosis, the inclusion of CHIKV samples and a broader geographic coverage with the additional participation of national-level public health laboratories from the WHO South-East Asia Region.

\section{METHODS}

\section{Participating laboratories}

Twenty-four national-level public health laboratories from 22 countries and areas in the WHO South-East Asia and Western Pacific Regions participated in this EQA (listed at end of article). The EQA panel was dispatched between February and May 2015.

\section{Preparation of EQA panel}

The WHO Collaborating Centre for Reference and Research of Arbovirus and their Associated Vectors, located at the Environmental Health Institute of the National Environment Agency, Singapore, was selected as the EQA provider as it had the necessary technical expertise, access to samples and the required resources.

The 2015 EQA panel comprised two modules ( $A$ and $B$ ) containing $1 \mathrm{~mL}$ of serum spiked with inactivated DENV or CHIKV (Module A) and $0.2 \mathrm{~mL}$ of serum obtained from convalescent dengue patients (Module B) (Table 1). All patient samples were heattreated at $56^{\circ} \mathrm{C}$ for 1 hour and tested negative for human immunodeficiency virus, hepatitis B surface antigen and hepatitis $\mathrm{C}$ virus antibody.

For Module A, inactivated DENV and CHIKV isolates were prepared from mammalian cell culture (Vero and BHK Clone 21, respectively) supernatants of DENV-1 (SG(EHI)D1/19944Y13, Genotype III, GenBank: KP685234), DENV-3 (SG(EHI)D3/26592Y13, Genotype III, GenBank: KP685235) and CHIKV (SGEHICH06071Y13, GenBank: KP685237). Viral particles in cell supernatants were inactivated by heating at $60{ }^{\circ} \mathrm{C}$ for 1 hour and verified non-infective through three passages in an in-house, cell-based viral infectivity assay. Heat-treated samples were diluted in pathogen-free human serum (SeraCare Life Sciences, Milford, MA, USA) and the final viral loads (measured in genomic equivalents/millilitre $[\mathrm{GE} / \mathrm{mL}]$ ) of $\mathrm{DENV}$ and CHIKV were determined by an in-house realtime RT-PCR assay. ${ }^{18,19}$ The presence of NS1 antigen 


\section{Table 1. Characteristics of modules used in EQA of dengue and chikungunya diagnostics,} WHO South-East Asia and Western Pacific Regions, 2015

\begin{tabular}{|c|c|c|c|c|}
\hline Module & Sample ID & Contents & Serotype/strain and titre $(\mathrm{GE} / \mathrm{mL})^{*}$ & Antibodies \\
\hline \multirow{10}{*}{$\begin{array}{l}\text { Viral RNA/NS1 } \\
\text { antigen } \\
\text { (Module A) }\end{array}$} & A2015-V01 & Inactivated DENV in serum & DENV-1 $\left(1.1 \times 10^{6}\right)$ & - \\
\hline & A2015-V02 & Inactivated DENV in serum & DENV-1 $\left(1.0 \times 10^{6}\right)$ & - \\
\hline & A2015-V03 & Inactivated DENV in serum & DENV-1 $\left(1.7 \times 10^{5}\right)$ & - \\
\hline & A2015-V04 & Inactivated DENV in serum & DENV-1 $\left(1.5 \times 10^{6}\right)$ & - \\
\hline & A2015-V05 & Inactivated DENV in serum & DENV-1 $\left(1.4 \times 10^{6}\right)$ & - \\
\hline & A2015-V06 & Inactivated DENV in serum & DENV-1 $\left(5.0 \times 10^{5}\right)$ & - \\
\hline & A2015-V07 & Serum alone & Negative control & - \\
\hline & A2015-V08 & Inactivated $\mathrm{CHIKV}$ in serum & $\operatorname{ECSA}\left(8.2 \times 10^{4}\right)$ & - \\
\hline & A2015-V08 & Inactivated $\mathrm{CHIKV}$ in serum & $\operatorname{ECSA}\left(9.9 \times 10^{4}\right)$ & - \\
\hline & A2015-V10 & Serum alone & Negative control & - \\
\hline \multirow{6}{*}{$\begin{array}{l}\text { Antibody } \\
\text { (Module B) }\end{array}$} & B2015-S01 & Negative human serum & - & Negative control \\
\hline & $\mathrm{B}^{2015-S 02}{ }^{\dagger}$ & Convalescent serum & - & $\lg M, \lg G$ \\
\hline & B2015-S03 ${ }^{\dagger}$ & Convalescent serum & - & $\lg M, \lg G$ \\
\hline & B2015-S04 ${ }^{\dagger}$ & Convalescent serum & - & $\lg M, \lg G$ \\
\hline & B2015-S05 & Convalescent serum & - & $\lg M, \lg G$ \\
\hline & B2015-S06 & Negative human serum & - & Negative control \\
\hline
\end{tabular}

* Virus titre is defined as average genomic copy number (genomic equivalents, GE) per $\mathrm{mL}, n=5$.

B2015-S02 and B2015-S03, and B2015-S04 and B2015-S05, were the same samples collected from two recently recovered dengue patients used to assess reproducibility of testing results.

CHIKV, chikungunya virus; DENV, dengue virus; ECSA, East Central and South African lineage; ID, identification; and NS1, non-structural protein 1.

in DENV samples was confirmed using commercial dengue NS1 assays (Panbio Dengue Early NS1 antigen capture ELISA [Alere Inc., Waltham, MA, USA] and Dengue NS1 Ag cassette [Standard Diagnostics Inc., Kyonggi-do, Republic of Korea]). Only samples containing DENV detectable by both NS1 and RT-PCR assays were included in the module. Two samples (A2015-V07 and A2015-V10) were included as negative controls (serum only) and were confirmed DENV- and CHIKV-negative by the real-time RT-PCR and commercial dengue NS1 assays mentioned above.

For Module B, the convalescent sera of two recently recovered dengue patients were split into two sets (B2015-S02 and B2015-S03; and B2015-S04 and B2015-S05). These sera contained neutralizing antibodies to DENV 1-4 ( $>1: 1000$, as determined by an in-house cell-based plaque-reduction neutralization technique [PRNT]). ${ }^{20}$ These samples also tested positive for the presence of dengue IgM and IgG antibodies using DENV commercial assays (Bioline Dengue Duo [Standard Diagnostics Inc.], Dengue Virus IgM Capture DxSelect [Focus Diagnostics, Cypress, CA, USA], and Panbio Dengue IgG Capture and IgG Indirect ELISA [Alere Inc.]). Samples B2015-S02 and B2015-S03 were designated as high IgM
( $>72$ Panbio units by IgM capture; positive is $>11$ ) and high IgG (> 97 Panbio units by IgG capture; positive is $>22$ ), while samples B2015-S04 and B2015-S05 were designated as low IgM (18 Panbio units by IgM capture; positive is $>11$ ) and high IgG (> 87 Panbio units by IgG capture; positive is $>22$ ). Two samples (B2015-S01 and B2015-S06) were included as negative controls (human sera only) and were confirmed negative for anti-DENV antibodies using the above-mentioned commercial and PRNT assays.

Before dispatch to participating laboratories, all EQA samples were tested by an independent International Organization for Standardization (ISO) 15189 and College of American Pathologists (CAP)-accredited laboratory, using DENV and CHIKV RT-PCR assays, ${ }^{21,22}$ and the SD Bioline Dengue Duo kit [Standard Diagnostics Inc.].

Participating laboratories could subscribe to one or both modules. Individual samples were number-coded and frozen at $-80{ }^{\circ} \mathrm{C}$ until dispatch. One laboratory requested and was provided with positive controls for the four DENV serotypes in its shipment to validate its dengue RT-PCR protocols. Similarly, laboratories were provided with a CHIKV-positive control as well as 
Figure 1. Proportion of participating laboratories by test conducted and results, EQA of dengue and chikungunya diagnostics, WHO South-East Asia and Western Pacific Regions, 2015

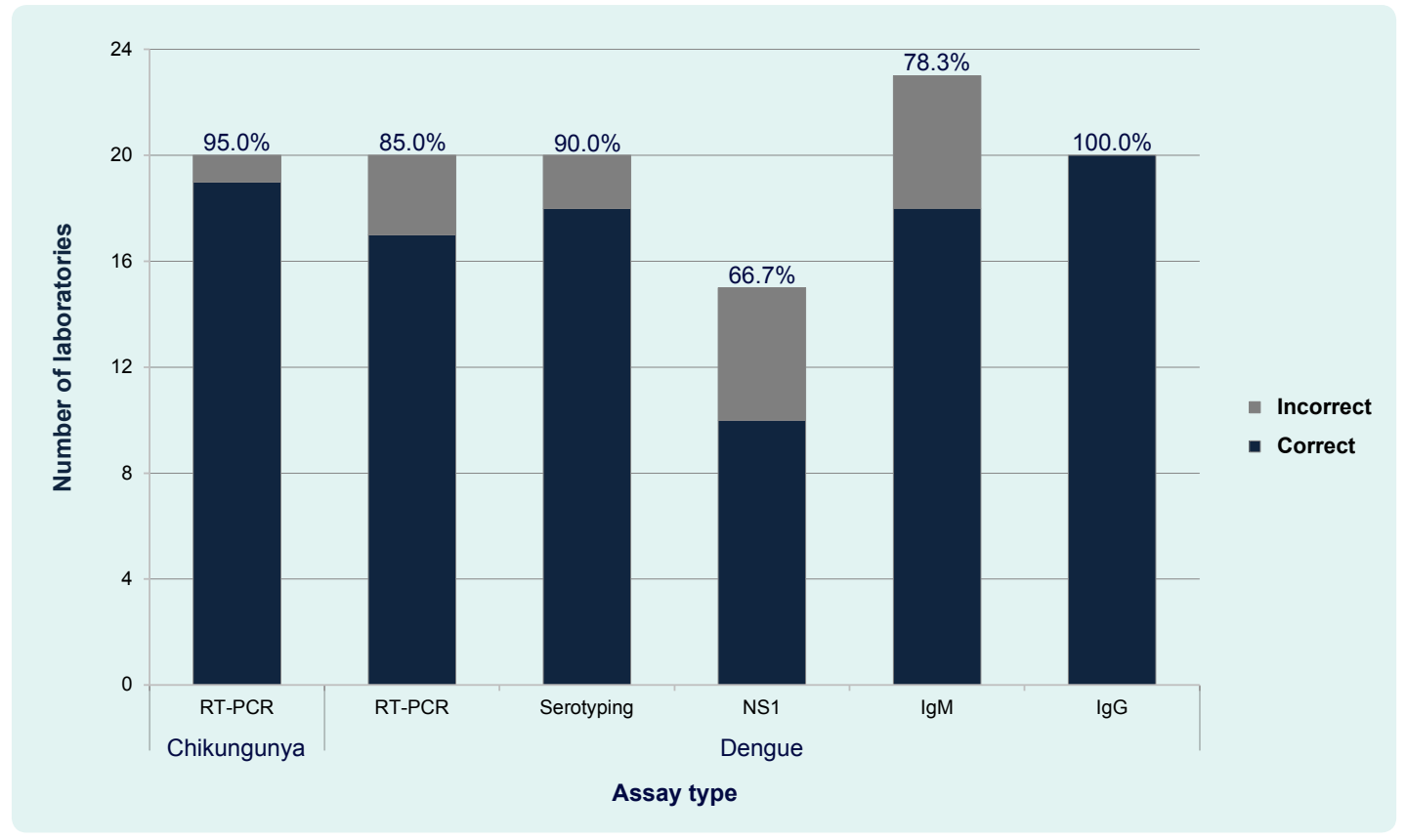

Note: Percentage of laboratories performing each test correctly is displayed above columns.

NS1, non-structural protein 1 ; and RT-PCR, reverse transcription polymerase chain reaction.

recommended references for conventional or real-time RT-PCR protocols and primer/probe sequences if they requested them.

\section{Data collection and analysis}

Each participant was given a unique identifier to assure anonymous participation, an instruction form as well as results submission and feedback forms. Clinical notes accompanied Module B samples. Intentional sample labelling errors were included to assess the sample preprocessing measures of the participating laboratories. Laboratories were requested to examine the EQA samples by routine diagnostic methods; report any clerical errors identified; and submit background technical information on methods, kits, protocols and reagents used.

In Module A, two points each were awarded for the correct detection of DENV either by RT-PCR or NS1 assays, correct serotyping of DENV and correct detection of CHIKV by RT-PCR. In Module B, two points each were awarded for the correct detection of dengue IgM and IgG antibodies. All (including complementary) assays performed were scored; no penalty was applied for assays not done. Equivocal results submitted for true positive samples were awarded one point. ${ }^{23}$ Using indate reagents or validating expired reagents earned up to four additional points for each module. Identification of intentional clerical errors scored an additional point for each module. The final score was the proportion of points earned out of the possible awardable points.

\section{RESULTS}

\section{Overall laboratory proficiency}

Twenty-four laboratories participated in this 2015 EQA, with 20 and 23 laboratories testing Modules $A$ and $B$, respectively. Nineteen laboratories tested both. Overall results are presented in Figure 1. The majority of participants detected DENV (17/20, $85 \%)$, DENV serotype $(18 / 20,90 \%)$ and CHIKV (19/20, 95\%) by RT-PCR correctly. Accuracy was moderate $(10 / 15,66.7 \%)$ for NS1 testing. The most commonly performed EQA component was anti-DENV IgM detection with 18/23 (78.3\%) laboratories reporting correct results. Twenty laboratories detected anti-DENV IgG in samples with $100 \%$ accuracy. Seven laboratories performed complementary assays for a single sample type (this approach aids in eliminating false positives or negatives in routine diagnostics) and reported correct results for at least one of the assays used (Table 2). Eighteen of 24 laboratories (75\%) failed to identify the intentional clerical errors on sample labels. 
Table 2. Performance summary of participating laboratories, EQA of dengue and chikungunya diagnostics, WHO South-East Asia and Western Pacific Regions, 2015

\begin{tabular}{|c|c|c|c|c|c|c|c|c|c|c|c|c|c|c|c|c|c|c|c|c|c|c|c|c|}
\hline Laboratory identifier & $\begin{array}{l}13 \\
01\end{array}$ & $\begin{array}{l}13 \\
02\end{array}$ & $\begin{array}{l}13 \\
03\end{array}$ & $\begin{array}{l}13 \\
04\end{array}$ & $\begin{array}{l}13 \\
06\end{array}$ & $\begin{array}{l}13 \\
07\end{array}$ & $\begin{array}{l}13 \\
08\end{array}$ & $\begin{array}{l}13 \\
09\end{array}$ & $\begin{array}{l}13 \\
10\end{array}$ & $\begin{array}{l}13 \\
11\end{array}$ & $\begin{array}{l}13 \\
12\end{array}$ & $\begin{array}{l}13 \\
13\end{array}$ & $\begin{array}{l}13 \\
14\end{array}$ & $\begin{array}{l}13 \\
15\end{array}$ & $\begin{array}{l}13 \\
16\end{array}$ & $\begin{array}{l}13 \\
17\end{array}$ & $\begin{array}{l}13 \\
18\end{array}$ & $\begin{array}{l}13 \\
19\end{array}$ & $\begin{array}{l}14 \\
20\end{array}$ & $\begin{array}{l}14 \\
21\end{array}$ & $\begin{array}{l}14 \\
22\end{array}$ & $\begin{array}{l}14 \\
23\end{array}$ & $\begin{array}{l}14 \\
24\end{array}$ & $\begin{array}{l}14 \\
25\end{array}$ \\
\hline \multirow{2}{*}{\multicolumn{25}{|c|}{$\begin{array}{l}\text { Nucleic acid detection (RT-PCR) } \\
\text { DENV }\end{array}$}} \\
\hline & & & & & & & & & & & & & & & & & & & & & & & & \\
\hline \multirow{2}{*}{$\begin{array}{l}\text { Real-time } \\
\text { Conventional }\end{array}$} & $\bullet$ & $\bullet$ & $\bullet$ & & & $\bullet$ & & $\bullet$ & $\bullet$ & - & O & & & $\bullet$ & - & $\bullet$ & & $\bullet$ & $\bullet$ & & & & & \\
\hline & $\bullet$ & & & $\bullet$ & 0 & & & & & & & $\bullet$ & $\bullet$ & & & & 0 & & & & & & $\bullet$ & $\bullet$ \\
\hline \multicolumn{25}{|l|}{ DENV serotyping } \\
\hline Real-time & $\bullet$ & $\bullet$ & $\bullet$ & & & 0 & & $\bullet$ & $\bullet$ & $\bullet$ & $\bullet$ & & & $\bullet$ & $\bullet$ & $\bullet$ & & $\bullet$ & $\bullet$ & & & & & \\
\hline Conventional & $\bullet$ & & & $\bullet$ & $\bullet$ & & & & & & & $\bullet$ & $\bullet$ & & & & $\bullet$ & & & & & & 0 & - \\
\hline \multicolumn{25}{|l|}{ CHIKV } \\
\hline Real-time & $\bullet$ & $\bullet$ & $\bullet$ & & & o & & $\bullet$ & $\bullet$ & & $\bullet$ & $\bullet$ & & $\bullet$ & $\bullet$ & $\bullet$ & & $\bullet$ & $\bullet$ & & & & $\bullet$ & \\
\hline Conventional & & & & $\bullet$ & $\bullet$ & & & & & $\bullet$ & & & $\bullet$ & & & $\bullet$ & $\bullet$ & & & & & & & - \\
\hline \multicolumn{25}{|l|}{ DENV NS1 antigen detection } \\
\hline ELISA & O & & & $\bullet$ & & $\bullet$ & & $\bullet$ & & & & & & $\bullet$ & 0 & 0 & $\bullet$ & $\circ$ & O & & & & O & \\
\hline RDT & $\bullet$ & $\bullet$ & & $\bullet$ & - & & & & & $\bullet$ & & & $\circ$ & ○ & & & & & $\bullet$ & & & & & \\
\hline \multicolumn{25}{|l|}{ Anti-DENV IgM detection } \\
\hline ELISA & $\bullet$ & $\bullet$ & $\bullet$ & $\bullet$ & & $\bullet$ & $\bullet$ & $\bullet$ & $\bullet$ & o & & $\bullet$ & $\circ$ & $\bullet$ & - & 0 & o & $\bullet$ & O & $\bullet$ & $\bullet$ & $\bullet$ & $\bullet$ & $\bullet$ \\
\hline $\mathrm{RDT}$ & $\bullet$ & $\bullet$ & & & - & & & & & & & & & & & $\bullet$ & & & & & & $\bullet$ & & \\
\hline \multicolumn{25}{|l|}{ Anti-DENV IgG detection } \\
\hline ELISA & $\bullet$ & & $\bullet$ & $\bullet$ & & $\bullet$ & & & $\bullet$ & $\bullet$ & & $\bullet$ & $\bullet$ & $\bullet$ & & & $\bullet$ & $\bullet$ & $\bullet$ & $\bullet$ & & & $\bullet$ & $\bullet$ \\
\hline RDT & $\bullet$ & $\bullet$ & & & $\bullet$ & & & & & & & & & & & $\bullet$ & & & & & & $\bullet$ & & \\
\hline $\mathrm{HI}$ & $\bullet$ & & & & & & & & & & & & & & $\bullet$ & $\bullet$ & & & & & & & & \\
\hline Module shipment (days) & 2 & 1 & 3 & 2 & 1 & 8 & 2 & 3 & 3 & 2 & 4 & 1 & 2 & 3 & 1 & 1 & 2 & 2 & 2 & 6 & 1 & 1 & 8 & 2 \\
\hline Testing turnaround (days) & 41 & 27 & 36 & 72 & 54 & 29 & 41 & 7 & 25 & 27 & 28 & 12 & 30 & 32 & 21 & 27 & 49 & 30 & 27 & 28 & 13 & 24 & 50 & 44 \\
\hline
\end{tabular}

Note: Filled circles indicate correct results for all samples; open circles indicate incorrect results for at least one sample.

CHIKV, chikungunya virus; DENV, dengue virus; ELISA, enzyme-linked immunosorbent assay; HI, haemagglutination inhibition assay; NS1: non-structural protein 1; RDT, rapid diagnostic test; and RT-PCR, reverse transcription polymerase chain reaction.

\section{Module A: Viral RNA and NS1 antigen}

Of the 20 laboratories performing RT-PCR in Module A, $15(75 \%)$ used real-time RT-PCR technology for nucleic acid detection at some point during their testing and 10 laboratories (50\%) used it exclusively (Table 2). Few laboratories demonstrated errors in detection of DENV, DENV serotype or CHIKV by RT-PCR. Of the three laboratories with errors in DENV detection, two using conventional RT-PCR reported the DENV-positive samples (A2015-V01, V02 and V03) as negative and one laboratory using real-time RT-PCR methodology reported the DENV-positive samples (A2015-V01, V02 and V06) as negative. Of the two laboratories exhibiting serotyping errors, one reported both DENV-1 and DENV-4 in a DENV-1-only sample (A2015-V03) and another reported the presence of DENV-4 in two DENV-3 samples (A2015-V04 and A2015-V05). One laboratory detected CHIKV in a serum-only sample (A2015-V10). DENV genome regions targeted for virus detection and serotyping varied with capsid and non-structural protein 5 being the most common. CHIKV detection targets included the envelope 1 , and the non-structural protein 1 and 4 genes.

Fifteen laboratories performed NS1 antigen detection assays using the ELISA methodology alone (7/15), both ELISA and commercial RDT (4/15) or RDT alone (4/15). Five laboratories performing ELISA on DENV-positive sample A2015-V03 using the Platelia Dengue NS1 Ag kit (Bio-Rad Laboratories, Inc., Hercules, CA, USA) demonstrated errors; four reported equivocal results and one reported a false-negative result.

\section{Module B: Serology}

Anti-DENV IgM assays were performed by all 23 laboratories testing Module B using the ELISA methodology alone (18/23), both ELISA and RDT (4/23) or RDT alone (1/23) (Table 2). Antibody capture ELISAs from Panbio (Alere Inc.) and SD (Standard Diagnostics Inc.) were the most commonly employed 
Figure 2. Overall accuracy (final score) of participating laboratories in the 2013 and 2015 WHO EQAs of dengue and chikungunya diagnostics

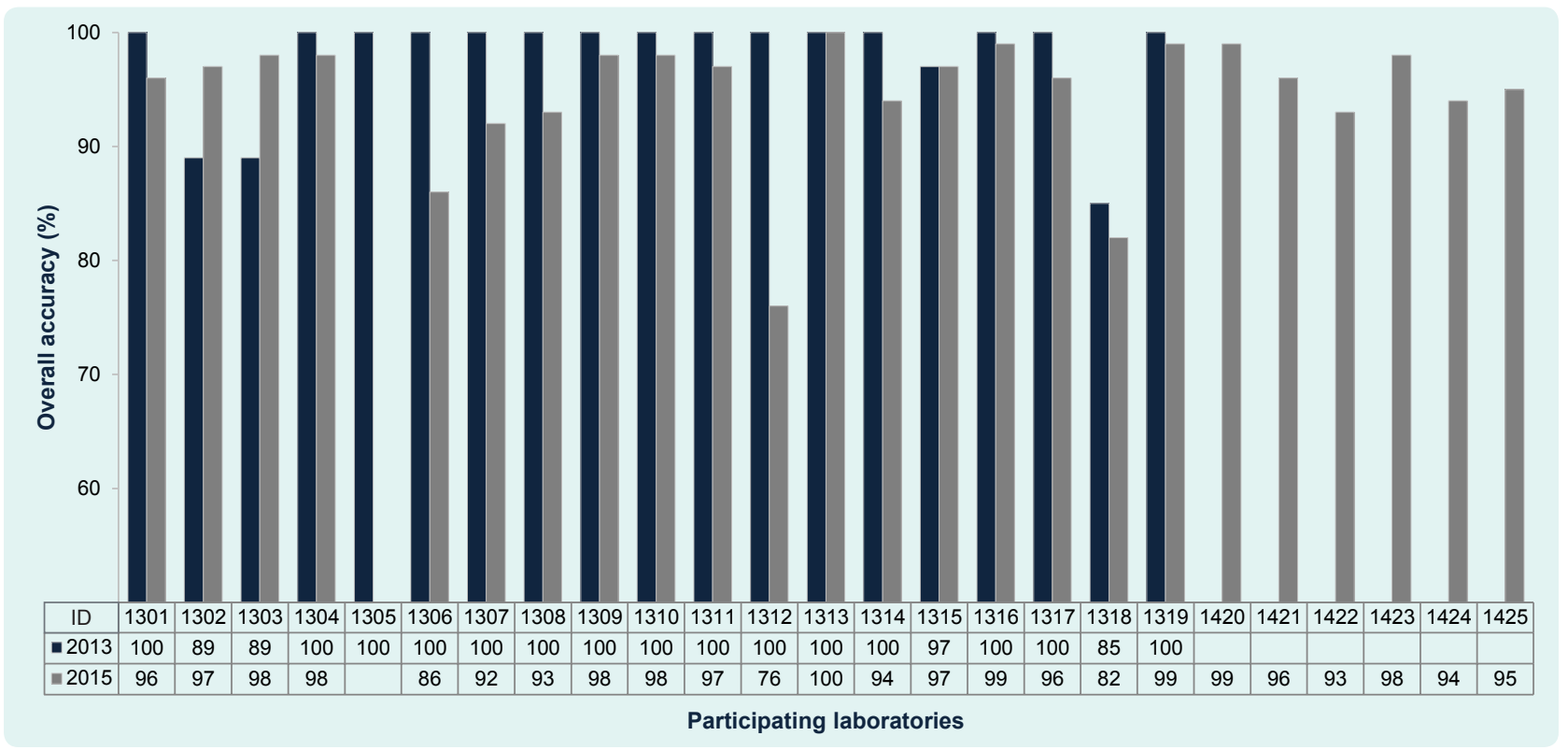

ID, laboratory identifier.

assays for IgM detection. Of the 22 laboratories performing anti-DENV IgM ELISAs, 17 (77.3\%) obtained correct results, while five (22.7\%) reported equivocal or false-negative results for at least one of two IgM-positive samples (B2015-S04 and B2015-S05). No errors were reported among RDT users.

Twenty laboratories tested for both anti-DENV IgG and IgM in Module B; only three tested for IgM alone. Anti-DENV IgG was correctly detected by all methods used. Fourteen (70\%) laboratories employed ELISA assays alone for IgG detection, while the remainder used a commercial RDT kit, a haemagglutination inhibition assay (HI), or both.

\section{Comparison with the 2013 EQA}

Of the 18 laboratories that participated in the $2013^{13}$ and 2015 EQAs, four (22\%) were able to maintain or improve their overall score (expressed as percentage) in this EQA, while the final score in the remaining 14 laboratories fell by a median of $3.5 \%$ (Figure 2). Scores for the majority (12/14) of these laboratories fell by $\leq 8 \%$. In contrast, scores for two laboratories fell by $14 \%$ and $24 \%$, and another, repeating the same serology detection error made in 2013 , scored consistently low ( $\leq 85 \%$ ) in both years.

\section{Logistics}

The average turnaround time for result submission was 32 days. The 20 laboratories requesting CHIKV samples were offered an additional 30 days to optimize their CHIKV RT-PCR protocols. Of the 13 laboratories accepting the extension, five used it, including two laboratories with a 14-day national holiday within their testing periods. One laboratory requested a 24-day extension due to shortage of reagents.

There were no major logistical challenges associated with shipment of test samples to participating laboratories. All samples arrived frozen at the time of receipt. Nearly all participating laboratories received test samples within four days; three laboratories received them in up to eight days due to extended customs clearance times.

\section{DISCUSSION}

This study reports on the second iteration of the WHO EQA for dengue diagnostics for national-level public health laboratories in the Western Pacific Region that has been expanded to include chikungunya diagnostics as well as national-level laboratories from the South-East Asia Region. 
The appropriate dengue diagnostic tools must be used at the correct time for the correct diagnosis of dengue. While 19/24 (79.2\%) laboratories employed assays for both acute (RT-PCR) and recent (antiDENV IgM) DENV infection, four performed antibody testing for dengue but lacked assays for early detection (pre-antibody immunological response) of dengue such as RT-PCR or NS1 kits and one could perform RT-PCR but had no serology capacity. With an incomplete set of diagnostics, these laboratories may be unable to diagnose a proportion of DENV infections and should consider quickly strengthening their capacity through the use of commercial ELISA assays for the detection of NS1 antigen or anti-DENV IgM antibodies.

Accuracy was high ( $\geq 85 \%$ ) for DENV and CHIKV detection and DENV serotyping by RT-PCR. The few errors in DENV detection (false-negatives) appeared to be clustered in samples A2015-V01 and V02, which were identical, high-titre DENV-1 samples. Most of the inaccuracies in Module A were in NS1 testing. Specifically, $87.5 \%$ of NS1 testing errors were derived from a single DENV-positive sample, A2015-V03, being reported as negative or equivocal (7/8 laboratories), particularly when using the Platelia Dengue NS1 Ag kit. This suggests that the NS1 levels in the sample may have been at the threshold of detection for the kit, making complementary assays for virus detection, such as RT-PCR, highly relevant.

This EQA served as a platform for building capacity for RT-PCR detection of CHIKV. Of the 20 laboratories performing RT-PCR, 16 (80\%) requested receipt of a CHIKV-positive control and $12(60 \%)$ requested realtime or conventional RT-PCR protocols to develop and validate their capacity for CHIKV diagnosis.

Laboratories also performed anti-DENV IgM detection with good accuracy (78.3\%). Errors in this component of the panel were the result of equivocal or false-negative ELISA results for samples B2015-S04 and/or B2015-S05. These were duplicate low titre IgM samples from a convalescent volunteer, suggesting that some laboratories should review the cut-off values of their anti-DENV IgM assays. All assays for detection of anti-DENV IgG were performed without error. Similar to the $2013 \mathrm{EQA}$, laboratories appeared to use either high titre IgG ELISAs suitable for detecting acute/recent infections or low titre IgG ELISAs for the detection of a prior dengue infection (such as in seroprevalence studies). Laboratories should be aware of the constraints of their IgG assays, but as Module B contained only high titre IgG samples, the recognition of these operational constraints could not be tested.

For laboratories participating in the 2013 and 2015 EQAs, a minimal decrease in final score on this round was anticipated, and was likely due to increased panel complexity as previously suggested. ${ }^{24}$ But while improving on the first iteration of the EQA in several ways, this second round also had limitations. Module A contained 10 test samples as opposed to three in 2013 and included both DENV and CHIKV; however, the module comprised just two DENV serotypes and one CHIKV strain. This round of the EQA also prioritized concomitant sample testing by both DENV NS1 and RT-PCR assays as the NS1 RDT, while less sensitive than RT-PCR, is a key diagnostic and epidemiological tool for detection of acute DENV infection in clinical settings. However, this meant that DENV titres below $10^{5} \mathrm{GE} / \mathrm{mL}$ could not be introduced to gauge the sensitivity of RT-PCR assays. This was not so for the CHIKV samples that were titred at $10^{4} \mathrm{GE} / \mathrm{mL}$ and detected with high accuracy compared to similar samples in another EQA. ${ }^{25}$ Future iterations of our study could place more emphasis on the sensitivity of DENV molecular testing by using lower titres considered suitable for surveillance and diagnostic purposes. ${ }^{26}$

Module B comprised high and low titre anti-DENV IgM samples but no low titre anti-DENV IgG samples that could be used to assess the sensitivity of IgG assays. The module also did not include any samples for serological detection of anti-CHIKV antibodies, though a subsequent study suggests this capacity is widely in place in the Western Pacific Region. ${ }^{27}$ Additionally, that most laboratories failed to report the clerical errors included in the EQA suggested that instructions in future rounds should place greater emphasis on the importance of this quality control measure. Together, these limitations can be used as opportunities in subsequent rounds of this $E Q A$, along with the introduction of testing for ZIKV. Given ZIKV's link to serious neurological disorders and its co-circulation with DENV and CHIKV that cause similar symptoms, differential testing for these pathogens is crucial. ${ }^{27}$ 
This second round of EQA demonstrated that good proficiency in dengue and chikungunya diagnostics is in place in the Asia Pacific region. Laboratories demonstrating lower proficiency may be able to benefit from technical assistance available through this EQA. Future iterations of the EQA, featuring increased complexity and the inclusion of other priority pathogens, including ZIKV, will continue to contribute to strengthening regional laboratories' diagnostic capacities for emerging diseases in line with APSED.

\section{Conflicts of interest}

None declared.

\section{Funding}

This 2015 round of proficiency testing was in part financially supported by the Global Partnership Program of Canada's Department of Foreign Affairs, Trade and Development.

\section{Acknowledgements}

The authors are grateful to the national-level public health laboratories that participated in the EQA and to Professor Leo Yee Sin of the Tan Tock Seng Hospital, Singapore, for assistance in obtaining dengue antibodypositive serum samples.

\section{List of participating laboratories}

PathWest Laboratory Medicine; QEII Medical Centre (Australia); Institute of Epidemiology, Disease Control and Research (Bangladesh); Institut Pasteur du Cambodge (Cambodia); Chinese Center for Disease Control and Prevention, National Institute for Viral Diseases Control and Prevention (China); Fiji Centre for Communicable Disease Control (Fiji); Institut Louis Malardé (French Polynesia); Public Health Laboratory Centre, Virology Division (Hong Kong Special Administrative Region); National Institute of Health Research and Development (Indonesia); National Institute of Infectious Diseases, Virology 1st (Japan); Korea National Institute of Health, Division of Arboviruses (Republic of Korea); National Center for Laboratory and Epidemiology (Lao People's Democratic Republic); Health Bureau, Public Health Laboratory (Macau Special Administrative Region); Tropical Infectious Diseases Research and Education Centre, University of Malaya (Malaysia);
National Public Health Laboratory (Malaysia); National Center for Zoonotic Diseases, Ministry of Health (Mongolia); National Health Laboratory (Myanmar); National Public Health Laboratory (Nepal); Institut Pasteur de Nouvelle-Calédonie, Laboratoire de Biologie Médicale (New Caledonia); Institute of Environmental Science and Research Ltd, Clinical Virology (New Zealand); Papa New Guinea Institute of Medical Research, Environmental \& Emerging Diseases Unit (Papua New Guinea); Research Institute for Tropical Medicine, Department of Virology (Philippines); Department of Virology, Medical Research Institute (Sri Lanka); National Institute of Hygiene and Epidemiology, Virology Department (Viet Nam); and Pasteur Institute in Ho Chi Minh, Laboratory of Arboviruses (Viet Nam).

\section{References}

1. Bhatt $S$ et al. The global distribution and burden of dengue. Nature, 2013, 496(7446):504-507. doi:10.1038/nature12060 pmid:23563266

2. Dengue Situation Update - 3 June 2014. Manila, World Health Organization Regional Office for the Western Pacific, 2014 (http://www.wpro.who.int/entity/emerging_diseases/Dengue. Biweekly.03Jun2014.pdf, accessed 17 December 2015).

3. Dengue Situation Update - 13 January 2015. Manila, World Health Organization Regional Office for the Western Pacific, 2015 (http://www.wpro.who.int/entity/emerging_diseases/dengue biweekly_13jan2015.pdf, accessed 17 December 2015).

4. Arima $Y$ et al. Ongoing local transmission of dengue in Japan, August to September 2014. Western Pacific Surveillance and Response Journal, 2014, 5(4):27-29. doi:10.5365/ wpsar.2014.5.3.007 pmid:25685602

5. Kutsuna $S$ et al. Autochthonous dengue fever, Tokyo, Japan, 2014. Emerging Infectious Diseases, 2015, 21(3):517-520. doi:10.3201/eid2103.141662 pmid:25695200

6. Cao-Lormeau VM et al. Dengue virus type 3, South Pacific Islands, 2013. Emerging Infectious Diseases, 2014, 20(6):1034-1036. doi:10.3201/eid2006.131413 pmid:24856252

7. Weaver SC, Lecuit M. Chikungunya virus and the global spread of a mosquito-borne disease. New England Journal Medicine, 2015, 372(13):1231-1239. doi:10.1056/NEJMra1406035 pmid:25806915

8. Horwood $\mathrm{P}$ et al. The threat of chikungunya in Oceania. Western Pacific Surveillance and Response Journal, 2013, 4(2):8-10. doi:10.5365/wpsar.2013.4.2.003 pmid:24015365

9. Kindhauser MK et al. Zika: the origin and spread of a mosquitoborne virus. Bulletin of the World Health Organization, 2016 (submitted). doi:10.2471/BLT.16.171082

10. WHO Director-General summarizes the outcome of the Emergency Committee regarding clusters of microcephaly and Guillain-Barré syndrome. Geneva, World Health Organization, $2016 \quad$ (http://www.who.int/mediacentre/news/ statements/2016/emergency-committee-zika-microcephaly/en/, accessed 21 March 2016).

11. Yap G et al. Evaluation of Chikungunya diagnostic assays: differences in sensitivity of serology assays in two independent outbreaks. PLoS Neglected Tropical Disease, 2010, 4(7):e753. doi:10.1371/journal.pntd.0000753 pmid:20651930 
12. World Health Organization and Special Programme for Research and Training in Tropical Diseases: Handbook for clinical management of dengue. Geneva, World Health Organization, 2012 (http://www.who.int/denguecontrol/9789241504713/en/, accessed 8 April 2016).

13. Pok KY et al. First round of external quality assessment of dengue diagnostics in the WHO Western Pacific Region, 2013. Western Pacific Surveillance and Response Journal, 2015, 6(2):73-81. doi:10.5365/wpsar.2015.6.1.017 pmid:26306220

14. Hapuarachchi $\mathrm{HC}$ et al. Intra-epidemic evolutionary dynamics of a Dengue virus type 1 population reveal mutant spectra that correlate with disease transmission. Science Report, 2016, 6:22592. doi:10.1038/srep22592 pmid:26940650

15. Prat $\mathrm{CM}$ et al. Evaluation of commercially available serologic diagnostic tests for chikungunya virus. Emerging Infectious Diseases, 2014, 20(12):2129-2132. doi:10.3201/ eid2012.141269 pmid:25418184

16. Asia Pacific Strategy for Emerging Diseases (2010). Manila, World Health Organization Regional Office for the Western Pacific, 2011 (http://www.wpro.who.int/emerging_diseases/APSED2010/ en/, accessed 17 December 2015).

17. WHO external quality assessment project for the detection of influenza virus type $A$ by PCR. Geneva, World Health Organization, $2012 \quad$ (http://www.who.int/influenza/gisrs laboratory/external_quality_assessment_project/en/, accessed 17 December 2015).

18. Lai YL et al. Cost-effective real-time reverse transcriptase PCR (RT-PCR) to screen for Dengue virus followed by rapid single-tube multiplex RT-PCR for serotyping of the virus. Journal of Clinical Microbiology, 2007, 45(3):935-941. doi:10.1128/JCM.0125806 pmid: 17215345

19. Hasebe $F$ et al. Combined detection and genotyping of Chikungunya virus by a specific reverse transcription-polymerase chain reaction. Journal of Medical Virology, 2002, 67(3):370374. doi:10.1002/jmv.10085 pmid:12116030
20. Low SL et al. Dengue seroprevalence of healthy adults in Singapore: serosurvey among blood donors, 2009. American Journal of Tropical Medicince and Hygiene, 2015, 93(1):40-45. doi:10.4269/ajtmh.14-0671 pmid:26013376

21. Johnson BW, Russell BJ, Lanciotti RS. Serotype-specific detection of dengue viruses in a fourplex real-time reverse transcriptase PCR assay. Journal Clinical Microbiology, 2005, 43(10): 4977-4983. doi:10.1128/JCM.43.10.4977-4983.2005 pmid:1620795

22. Pastorino B et al. Development of a TaqMan RT-PCR assay without RNA extraction step for the detection and quantification of African Chikungunya viruses. Journal of Virological Methods, 2005, 124(1-2):65-71. doi:10.1016/j.jviromet.2004.11.002 pmid: 15664052

23. Guidelines for organizing national external quality assessment schemes for HIV serological testing. Geneva, World Health Organization, 1996 (http://www.who.int/diagnostics laboratory/ quality/serology/en/, accessed 17 December 2015).

24. Donoso Mantke 0 et al. Quality control assessment for the serological diagnosis of dengue virus infections. Journal of Clinical Virology, 2004, 29(2):105-112. doi:10.1016/S13866532(03)00110-0 pmid:14747029

25. Jacobsen $\mathrm{S}$ et al. External quality assessment studies for laboratory performance of molecular and serological diagnosis of Chikungunya virus infection. Journal of Clinical Virology, 2016, 76:55-65. doi:10.1016/j.jcv.2016.01.008 pmid:26828561

26. Domingo $C$ et al. 2nd International external quality control assessment for the molecular diagnosis of dengue infections. PLoS Neg/ected Tropical Diseases, 2010, 4(10):e833. doi:10.1371/ journal.pntd.0000833 pmid:20957194

27. Squires RC, Konings F. Preparedness for Zika virus testing in the World Health Organization Western Pacific Region. Western Pacific Surveillance and Response Journal, 2016, 7(1):44-47. doi:10.5365/wpsar.2016.7.1.007 


\section{Prevalence of resistance to second-line tuberculosis drug among multidrug- resistant tuberculosis patients in Viet Nam, 2011}

Hoa Binh Nguyen, ${ }^{a b}$ Nhung Viet Nguyen, ${ }^{a c}$ Huong Thi Giang Tran, ${ }^{d}$ Hai Viet Nguyen e and Quyen Thi Tu Buif Correspondence to Nguyen Binh Hoa (email: nguyenbinhhoatb@yahoo.com).

Introduction: Extensively drug-resistant tuberculosis (XDR-TB) represents an emerging public health problem worldwide. According to the World Health Organization, an estimated 9.7\% of multidrug-resistant TB (MDR-TB) cases are defined as XDR-TB globally. The objective of this study was to determine the prevalence of drug resistance to second-line TB drugs among MDR-TB cases detected in the Fourth National Anti-Tuberculosis Drug Resistance Survey in Viet Nam.

Methods: Eighty clusters of TB cases were selected using a probability-proportion-to-size approach. To identify MDR-TB cases, drug susceptibility testing (DST) was performed for the four major first-line TB drugs. DST of second-line drugs (ofloxacin, amikacin, kanamycin, capreomycin) was performed on isolates from MDR-TB cases to identify pre-XDR and XDR cases.

Results: A total of 1629 smear-positive TB cases were eligible for culture and DST. Of those, DST results for first-line drugs were available for 1312 cases, and 91 (6.9\%) had MDR-TB. Second-line DST results were available for 84 of these cases. Of those, 15 cases (17.9\%) had ofloxacin resistance and $6.0 \%$ were resistant to kanamycin and capreomycin. Five MDRTB cases $(6.0 \%)$ met the criteria of XDR-TB.

Conclusion: This survey provides the first estimates of the proportion of XDR-TB among MDR-TB cases in Viet Nam and provides important information for local policies regarding second-line DST. Local policies and programmes that are geared towards TB prevention, early diagnosis and treatment with effective regimens are of high importance.

$\mathrm{T}$ uberculosis (TB) is a leading cause of death in communicable diseases. According to the World Health Organization (WHO), an estimated 9.6 million people developed TB and 1.5 million died from the disease worldwide in $2014 .{ }^{1}$ Viet Nam ranks 12th among the 22 high-burden TB countries. ${ }^{1}$ In 2007, the first nationwide TB prevalence survey in Viet Nam showed a prevalence of bacteriological-positive TB of 307 per 100000 adult population (15 years or older) and a prevalence of smear-positive TB of 197 per 100000 adult population. ${ }^{2}$

Resistance to anti-TB drugs is a public health threat to controlling TB worldwide. ${ }^{1,3,4}$ Globally, the proportion of cases with multidrug-resistant TB (MDR-TB) ${ }^{4}$ is $3.3 \%$ among new TB cases and $20 \%$ among previously treated TB cases, accounting for about 480000 people in $2014 .{ }^{1}$ Viet Nam is among the 27 high MDR-TB burden countries; the estimated proportion of new MDRTB cases in Viet Nam was $4.0 \%$, and the estimated proportion of MDR-TB among re-treatment cases was $23 \%$ in $2014 .{ }^{1,5}$ Based on the Fourth National AntiTuberculosis Drug Resistance Survey in Viet Nam and the WHO Global Tuberculosis Report 2015, there were an estimated 5100 cases with MDR-TB among notified TB cases in Viet Nam. ${ }^{1,5}$

In 2009, the Viet Nam National Tuberculosis Programme (NTP) implemented programmatic management of drug-resistant TB (PMDT) to diagnose and provide treatment with second-line TB drugs (SLDs) for MDR-TB under programme condition. The

\footnotetext{
National Tuberculosis Control Programme Viet Nam, Hanoi, Viet Nam.

Centre for Operational Research, International Union Against Tuberculosis and Lung Disease, Paris, France.

Viet Nam Association for Tuberculosis and Lung Disease, Hanoi, Viet Nam.

Ministry of Health, Department of International Cooperation, Viet Nam.

Hanoi Medical University, Hanoi, Viet Nam.

Hanoi School of Public Health, Hanoi, Viet Nam.

Submitted: 15 April 2016; Published: 8 June 2016

doi: 10.5365/wpsar.2016.7.2.002
} 
PMDT has been integrated into the general national TB control programme with additional financial and technical support to manage MDR-TB cases. The number of MDR-TB cases detected and enrolled for MDR treatment increased from 101 in 2009 to 2131 in 2015 . These cases account for $42 \%$ of the estimated 5100 MDR-TB cases in Viet Nam, which is much higher than the proportion (26\%) in the global estimation. ${ }^{1}$ However, this achievement still needs to be improved to achieve the national target of MDR-TB case enrolment for treatment.

Extensively drug-resistant TB (XDR-TB) represents an emerging public health problem worldwide. ${ }^{1,3}$ According to $\mathrm{WHO}$, an estimated $9.7 \%$ of global MDR-TB cases had XDR-TB. ${ }^{1}$ The emergence and spread of MDR and XDR-TB is a big challenge for TB control activities as treatment of MDR and XDR-TB cases is more expensive, has more adverse drug reactions, is less successful and has higher death rates than other types of TB. $1,3,4,6$

In 2011, the Viet Nam NTP conducted the Fourth National Anti-Tuberculosis Drug Resistance Survey in Viet Nam to assess the burden of TB drugs resistance in the country. ${ }^{5}$ In this study, we performed drug susceptibility testing (DST) for first-line TB drugs to estimate the prevalence of MDR-TB; we also conducted DST for SLDs (ofloxacin, amikacin, kanamycin and capreomycin). We aimed to determine the prevalence of XDR-TB among all MDR-TB cases detected in the Fourth National Anti-tuberculosis Drug Resistance Survey in Viet Nam.

\section{METHODS}

\section{Study subjects, sample size and sampling}

The full details of the study design, sampling strategy, sample size calculation and analysis of the Fourth National Anti-Tuberculosis Drug Resistance Survey in Viet Nam are described elsewhere. ${ }^{5}$ Briefly, it was a crosssectional survey that used a probability-proportional-tosize (PPS) sampling approach based on notifications of new smear-positive TB cases to assess the prevalence of MDR-TB among TB cases in Viet Nam. This survey was conducted in 80 clusters chosen from all district TB units in the country where TB cases were diagnosed and registered for treatment. Eligible cases were smearpositive TB cases newly registered for treatment (both new and previously treated TB cases) in the selected clusters during the period of recruitment. The required sample size was 1612 new smear-positive TB cases; therefore, each cluster was required to enrol at least 22 new TB cases during the six month period from June to December 2011. All previously treated smear-positive TB cases identified during this period were enrolled in this study.

\section{Data collection and laboratory procedures}

Data collection and laboratory procedures have also been described in detail elsewhere. ${ }^{5}$ Briefly, TB cases were interviewed face-to-face to collect information on age, sex, region of residence, previous TB treatment history, symptoms and HIV status. Two sputum samples were collected from each patient for culture and DST. The samples were transported, within 48 hours after collection, in chilled containers $\left(2-8{ }^{\circ} \mathrm{C}\right)$ to two national/regional laboratories and five provincial laboratories that have the capacity and facilities for TB culture. The specimens were decontaminated using $4 \% \mathrm{NaOH}$, and $0.1 \mathrm{~mL}$ of the mixture was inoculated onto two Ogawa tubes (according to the modified Petroff's method). ${ }^{7}$ The isolates were then sent to two national laboratories for identification and DST, using the proportion method on LoewensternJensen medium for four drugs: Isoniazid (INH), Rifampicin (RMP), Ethambutol (EMB) and Streptomycin (SM) with the following critical concentrations: INH $0.2 \mu \mathrm{g} / \mathrm{ml}$, RMP $40 \mu \mathrm{g} / \mathrm{ml}$, EMB $2 \mu \mathrm{g} / \mathrm{ml}$ and $\mathrm{SM} 4 \mu \mathrm{g} / \mathrm{ml}$. The proportion method on LoewensternJensen medium was also conducted for DST for all SLDs including ofloxacin (OFX), amikacin (AM), kanamycin (KM) and capreomycin (CM) with the following critical concentrations: OFX $2 \mu \mathrm{g} / \mathrm{ml}, \mathrm{KM} 30 \mu \mathrm{g} / \mathrm{ml}, \mathrm{AM} 40 \mu \mathrm{g} / \mathrm{ml}$, CM $40 \mu \mathrm{g} / \mathrm{ml}$, according to WHO standard. ${ }^{8}$

To ensure the quality of the DST, all samples of MDR-TB cases' isolates in the two national hospitals were sent for re-testing by crosscheck between two national and regional laboratories following WHO guidelines for surveillance of drug resistance in TB. ${ }^{9}$ Quality assurance for the culture and DST in this study was provided by a reference laboratory in Adelaide, Australia.

\section{TB case definitions}

We followed WHO-recommended definitions for TB drugs resistance cases: ${ }^{4}$ 
- MDR-TB: TB caused by strains of Mycobacterium tuberculosis that are resistant to at least INH and RMP;

- Pre-XDR-TB: TB resistance to INH, RMP, and to one of the three injectable drugs (KM, AM and $\mathrm{CM}$ ) or to fluoroquinolones (FQs); and

- XDR-TB: MDR-TB plus resistance to a FQ and at least one second-line injectable agent: AM, KM and/or CM.

\section{Data management and analysis}

All data were extracted from the survey database and laboratory database of the Fourth National AntiTuberculosis Drug Resistance Survey in Viet Nam. Data analysis was performed using Stata version 12 SE software (Stata Corporation, College Station, Texas, USA). We calculated the numbers and proportions of MDR-TB cases who had resistance to SLDs (based on the four SLDs as described previously). The 95\% confidence intervals $(\mathrm{Cl})$ were calculated throughout and the level of significance was set at $P \leq 0.05$.

The study protocol was approved by the Ethical Institutional Review Board of the National Lung Hospital, Viet Nam.

\section{RESULTS}

The survey was conducted in 80 TB clusters from 1 June to 31 December 2011 and enrolled 1840 smear-positive TB cases. Nine clusters were excluded due to a laboratory contamination problem identified after the end of the case enrolment period in one of the seven culture laboratories. In total, 1552 samples that had been cultured were included in the analysis. Of those, the total number of people diagnosed with smear- and culture-positive TB was 1341; DST results were available for 1312 cases. Of those, 91 MDR-TB cases were reported, including 46 MDR-TB among 1105 new TB cases (4.2\%, 95\% Cl: 2.5-5.4) and 45 MDR-TB among 195 previously treated TB cases $(23.1 \% ; 95 \% \mathrm{Cl}$ : 16.7-29.9). Table 1 shows the demographic characteristics of the 91 MDR-TB cases. The median age of these cases was 46.2 years (range $20-80$ years); $27.5 \%$ were in the 20-34 year age group. Of the
Table 1. Characteristics of MDR-TB cases, the Fourth National Anti-Tuberculosis Drug Resistance Survey in Viet Nam, $2011(n=91)$

\begin{tabular}{lll}
\hline Characteristics & $n$ & $\%$ \\
\hline Sex & 71 & 78.0 \\
$\quad$ Male & 20 & 22.0 \\
$\quad$ Female & & \\
Age group (years) & 25 & 27.5 \\
$20-34$ & 14 & 15.4 \\
35-44 & 25 & 27.5 \\
$45-54$ & 17 & 18.7 \\
55-64 & 10 & 11.0 \\
$\quad 65-80$ & & \\
Region of residence in Viet Nam & 16 & 17.6 \\
$\quad$ North & 15 & 16.5 \\
Central & 60 & 65.9 \\
$\quad$ South & & \\
Tuberculosis history & 46 & 50.5 \\
$\quad$ No TB history & 45 & 49.5 \\
$\quad$ Previous TB & & \\
\hline
\end{tabular}

TB, tuberculosis.

91 MDR-TB cases, $78.0 \%$ were male and $65.9 \%$ were residents of the southern region in Viet Nam.

\section{Patterns of resistance to the first-line anti-TB drugs}

By definition, all of the 91 MDR-TB cases were resistant to INH and RMP (Table 2). In addition, 50 MDR-TB cases (54.9\%; 95\% Cl: 44.5-65.4) were resistant to $\mathrm{EMB}, 84(92.3 \%$; 95\% Cl: 86.7-97.9) were resistant to SM and 47 (51.6\%; 95\% Cl: 41.2 62.1) were resistant to both $\mathrm{EMB}$ and $\mathrm{SM}$. Of the 46 new MDR-TB cases, 29 (63.0\%; 95\% Cl: 48.6-77.5) were resistant to EMB, 44 (95.7\%; 95\% Cl: 89.5-100.0) were resistant to SM and 27 (58.7\%; 95\% Cl: 43.9-73.5) were resistant to both EMB and SM. Of 45 re-treated cases, $21(46.7 \% ; 95 \% \mathrm{Cl}$ : $31.5-61.8)$ were resistant to $\mathrm{EMB}, 40(88.9 \%$; $95 \% \mathrm{Cl}$ : 79.3-98.4) were resistant to SM and $20(44.4 \% ; 95 \% \mathrm{Cl}$ : 29.3-59.5) were resistant to both EMB and SM.

\section{Patterns of resistance to the second-line anti-TB drugs}

Of the 91 MDR-TB cases, second-line DST results were available for $84(92.3 \%)$ of them (Table 2$)$. The overall 
Table 2. Pattern of resistance to anti-TB drugs in MDR-TB cases, the Fourth National Anti-Tuberculosis Drug Resistance Survey in Viet Nam, 2011

\begin{tabular}{|c|c|c|c|c|c|c|}
\hline & & Total & & New cases & Previo & sly treated cases \\
\hline & $\begin{array}{c}\text { Number } \\
\text { tested }\end{array}$ & $\begin{array}{c}\text { Resistance } \\
n(\%, 95 \% \mathrm{Cl})\end{array}$ & $\begin{array}{l}\text { Number } \\
\text { tested }\end{array}$ & $\begin{array}{c}\text { Resistance } \\
n(\%, 95 \% \mathrm{Cl})\end{array}$ & $\begin{array}{l}\text { Number } \\
\text { tested }\end{array}$ & $\begin{array}{c}\text { Resistance } \\
n(\%, 95 \% \mathrm{Cl})\end{array}$ \\
\hline First-line drug & & & & & & \\
\hline Ethambutol (EMB) & 91 & $50(54.9 ; 44.5-65.4)$ & 46 & $29(63.0 ; 48.6-77.5)$ & 45 & $21(46.7 ; 31.5-61.8)$ \\
\hline Streptomycin (SM) & 91 & $84(92.3 ; 86.7-97.9)$ & 46 & $44(95.7 ; 89.5-100)$ & 45 & $40(88.9 ; 79.3-98.4)$ \\
\hline Isoniazid (INH) & 91 & $91(100)$ & 46 & $46(100)$ & 45 & $45(100)$ \\
\hline Rifampicin (RMP) & 91 & $91(100)$ & 46 & $46(100)$ & 45 & $45(100)$ \\
\hline Second-line drug & & & & & & \\
\hline Amikacin (AM) & 84 & $1(1.2 ; 0-3.6)$ & 41 & $0(0)$ & 43 & $1(2.3 ; 0-7.0)$ \\
\hline Capreomycin (CM) & 84 & $5(6.0 ; 0.8-11.1)$ & 41 & $2(4.9 ; 0-11.8)$ & 43 & $3(7.0 ; 0-14.9)$ \\
\hline Kanamycin (KM) & 84 & $5(6.0 ; 0.8-11.1)$ & 41 & $2(4.9 ; 0-11.8)$ & 43 & $3(7.0 ; 0-14.9)$ \\
\hline Ofloxacin (OFX) & 84 & $15(17.9 ; 9.4-26.2)$ & 41 & $8(19.5 ; 6.8-32.1)$ & 43 & $7(16.3 ; 4.7-27.8)$ \\
\hline Pre-XDR-TB & 84 & $15(17.9 ; 9.4-26.2)$ & 41 & $8(19.5 ; 6.8-32.1)$ & 43 & 7 (16.3; 4.7-27.8) \\
\hline XDR-TB & 84 & $5(6.0 ; 0.8-11.1)$ & 41 & $2(4.9 ; 0-11.8)$ & 43 & $3(7.0 ; 0-14.9)$ \\
\hline $\mathrm{AM}+\mathrm{CM}+\mathrm{KM}+\mathrm{OFX}$ & 84 & $1(1.2 ; 0-3.6)$ & 41 & $0(0)$ & 43 & $1(2.3 ; 0-7.0)$ \\
\hline $\mathrm{CM}+\mathrm{KM}+\mathrm{OFX}$ & 84 & $5(6.0 ; 0.8-11.1)$ & 41 & $2(4.9 ; 0-11.8)$ & 43 & $3(7.0 ; 0-14.9)$ \\
\hline
\end{tabular}

$\mathrm{Cl}$, confidence interval; TB, tuberculosis; and XDR-TB, extensively drug-resistant tuberculosis.

proportion of pre-XDR was 17.9\% (95\% Cl: 9.4-26.2). The proportion of pre-XDR in new cases $(n=41)$ was $19.5 \%(95 \% \mathrm{Cl}: 6.8-32.1)$ and $16.3 \%(95 \% \mathrm{Cl}$ : 4.7-27.8) in previously treated cases $(n=43)$. A further five cases, $6.0 \%(95 \% \mathrm{Cl}: 0.8-11.1)$ were classified as XDR-TB, including two new $(4.9 \%, 95 \% \mathrm{Cl}$ : $0-11.8)$ and three previously treated cases $(7.0 \%, 95 \% \mathrm{Cl}$ : 0-14.9).

Table 3 presents the characteristics of the five XDRTB cases. All of them were male and were HIV seronegative. The median age of XDR-TB cases was 48 years with the youngest aged 23 years and the oldest 63 years old. The XDR-MTB isolates originated from the central $(n=2)$ and southern $(n=3)$ regions of Viet Nam.

\section{DISCUSSION}

We observed high levels of resistance to SLDs among MDR-TB cases. Our findings support data presented by other studies. ${ }^{4,6,10-14}$ The overall proportion of XDR-TB among MDR-TB cases in this study was still lower than the global average estimate. ${ }^{1}$ Whereas the proportion of XDR-TB among MDR-TB cases elsewhere varied from 5\% to $21 \%{ }^{4,6,10-14}$ However, James et al. reported a very high percentage of XDR-TB among MDR-TB cases (60\%) in India. ${ }^{15}$ This could be due to referral bias because that study was conducted among the cases referred to the tertiary care hospital.
We believe the main reason for XDR-TB is indiscriminate use of antibiotics that are also used as second-line anti-TB drugs. (FQs and others second-line drugs were available in pharmacies in high TB burden countries. $)^{16}$ It is also due to inadequate treatment by health staff and low compliance to full therapy by TB cases. In Viet Nam, of 1380 MDR-TB cases enrolled for treatment during 2010-2012, 372 (27\%) were unable to complete treatment. (This proportion varied in different parts of Viet Nam.) Loss-to-follow-up was the main unfavourable treatment outcome (13\%) and may be due to the long treatment period. ${ }^{17}$

MDR-TB and XDR-TB are indicators of TB control failures; they emerge due to several reasons: (1) provider may prescribe insufficient drug regiments for TB cases; (2) TB cases may not adhere to an appropriate regimen; (3) drugs may be of poor quality; and (4) there is transmission of MDR-TB and XDR-TB in the community. In Viet Nam, anti-TB drugs (both first-line and second-line drugs) are available without a medical prescription. About half of the private pharmacies were willing to dispense drugs either to TB cases or to those who asked for TB medication. ${ }^{18}$ We found a high prevalence of resistance to OFX (9.4-26.2\%), similar to other studies. ${ }^{10,13,14,19,20}$ This may be due to the fact that TB cases who received treatment may have used OFX before. The high prevalence of pre-XDR TB cases might imply the inappropriate usage of drugs, especially FQs including OFX. This 
Table 3. Characteristics of XDR-TB cases detected in the Fourth National Anti-Tuberculosis Drug Resistance Survey in Viet Nam, 2011

\begin{tabular}{cccccccc}
\hline Case & Age & Sex & $\begin{array}{c}\text { Region of } \\
\text { residence }\end{array}$ & $\begin{array}{c}\text { TB previously } \\
\text { treated }\end{array}$ & HIV status & $\begin{array}{c}\text { Pattern of drug } \\
\text { resistance for FLDs }\end{array}$ & $\begin{array}{c}\text { Pattern for drug } \\
\text { resistance of SLDs }\end{array}$ \\
\hline 1 & 23 & Male & Central & No & Negative & H; R; S & CM; KM; OFL \\
2 & 53 & Male & Central & Yes & Negative & E; H; R; S & CM; KM; OFL \\
3 & 63 & Male & South & Yes & Negative & E; H; R; S & CM; KM; OFL \\
4 & 46 & Male & South & No & Negative & E; H; R; S & CM; KM; OFL \\
5 & 48 & Male & South & Yes & Negative & E; H; R; S & AM; CM; KM; OFL \\
\hline
\end{tabular}

AM, Amikacin; CM, Capreomycin; E, Ethambutol; FLDs, first-line TB drugs; H, Isonoazid; KM, Kanamycin; OFL, Ofloxacin; R, Rifampicin; SLDs, second-line TB drugs; S, Streptomycin; and TB, tuberculosis.

drug is the most commonly prescribed antibiotic for respiratory tract infections as well as other bacterial infections, and in some cases it is available in local drug stores in Viet Nam without presenting a prescription. ${ }^{16}$ Easy access and inappropriate use of these drugs increase the risk for drug-resistant TB emergence.

In this study, all TB cases who were resistant to $\mathrm{KM}$ were also resistant to $\mathrm{CM}$, consistent with other studies. ${ }^{21,22} \mathrm{CM}$ is not widely available as it is expensive, and is not commonly used in Viet Nam. Maus et al. reported the cross-resistance between $\mathrm{KM}$ and $\mathrm{CM}$ in a study in the United States of America. ${ }^{21}$ The study describes isolates resistant to $\mathrm{CM}$ and LM caused by mutations in the rrs gene. The isolates recovered from TB cases treated with $\mathrm{KM}$ were resistant to $\mathrm{KM}$ and $\mathrm{CM}$, and the resistance of the strains to $\mathrm{CM}$ varied with the level of KM resistance. ${ }^{21}$ Further investigation of the rrs gene for MDR-TB cases is needed to confirm the crossresistance to $\mathrm{KM}$ and $\mathrm{CM}$ in Viet Nam.

There are limitations in this study. First, the clusters were selected based on the notification of new smearpositive TB cases in 2003 but not on more recent data. However, case distribution for TB notifications remained fairly stable from 2003 to $2011 .{ }^{5}$ Second, this study did not include the private health sector, therefore we could not estimate the burden of MDR-TB in the private sector. Nevertheless, in spite of these shortcomings, samples in this study generally represent all of Viet Nam.

\section{CONCLUSIONS}

This survey provides the first estimates of the proportion of XDR-TB among MDR-TB cases in Viet Nam. The results provide important information for clinicians and local policy-makers as well as international health agencies regarding the conduct of second-line DST. Local TB policies and programmes that are geared towards prevention, early diagnosis and treatment with effective regimens are of high importance.

\section{Conflicts of interest}

None declared.

\section{Funding}

None.

\section{Acknowledgements}

The authors thank the National Tuberculosis Programme Board; all national, regional, provincial, district and commune-level staff involved in the survey; and all patients taking part in the study. We sincerely thank Dr Edine W Tiemersma, from the KNCV Tuberculosis Foundation, The Hague, the Netherlands for her support in data management and validations as well as Richard Lumb from the Mycobacterium Reference Laboratory, Adelaide, Australia for his support in quality assurance for the culture and DST in this survey.

\section{References}

1. Global tuberculosis report 2015. Geneva, World Health Organization $2015 \quad$ (http://apps.who.int/iris/bitstream/ 10665/191102/1/9789241565059 eng.pdf?ua=1, accessed 16 May 2016).

2. Hoa NB et al. National survey of tuberculosis prevalence in Viet Nam. Bulletin of World Health Organiztion, 2010, 88(4):273280. doi:10.2471/BLT.09.067801 pmid:20431791

3. Anti-tuberculosis drug resistance in the world, Report No. 4: The WHO/IUATLD global project on anti-tuberculosis drug resistance surveillance. Geneva, World Health Organization, 2008 (http://apps.who.int/iris/bitstream/10665/ 43889/1/WHO_HTM_TB_2008.394_eng.pdf?ua $=1 \& u a=1$, accessed 16 May 2016). 
4. Multidrug and extensively drug-resistant TB (M/XDR-TB): 2010 global report on surveillance and response. Geneva, World Health Organization, 2010 (http://apps.who.int/ iris/bitstream/10665/44286/1/9789241599191_eng. pdf?ua $=1 \& u a=1$, accessed 16 May 2016).

5. Nhung NV et al. The fourth national anti-tuberculosis drug resistance survey in Viet Nam. International Journal of Tuberculosis and Lung Diseases, 2015, 19(6):670-675. doi:10.5588/ ijtld.14.0785 pmid:25946357

6. Poudel $A$ et al. Characterization of extensively drug-resistant Mycobacterium tuberculosis in Nepal. Tuberculosis (Edinburgh), 2013, 93(1):84-88. doi:10.1016/j.tube.2012.10.007 pmid: 23146281

7. Guidelines on Standard Operating Procedures for Laboratory Diagnosis of HIV-Opportunistic Infections. New Delhi, World Health Organization Regional Office for South-East Asia, 2001 (http://apps.searo.who.int/PDS_DOCS/B0189.pdf, accessed 16 May 2016).

8. Policy guidance on drug-susceptibility testing (DST) of secondline antituberculosis drugs. Geneva, World Health Organization, 2008 (http://apps.who.int/iris/bitstream/10665/70500/1/WHO_ HTM_TB_2008.392_eng.pdf, accessed 16 May 2016).

9. Guidelines for surveillance of drug resistance in tuberculosis. Fourth edition. Geneva, World Health Organization Document, 2009 (http://apps.who.int/iris/bitstream/10665/44206/1/9789 241598675_eng.pdf, accessed 16 May 2016).

10. Paramasivan $\mathrm{CN}$ et al. First- and second-line drug resistance patterns among previously treated tuberculosis patients in India. International Journal of Tuberculosis and Lung Diseases, 2010, 14(2):243-246. pmid:20074419

11. Migliori GB et al. Multidrug-resistant and extensively drugresistant tuberculosis in the West. Europe and United States: epidemiology, surveillance, and control. Clinics in Chest Medicine, 2009, 30(4):637-665, vii. doi:10.1016/j.ccm.2009.08.015 pmid:19925959

12. Li $X$ et al. Population-based surveillance of extensively drugresistant tuberculosis in Shandong Province, China. International Journal of Tuberculosis and Lung Diseases, 2012, 16(5):612614. pmid:22410186
13. Hu Y et al. Prevalence and genetic characterization of secondline drug-resistant and extensively drug-resistant Mycobacterium tuberculosis in Rural China. Antimicrobial Agents Chemotherapy, 2013, 57(8):3857-3863. doi:10.1128/AAC.00102-13 pmid: 23733477

14. Punga VV et al. Prevalence of extensively drug-resistant tuberculosis in Vladimir and Orel regions, Russia. International Journal of Tuberculosis and Lung Diseases, 2009, 13(10):13091312. pmid: 19793439

15. James $P$ et al. MDR- and XDR-TB among suspected drugresistant TB patients in a tertiary care hospital in India. Clinical Respiratory Journal, 2011, 5(1):19-25. doi:10.1111/j.1752699X.2009.00184.x pmid:21159137

16. Wells WA et al. Size and usage patterns of private TB drug markets in the high burden countries. PLoS One. 2011 05 04;6(5):e18964. doi:10.1371/journal.pone.0018964 pmid:21573227

17. Phuong NTM et al. Management and treatment outcomes of patients enrolled in MDR-TB treatment in Viet Nam. Public Health Action, 2016, 6(1):25-31. doi:10.5588/pha.15.0068 pmid:27051608

18. Vu DH et al. Suspected tuberculosis case detection and referral in private pharmacies in Viet Nam. International Journal of Tuberculosis and Lung Diseases, 2012, 16(12):1625-1629. doi:10.5588/ijtld.12.0295 pmid:23131260

19. Iqbal R et al. The First and Second Line Anti TB Drug Resistance Pattern in Lahore. Pakistan. The Journal of Medical Research, 2012, 51(1).

20. Agrawal D et al. Increasing incidence of fluoroquinolone-resistant Mycobacterium tuberculosis in Mumbai, India. International Journal of Tuberculosis and Lung Diseases, 2009, 13(1):79-83. pmid: 19105883

21. Maus CE, Plikaytis BB, Shinnick TM. Molecular analysis of crossresistance to capreomycin, kanamycin, amikacin, and viomycin in Mycobacterium tuberculosis. Antimicrobial Agents Chemotherapy, 2005, 49(8):3192-3197. doi:10.1128/AAC.49.8.31923197.2005 pmid: 16048924

22. Jugheli $L$ et al. High levels of resistance to second-line antituberculosis drugs among prisoners with pulmonary tuberculosis in Georgia. International Journal of Tuberculosis and Lung Diseases, 2008, 12(5):561-566. pmid:18419893 


\title{
Epidemiology and control of tuberculosis in the Western Pacific Region: update with 2013 case notification data
}

\author{
Tom Hiatt ${ }^{a}$ and Nobuyuki Nishikiori ${ }^{a}$ \\ Correspondence to Tom Hiatt (email: hiatt@wpro.who.int)
}

Introduction: Since the year 2000, tuberculosis (TB) prevalence in the World Health Organization (WHO) Western Pacific Region decreased 36\%. However, there were an estimated 1.6 million TB cases in the Region in 2013. This study describes a regional analysis using the WHO global TB database data from 2000 to 2013.

Methods: TB surveillance data are annually collected from 36 countries and areas in the Western Pacific Region using a web-based system. TB case notifications, treatment outcomes and information on TB/HIV coinfection are analysed descriptively. Stratified analysis of the TB data by age, sex and countries and areas were conducted.

Results: Countries and areas in the Western Pacific Region notified 1.3 million new and relapse TB cases in 2013. TB notification rate increased in the early 2000s, stabilized for several years and declined recently. Country-specific TB notification rates declined over time for all age groups in most countries. TB treatment success rates remain high in the Region with 16 countries reaching or maintaining 85\% (or higher) in 2013. HIV testing among TB cases has increased gradually with approximately 11000 HIV-positive TB cases diagnosed each year since 2009.

Discussion: The results suggest that true TB incidence is possibly declining. Treatment success rates have remained high for six of seven high-burden countries. TB surveillance data analysis is an important source of programmatic and epidemiological information. Careful interpretation of these findings can provide useful insight for programmatic decisionmaking. While the TB burden remains immense, national TB programmes must evolve and adapt to build upon previous efforts.

$\mathrm{T}$ he burden of tuberculosis (TB) in the World Health Organization (WHO) Western Pacific Region has been greatly reduced since 2000. Estimated TB prevalence fell in the Region from 3.5 million cases in 2000 to 2.3 million in $2013 .^{1}$ During the same period, 16.7 million TB cases were diagnosed and treated. However, national TB control programmes must continue to evolve and take advantage of new tools to further combat the epidemic. Under the new WHO End TB Strategy with ambitious targets, ${ }^{2}$ effective monitoring and evaluation is needed to track progress and understand how to best adapt interventions. Surveillance data analysis provides valuable information on the current epidemiological situation, programmatic progress and future directions.

This article presents an updated regional analysis of TB notification data which provides revised information for our previous study. ${ }^{3}$ It describes the epidemiological situation and progress in programmatic response with particular focus on seven countries having a high burden of TB: Cambodia, China, the Lao People's Democratic Republic, Mongolia, Papua New Guinea, the Philippines and Viet Nam.

\section{METHODS}

Thirty-two countries and areas of the Western Pacific Region reported data representing more than $99.9 \%$ of the total population in 2013. Around March of each year, TB surveillance data are collected from countries and areas in the Region ( $n=36$ ) by WHO using a web-based data collection form. Collected data cover the following areas: TB case notifications and treatment outcomes, diagnostic and treatment services, drug management, surveillance and surveys of drug resistance, information on TB/HIV coinfection, infection control, engagement of care providers and budgets and expenditures for TB control. The full description of data collection methods is available in the Global Tuberculosis Report, ${ }^{1}$ and the data sets are available from the WHO global TB database. ${ }^{4}$

\footnotetext{
Stop TB and Leprosy Elimination, Division of Communicable Diseases, World Health Organization Regional Office for the Western Pacific, Manila Philippines. 
Case definitions for TB were revised in $2013,{ }^{5}$ and cases previously known as smear-positive are now included in the category of bacteriologically confirmed cases which includes cases confirmed by any laboratory method. Similarly, smear-negative cases are combined with all clinically diagnosed cases including where smear was not done or results are unknown. (This obscures the number of cases where laboratory confirmation was sought by including them with the number of cases for which confirmation was not attempted. Knowing this information can indicate uncertainty around the number of notified cases.)

Descriptive analysis of TB case notifications in the Region and by country and area was done. TB notifications were stratified by age and sex for analysis. TB treatment outcomes and progress in TB/HIV activities (HIV testing, HIV positivity rate, co-trimoxazole preventive therapy [CPT] coverage and antiretroviral therapy [ART] coverage) were also analysed. All analyses were conducted by the statistical software environment $R$ version 3.2.1 (R Core Team, Vienna, Austria, 2015).

\section{RESULTS}

\section{TB case notification}

In 2013, countries and areas in the Western Pacific Region $(n=36)$ reported 1375213 people with TB disease (Table 1), making up $23 \%$ of the global burden. Of these, $97.6 \%$ (1 342404 cases) were either new or relapse TB cases. Within the Region, China accounted for $62 \%$ (855 241 cases) of the caseload followed by the Philippines and Viet Nam with $18 \%$ (244 392 cases) and $7.4 \%$ (102 196 cases), respectively. TB notification rates in 2013, expressed as cases per 100000 person years (PYs), varied substantially in the Region with the highest rates ( $\geq 200$ per 100000 PYs) found in Kiribati, Papua New Guinea, Marshall Islands, Cambodia and the Philippines with 375, 310, 282, 250 and 236 per 100000 PYs, respectively (Figure 1 ).

Between 2002 and 2005, case notification rates in the Region of all forms of TB increased from 47 to 74 cases per 100000 PYs and have stabilized at 73-78 cases per 100000 PYs since 2005. New bacteriologically confirmed cases increased from 22 cases per 100000 PYs in 2002 to a peak in 2005 of 39 cases per 100000 PYs and have declined steadily to 2013 at an average rate of $4.3 \%$ per year (Figure 2).

\section{Distribution of TB notifications by age and sex}

Figure 3 shows age- and sex-specific case notification rates of new bacteriologically confirmed cases for the Western Pacific Region and countries with a high burden of TB in the Region in 2013. In general, TB affected males more than females with an overall male-to-female ratio of 2.2 in the Region (highest in Viet Nam, 2.9 and lowest in Cambodia, 1.2).

All countries follow a typical pattern for crosssectional observations with increasing notification rates for older populations, except Mongolia. Children aged 0-14 showed the lowest rates, with Viet Nam showing the lowest rates for this age group (unweighted mean of males and females was 0.68 cases per 100000 PYs). Among the population 15 years and older in the Region, the difference in TB notification rates was the lowest in Mongolia, among male cases, where the highest rate (55-64 age group) was only 1.1 times to the lowest ( $\geq 65$ age group). The difference in TB notification rates was the highest in the Lao People's Democratic Republic, among male cases, where the highest rate ( $\geq 65$ age group) was 17 times that of the lowest (15-24 age group).

Figure 4 shows trends of notification rates of new bacteriologically confirmed cases of age- and sexspecific groups in the Region and seven countries with a high burden of TB from 2000 to 2013. Cambodia and Viet Nam demonstrated a declining trend for all age- and sex- groups, ordered youngest to eldest with distinct separation, except for female cases in Viet Nam, where the three youngest age groups plateaued while the older age groups declined. Case rates in the Philippines trended toward convergence with rates increasing in younger age groups and decreasing in older age groups. The $\geq 65$ age group in the Philippines had rates similar to that of the 45-54 age group. Rates in China differed by sex. Male cases nearly maintained the order of youngest to eldest; female cases aged 15-24 years broke the order and were more similar to the 55-64 age group. The trends in Mongolia and Papua New Guinea were less distinct and did not follow the youngest to eldest order. 


\begin{tabular}{|c|c|c|c|c|c|c|c|c|c|c|}
\hline \multirow[b]{2}{*}{ Countries and areas } & \multirow[b]{2}{*}{$\begin{array}{c}\text { Total } \\
\text { notified }\end{array}$} & \multirow[b]{2}{*}{$\begin{array}{l}\text { New and } \\
\text { relapse* }\end{array}$} & \multirow{2}{*}{$\begin{array}{l}\text { Re- } \\
\text { treatment } \\
\text { excluding } \\
\text { relapse }\end{array}$} & \multicolumn{3}{|c|}{$\begin{array}{c}\text { New or previous treatment history } \\
\text { unknown }\end{array}$} & \multicolumn{3}{|c|}{ Relapse } & \multirow{2}{*}{$\begin{array}{l}\text { Percentage } \\
\text { of pulmonary } \\
\text { cases bacte- } \\
\text { riologically } \\
\text { confirmed }\end{array}$} \\
\hline & & & & $\begin{array}{l}\text { Pulmonary } \\
\text { bacterio- } \\
\text { logically } \\
\text { confirmed }\end{array}$ & $\begin{array}{l}\text { Pulmonary } \\
\text { clinically } \\
\text { diagnosed }\end{array}$ & $\begin{array}{c}\text { Extra- } \\
\text { pulmonary }\end{array}$ & $\begin{array}{l}\text { Pulmonary } \\
\text { bacterio- } \\
\text { logically } \\
\text { confirmed }\end{array}$ & $\begin{array}{l}\text { Pulmonary } \\
\text { clinically } \\
\text { diagnosed }\end{array}$ & $\begin{array}{l}\text { Extra- } \\
\text { pulmonary }\end{array}$ & \\
\hline American Samoa & & & & & & & & & & - \\
\hline Australia & 1256 & 1250 & 6 & 612 & 86 & 512 & 26 & 1 & 13 & 88 \\
\hline Brunei Darussalam & 212 & 212 & 0 & 149 & 9 & 48 & 6 & 0 & 0 & 95 \\
\hline Cambodia & 39055 & 37743 & 1312 & 14082 & 9069 & 14203 & 389 & 0 & 0 & 61 \\
\hline China & 855241 & 847176 & 8065 & 275915 & 512469 & 30767 & 28025 & & & 37 \\
\hline $\begin{array}{l}\text { Hong Kong Special } \\
\text { Administrative Region } \\
\text { (China) }\end{array}$ & 4773 & 4744 & 29 & 2439 & 1033 & 893 & 259 & 66 & 54 & 71 \\
\hline $\begin{array}{l}\text { Macao Special } \\
\text { Administrative Region } \\
\text { (China) }\end{array}$ & 437 & 433 & 4 & 286 & 61 & 57 & 25 & 3 & 1 & 83 \\
\hline Cook Islands & 2 & 2 & 0 & 1 & 0 & 1 & 0 & 0 & 0 & 100 \\
\hline Fiji & 269 & 254 & 15 & 106 & 74 & 71 & 3 & 0 & 0 & 60 \\
\hline French Polynesia & 61 & 52 & 9 & 29 & 8 & 6 & 7 & 1 & 1 & 80 \\
\hline Guam & 48 & 48 & 0 & 22 & 22 & 4 & 0 & 0 & 0 & 50 \\
\hline Japan & 20495 & 20495 & & 12758 & 2201 & 4274 & 831 & 182 & 249 & 85 \\
\hline Kiribati & 420 & 407 & 13 & 128 & 159 & 85 & 22 & 10 & 3 & 47 \\
\hline $\begin{array}{l}\text { Lao People's Democratic } \\
\text { Republic }\end{array}$ & 4214 & 4130 & 84 & 3004 & 541 & 392 & 193 & 0 & 0 & 86 \\
\hline Malaysia & 24071 & 23417 & 654 & 13641 & 5640 & 3046 & 676 & 307 & 107 & 71 \\
\hline Marshall Islands & 153 & 149 & 4 & 70 & 48 & 28 & 3 & 0 & 0 & 60 \\
\hline $\begin{array}{l}\text { Micronesia, Federated } \\
\text { States of }\end{array}$ & & & & & & & & & & - \\
\hline Mongolia & 4733 & 4331 & 402 & 1622 & 733 & 1756 & 220 & 0 & 0 & 72 \\
\hline Nauru & & & & & & & & & & - \\
\hline New Caledonia & & & & & & & & & & - \\
\hline New Zealand & 277 & 272 & 5 & 125 & 15 & 125 & 6 & 0 & 1 & 90 \\
\hline Niue & 0 & 0 & 0 & 0 & 0 & 0 & 0 & 0 & 0 & - \\
\hline $\begin{array}{l}\text { Northern Mariana Islands, } \\
\text { Commonwealth of the }\end{array}$ & 33 & 33 & 0 & 15 & 12 & 1 & 5 & 0 & 0 & 62 \\
\hline Palau & 8 & 8 & 0 & 7 & 0 & 1 & 0 & 0 & 0 & 100 \\
\hline Papua New Guinea & 24860 & 22657 & 2203 & 3150 & 9390 & 9919 & 198 & & & 26 \\
\hline Philippines & 244392 & 229918 & 14474 & 97353 & 123510 & 4386 & 4669 & 0 & 0 & 45 \\
\hline Republic of Korea & 45292 & 41579 & 3713 & 18860 & 9860 & 7369 & 2957 & 1699 & 834 & 65 \\
\hline Samoa & 22 & 22 & 0 & 11 & 4 & 7 & 0 & 0 & 0 & 73 \\
\hline Singapore & 2172 & 2164 & 8 & 1103 & 647 & 278 & 92 & 28 & 16 & 64 \\
\hline Solomon Islands & 368 & 360 & 8 & 136 & 105 & 114 & 5 & 0 & 0 & 57 \\
\hline Tokelau & 0 & 0 & 0 & 0 & 0 & 0 & 0 & 0 & 0 & - \\
\hline Tonga & 10 & 10 & 0 & 8 & 0 & 2 & 0 & 0 & 0 & 100 \\
\hline Tuvalu & 18 & 18 & 0 & 10 & 6 & 2 & & & & 62 \\
\hline Vanuatu & 123 & 123 & 0 & 42 & 24 & 56 & 1 & 0 & 0 & 64 \\
\hline Viet Nam & 102196 & 100395 & 1801 & 50607 & 24403 & 18326 & 7059 & & & 70 \\
\hline Wallis and Futuna Islands & 2 & 2 & 0 & 2 & 0 & 0 & 0 & 0 & 0 & 100 \\
\hline Western Pacific Region & 1375213 & 1342404 & 32809 & 496293 & 700129 & 96729 & 45677 & 2297 & 1279 & 44 \\
\hline
\end{tabular}

Note: Blank cells indicate data not reported.

* New and relapse includes cases for which the treatment history is unknown. 
Figure 1. TB case notifications (new and relapse) per 100000 population in countries and areas of the Western Pacific Region, 2013*

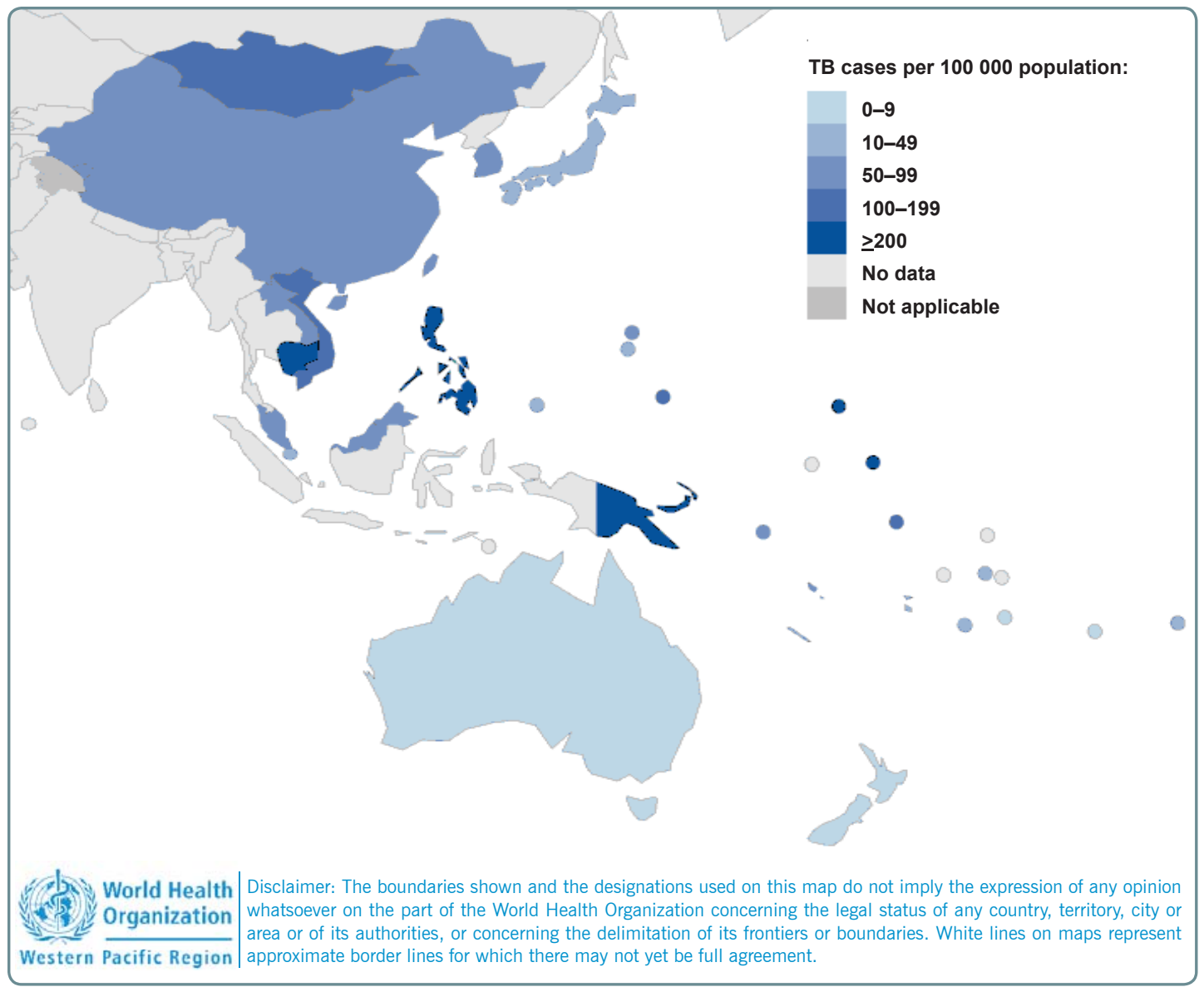

* New and relapse TB cases include cases for which the treatment history is unknown.

Figure 2. TB case notification rate (all forms and new bacteriologically confirmed) per 100000 PYs in the Western Pacific Region, 2000-2013*

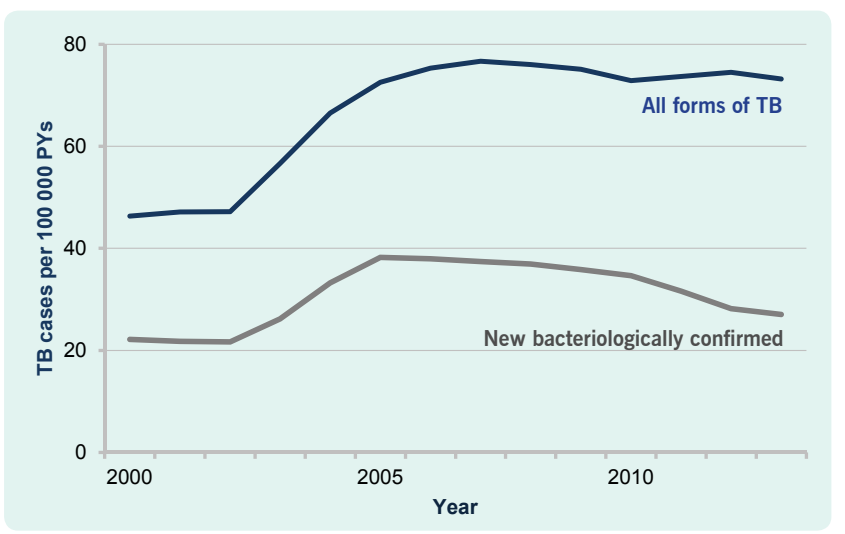

* All forms of TB include new and relapse TB cases, pulmonary and extrapulmonary, and bacteriologically confirmed or clinically diagnosed. New bacteriologically confirmed includes pulmonary TB cases only. Both categories include cases that have unknown treatment history.

PY, person year; TB, tuberculosis.

\section{Treatment outcomes}

The overall trend of TB treatment success in the Western Pacific Region continues to be over 85\% (Figure 5) since 1997. Across the Region, 16 countries and areas reached or maintained an $85 \%$ (or higher) treatment success in 2012. Among the seven countries with a high burden of TB, treatment success was highest in China (95\%) followed by Cambodia (94\%), Viet Nam (91\%), the Lao People's Democratic Republic (90\%), Mongolia (88\%) and the Philippines (88\%). The treatment success rate of Papua New Guinea was the lowest at $68 \%$ with approximately one quarter of the 2012 cohort either lost to follow-up or un-evaluated. The proportion of 2012 notified cases that were not reported as being put on treatment was highest in Papua New Guinea, the Lao People's Democratic Republic and Cambodia with $85 \%, 5.4 \%$ and $4.7 \%$, respectively. 
Figure 3. Age- and sex-specific notification rates (per 100000 population) of new and relapse TB cases in the Western Pacific Region and countries with a high burden of TB in the Region, 2013*

\section{Cambodia}

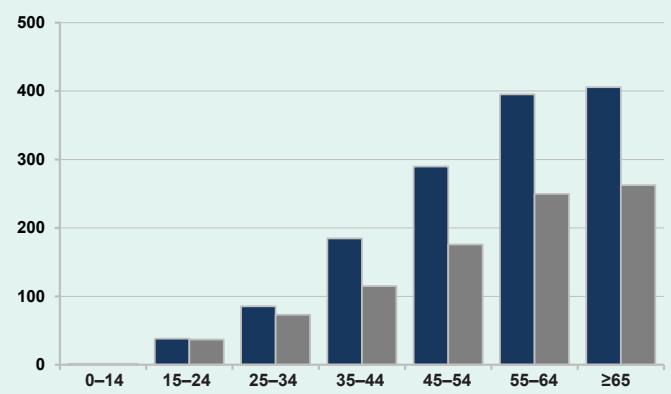

Lao People's Democratic Republic

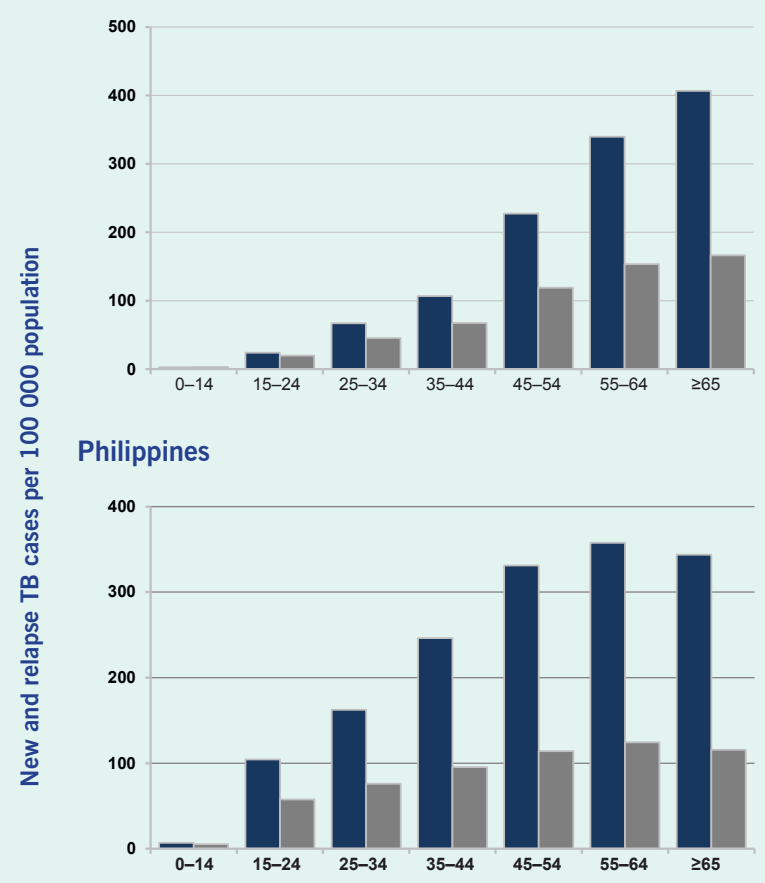

Western Pacific Region

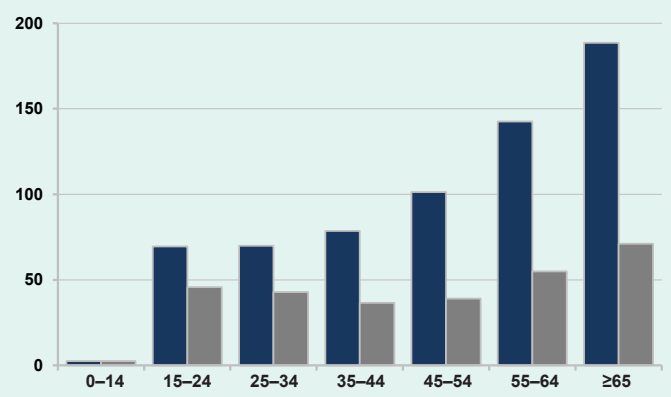

\section{China}

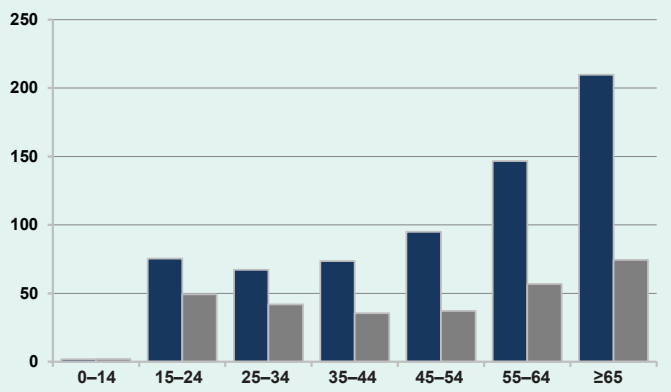

Mongolia

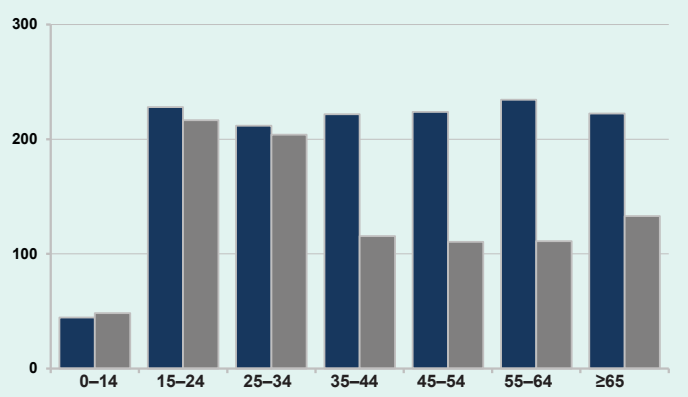

Viet Nam

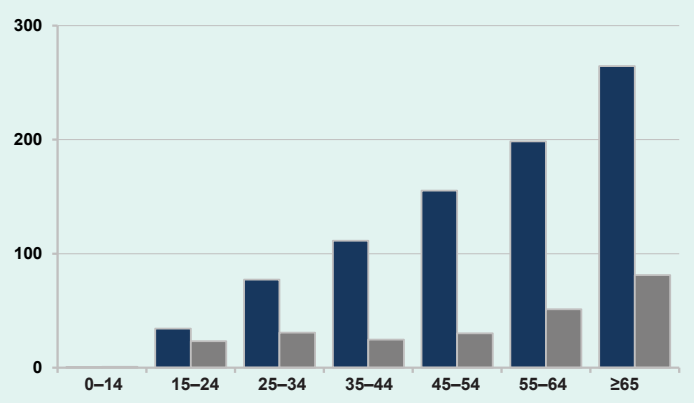

* Scale of the vertical axis is different for each country. Data from Papua New Guinea were not available and excluded. 
Figure 4. Trend of age- and sex-specific notification rates (per 100000 PYs) of new and relapse TB cases in the Western Pacific Region and countries with a high burden of TB in the Region, 2000-2013*

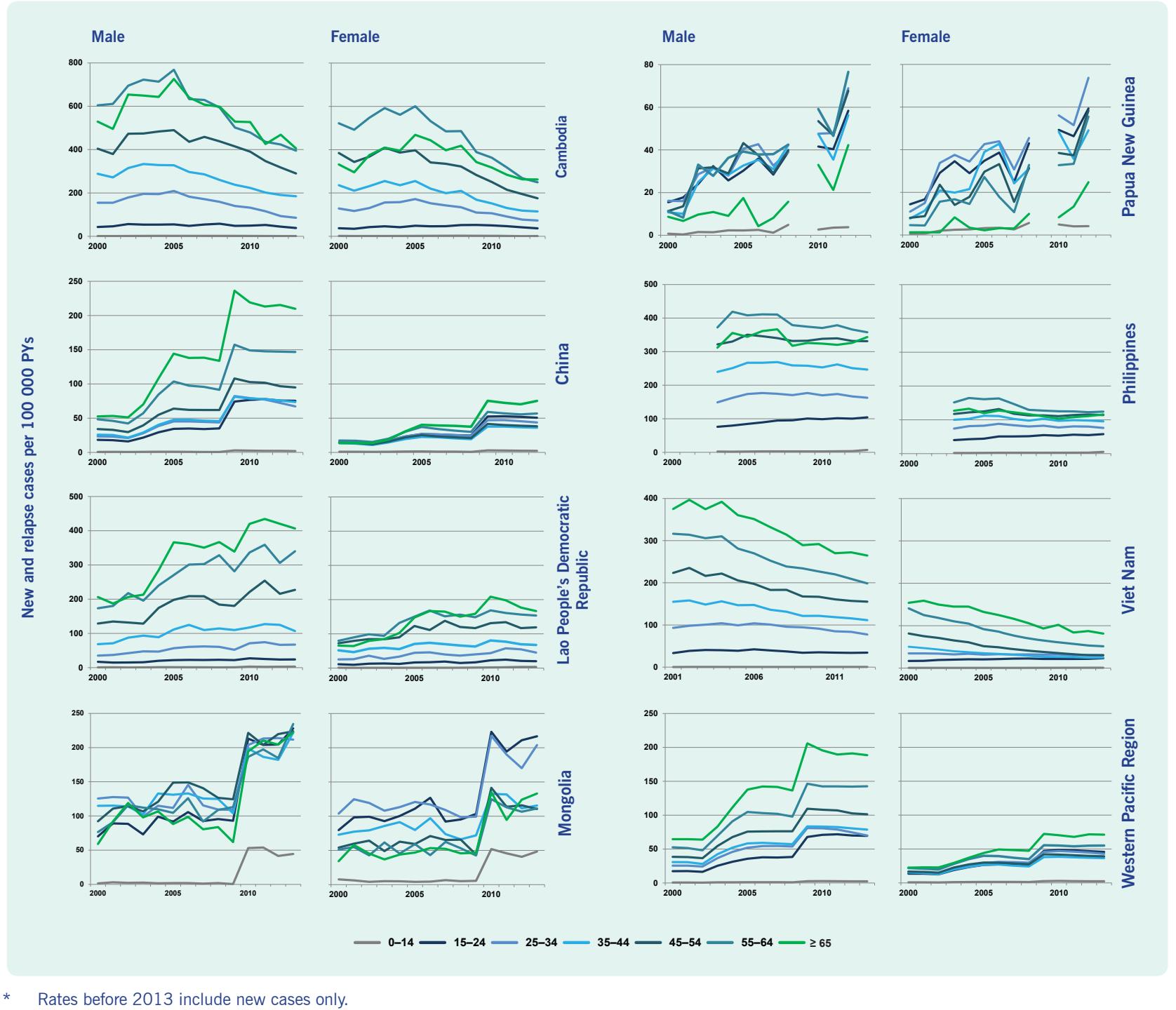

\section{TB/HIV coinfection and collaborative activities}

Figure 6 summarizes the four basic indicators (HIV testing, HIV positivity rate, CPT coverage and ART coverage) for the Region and seven countries with a high burden of TB in the Region. Overall, HIV testing in the Region had steadily increased from $0.72 \%$ in 2006 to $35 \%$ in 2013 . The proportion of TB/HIV cases had steadily declined from $24 \%$ in 2006 to $2.5 \%$ (equivalent to 11432 cases) over the same period. CPT coverage increased from 2007 to 2009 , levelled off between 64\% and $80 \%$, and possibly declined in 2013 . ART coverage had also increased, reaching the highest point in 2013 at $65 \%$.
Cambodia and Viet Nam reported the most comprehensive data completeness and programmatic progress. The coverage of HIV testing, CPT and ART progressively increased with a steady decrease in the proportion of HIV-positive individuals among TB cases in these two countries. Mongolia also reported a high level of HIV testing with no more than five positive cases per year since 2006. HIV testing was the lowest (2.1\%) in the Philippines in 2013, detecting the second lowest proportion of HIV-positive cases $(0.52 \%)$ after Mongolia. The next lowest proportion tested was Papua New Guinea (24\%) but with the highest proportion (14\%) of HIV-positive cases among those TB cases tested. 
Figure 5. Trend of treatment success among new bacteriologically confirmed cases in the Western Pacific Region and countries with a high burden of TB in the Region, 2000-2013

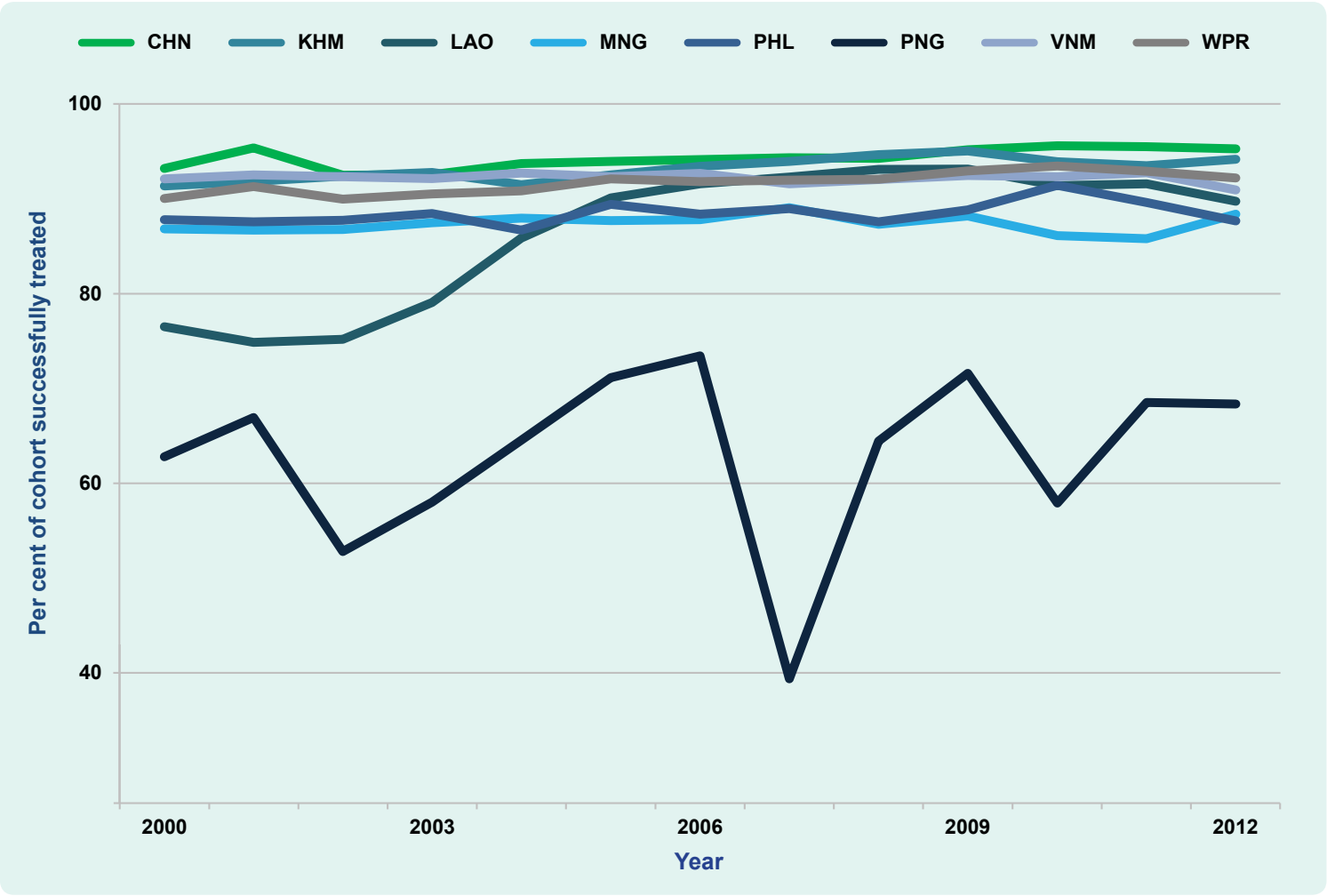

CHN, China; KHM, Cambodia; LAO, Lao People's Democratic Republic; MNG, Mongolia; PNG, Papua New Guinea; PHL, Philippines; VNM, Viet Nam; WPR, Western Pacific Region.

\section{DISCUSSION}

The overall level of new and relapse TB notified cases (all forms) from countries and areas of the Western Pacific has held steady for the past several years (Figure 2). In contrast, the rate of new bacteriologically confirmed cases gradually declined by $1.9 \%$ from 2005 to 2010 but accelerated to $8.2 \%$ from 2010 to 2013. The difference in these trends suggests that true TB incidence is possibly declining while programme efforts for early case-finding, including clinically diagnosed cases, are increasing. Increased case-finding efforts can result in a lower proportion of cases with bacteriological confirmation as some cases are found before the bacterial load increases to a detectable level. ${ }^{6}$ The proportion of cases bacteriologically confirmed among all TB cases decreased from 52\% in 2005 to $37 \%$ in 2013.

Two changes in the recording and reporting framework influence the last data point in this trend of bacteriologically confirmed TB cases. First, the trendline previous to 2013 only included smear microscopy as a method of laboratory confirmation. Starting in
2013 , any form of laboratory confirmation was included in this indicator, including more sensitive diagnostics. This may be responsible for the slight increase of TB cases in 2013. Second, clinically diagnosed TB cases were either disaggregated by smear-negative and smear-unknown or not done before 2013. This gave some information around the certainty of the cases diagnosed. From 2013 onwards, this disaggregation is no longer included in annual reporting. The proportion of non-bacteriologically confirmed cases who were not tested is unknown. Between 2008 and 2012, this proportion was small at the regional level (with a maximum of $1.4 \%$ cases who did not have a smear result in any given year). However, the proportion was high in some countries and areas (35\%, 25\% and 23\% in Papua New Guinea, Guam and Republic of Korea, respectively). The changes in the recording and reporting framework also affected TB notification data disaggregated by age and sex. Prior to 2013, notifications by age and sex were further disaggregated by site of the disease (pulmonary or extrapulmonary) and by smear status (smear-positive and smear-negative/unknown/ not done) for pulmonary cases. These data were only collected for new TB cases. Since the introduction of the 
Figure 6. Progress in TB/HIV activities in the Western Pacific Region and countries with a high burden of TB in the Region, 2006-2013*

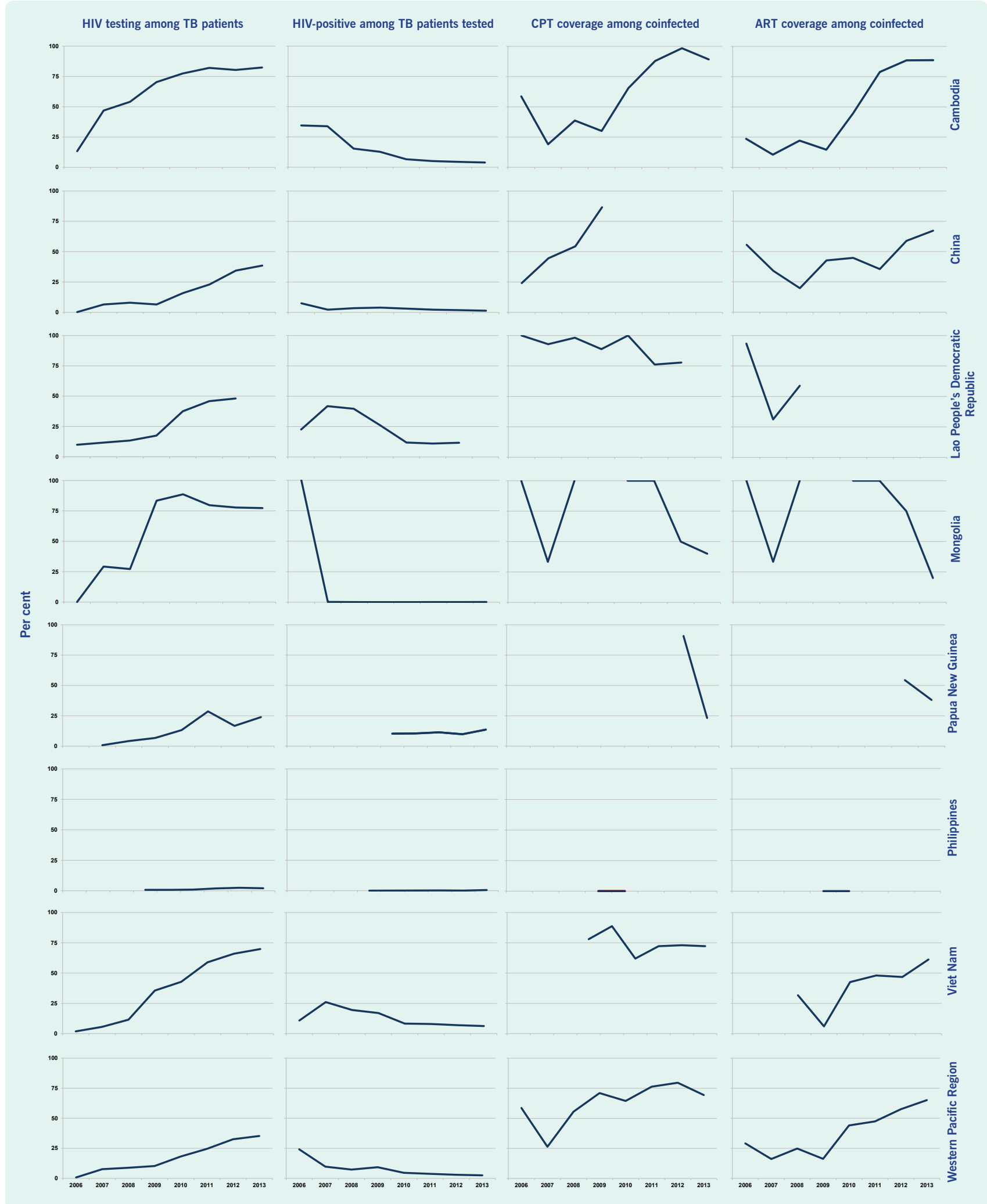

* Only available data were shown.

ART, antiretroviral therapy; CPT, co-trimoxacole preventive therapy; HIV, human immunodeficiency virus; TB, tuberculosis. 
revised recording and reporting framework, this further disaggregation was discontinued in favour of one table having age and sex data and including relapse cases. Besides restriction on more granular analysis, this also affects the time trend of notifications as relapse cases are now included. This also increases uncertainty around diagnosed cases since clinically diagnosed cases may not be actual TB cases.

TB control under stable conditions frequently results in TB case rates that increase with age as individuals have more time to be exposed to the disease and for the disease to develop. ${ }^{7}$ Most countries in Figure $\mathbf{3}$ follow this pattern. Slight deviations from this pattern may be attributed to inaccuracies in population estimates; however, the pattern in Mongolia showed rates in the 15-34 year age group were much higher than expected and warrants further investigation. The male-to-female ratio varies substantially among countries and areas in the Region. The reason for these differences is likely a combination of biological and social factors. ${ }^{8}$ However, despite the efforts taken to understand the role of gender in TB epidemiology, ${ }^{9,10}$ much is still unknown. In situations where the demographic composition, specifically age and sex, is changing over time, the crude TB notification rate may not present a clear picture of epidemiological trends. The TB rates may be decreasing in all age groups, but if the mean age of the population is increasing, thus moving a larger proportion of the population into older age groups where TB rates are highest, the crude trend may show no decline or even an increase. For this reason, examining age- and sexspecific case notification rates may provide more insight into the underlying epidemiology.

With the disaggregated view of TB notifications in Figure 4, it appears probable that TB incidence in Cambodia and Viet Nam is indeed declining. Both countries reported the age and sex breakdown only for bacteriologically confirmed cases, and the proportion of cases tested is continuously high. These reductions, in light of sustained programme performance, would be difficult to explain otherwise. WHO global estimates and other studies have come to similar conclusions. ${ }^{11,12}$

TB treatment success has remained high for six of seven high-burden countries in the Western Pacific Region since 2005. In addition to patient benefit, this high level of success will help drive the TB incidence downward if patients are put on treatment early. The trend for treatment success is erratic in the remaining high-burden country, Papua New Guinea, with a large proportion of cases not put on treatment and a large number of patients lost to follow-up or not evaluated. The high number of cases not put on treatment is also a concern in the Lao People's Democratic Republic and Cambodia, although if these cases were included in the treatment cohort, treatment success would still be over $85 \%$.

An estimated 32000 (range: 29 000-36 000) people living with HIV develop TB every year in the Region. ${ }^{1}$ Although the HIV burden in the Region remains comparatively low, coinfection of HIV and TB poses a dangerous threat. Collaborative TB/HIV services are vital to save lives. HIV testing continued to increase gradually, but it was still below 50\% in 2013. CPT coverage levelled off and perhaps began to decline, representing a possible risk for essential services. ART coverage increased but still shows major gaps in most countries in the Region.

Many countries reported case data stratified by age for bacteriologically confirmed cases only, although WHO has been requesting this information since 2006. ${ }^{13}$ This obscures the number of young children detected and poses a great limitation to the analysis of notifications by age and sex. Bacteriological confirmation is much rarer in young children due to difficulty in producing sputum. With the expanding coverage of central case-based recording and reporting systems, these data are becoming more available. Also, analysis of surveillance data has inherent limitations. While the primary aim of TB surveillance is to provide insights into the TB situation in a specific population, under-capturing systems often reflect more the fluctuating performance of the TB control programme than the epidemiology of TB in the population. Systems meeting minimum standards of quality for their TB surveillance systems ${ }^{14}$ provide more robust estimates of disease burden and can be used as a proxy for TB incidence, which has not yet been directly measured in any country. A careful assessment of programmatic progress and the quality of surveillance data for each country is needed when interpreting these findings.

This report provides a snapshot of the epidemiological and programmatic situation of TB in the Western Pacific Region based on the case notification data in 2000-2013. TB surveillance continues to be an important source of information for assessing the 
TB situation and measuring progress to inform decisionmaking. The WHO Regional Office for the Western Pacific will continue to conduct regional analyses on various topics related to TB epidemiology and programmatic progress such as the situation of drug-resistant TB, subnational data analysis and utilization, TB in low- and intermediate-burden countries, contact investigation and other forms of TB screening activities to stimulate the utilization of surveillance data for informed programme decision-making. WHO also will continue to provide support to countries for conducting epidemiological and programmatic assessments at national and subnational levels.

\section{SUPPLEMENTARY MATERIALS}

In response to calls for transparent and reproducible research, ${ }^{15,16}$ we have published the programme code to generate the entire contents of this article including all figures and tables by using $R$ with the knitr package version 1.10.5 (Yihui Xie, 2015). Readers can download the code (available on request) and reproduce all figures and tables under an appropriate personal computing environment. For noncommercial purposes, readers may modify the code to produce figures and tables that are not presented in this article. For instance, readers may wish to produce tables and figures for countries or regions other than the WHO Western Pacific Region.

\section{Conflict of interest}

None declared.

\section{Funding}

None.

\section{Acknowledgement}

The authors are very grateful to the national TB control programmes of the countries of the Western Pacific Region.

\section{References}

1. Global Tuberculosis Report 2014. Geneva, World Health Organization, $2014 \quad$ (http://apps.who.int/iris/bit stream/10665/137094/1/9789241564809_eng.pdf, accessed 29 March 2016).
2. Resolution WHA67.1. Global strategy and targets for tuberculosis prevention, care and control after 2015. In: Sixtyseventh World Health Assembly, Geneva, 19-24 May 2014. Resolutions and decisions, annexes. Geneva, World Health Organization, 2014:1-3 (http://apps.who.int/gb/ebwha/pdf files/ WHA67-REC1/A67_2014_REC1-en.pdf\#page $=25$, accessed 29 March 2016).

3. Hiatt T, Nishikiori N. Epidemiology and control of tuberculosis in the Western Pacific Region: analysis of 2012 case notification data. Western Pacific Surveillance and Response Journal, 2014, 5(1):25-34. doi:10.5365/wpsar.2014.5.1.013 pmid:24734214

4. Global tuberculosis database. Geneva, World Health Organization, 2015 (http://www.who.int/tb/data, accessed 29 March 2016).

5. Definitions and reporting framework for tuberculosis-2013 revision (updated December 2014). Geneva, World Health Organization, $2013 \quad$ (http://apps.who.int/iris/ bitstream/10665/79199/1/9789241505345_eng.pdf, accessed 29 March 2016).

6. Systematic screening for active tuberculosis: principles and recommendations. Geneva, World Health Organization, 2013 (http://www.who.int/tb/tbscreening/en/, accessed 29 March 2016).

7. Rieder HL. Epidemiologic basis of tuberculosis control. Paris, International Union Against Tuberculosis and Lung Diseases (UATLD), 1999 (http://www.cabdirect.org/ abstracts/20002005361.html, accessed 29 March 2016).

8. Thorson A, Diwan VK. Gender inequalities in tuberculosis: aspects of infection, notification rates, and compliance. Current Opinion in Pulmonary Medicine, 2001, 7:165169. doi:10.1097/00063198-200105000-00009 pmid: 11371773

9. Borgdorff MW et al. Gender and tuberculosis: a comparison of prevalence surveys with notification data to explore sex differences in case detection. The International Journal of Tuberculosis and Lung Disease, 2000, 4:123-132. pmid:10694090

10. Uplekar MW et al. Attention to gender issues in tuberculosis control. International Journal of Tuberculosis and Lung Disease, 2001, 5(3): 220-224(5) (http://www.ingentaconnect.com/ content/iuatld/ijtld/2001/00000005/00000003/art00005, accessed 29 march 2016).

11. Morishita $\mathrm{F}$ et al. Tuberculosis case-finding in Cambodia: analysis of case notification data, 2000 to 2013. Western Pacific Surveillance and Response Journal, 2015, 6(1):15-24. doi:10.5365/wpsar.2014.5.4.005 pmid:25960919

12. Huong NT et al. Tuberculosis epidemiology in six provinces of Vietnam after the introduction of the DOTS strategy. The International Journal of Tuberculosis and Lung Disease, 2006, 10:963-969. pmid:16964785

13. Revised TB recording and reporting forms and registers - version 2006. Geneva, World Health Organization, 2006 (http://apps. who int/iris/bitstream/10665/69608/1/WHO_HTM_TB_2006.373_ eng.pdf, accessed 6 April 2016).

14. Standards and benchmarks for tuberculosis surveillance and vital registration systems: checklist and user guide. Geneva, World Health Organization, 2014 (http://www.who.int/tb/publications/ standardsandbenchmarks/en/, accessed 29 March 2016).

15. Peng RD, Dominici F, Zeger SL. Reproducible epidemiologic research. American Journal of Epidemiology, 2006, 163:783789. doi:10.1093/aje/kwj093 pmid:16510544

16. Groves T, Godlee F. Open science and reproducible research. BMJ (Clinical Research Ed.), 2012, 344:e4383. pmid:22736475 

